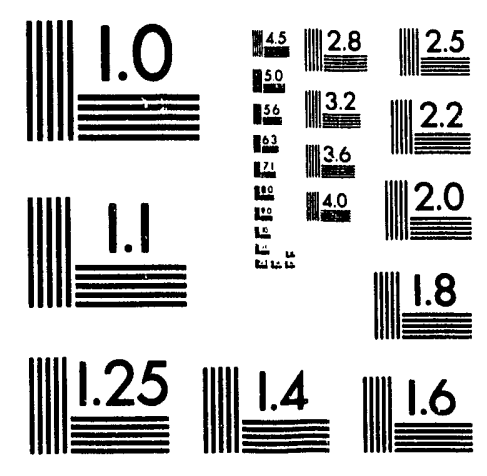



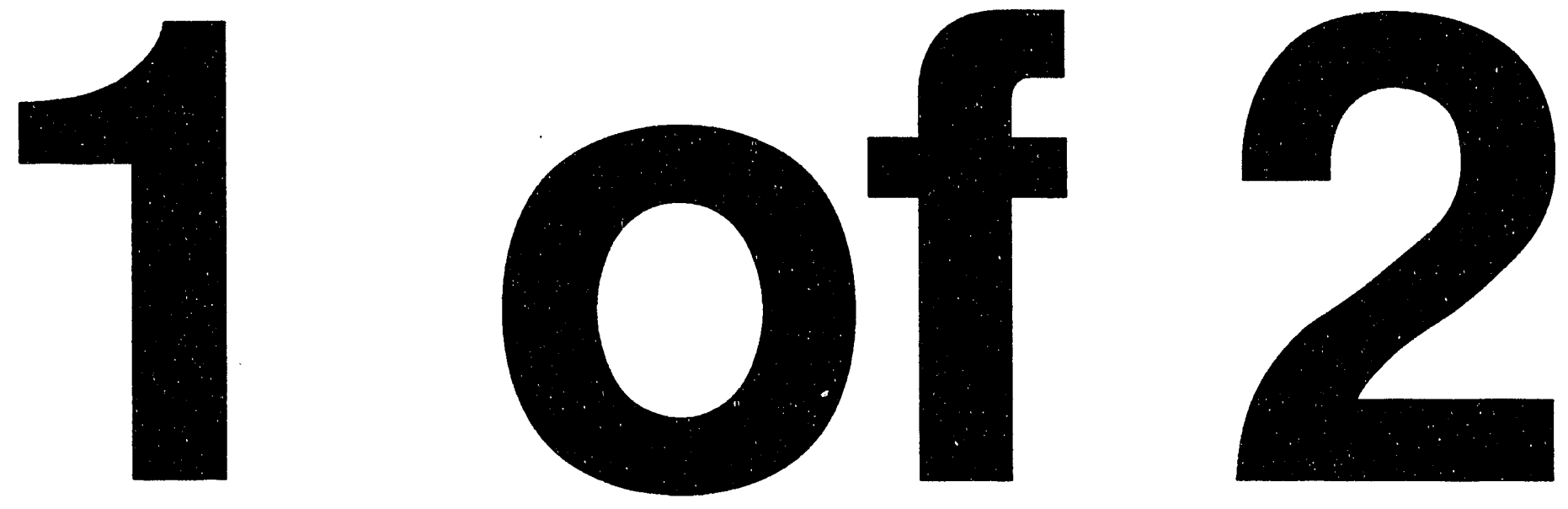
LBL-34362

UC-350

Master of Science Thesis in the Energy and Resources Group, University of California Berkeley, Spring 1993

\title{
THE EFFECT OF SIMPLIFYING THE BUILDING DESCRIPTION ON THE NUMERICAL MODELLING OF ITS THERMAL PERFORMANCE
}

\author{
Corina Stetiu \\ Indoor Environment Program \\ Energy and Environment Division \\ Lawrence Berkeley LaboratoryUniversity of California \\ Berkeley, California
}

July 1993

This research was supported by the Assistant Secretary for Conservation and Renewable Energy, Office of Building Technologies, Building Systems Division of the U.S. Department of Energy under Contract No. DE-AC03-76SF00098

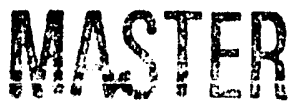




\section{TABLE OF CONTENTS}

EXECUTIVE SUMMARY

ACKNOWLEDGMENTS 2

INTRODUCTION

The Development Of Thermal Energy Simulation Programs - A Necessity 3

The Rationale Of Simplifying The Floor Plans Of A Building When Modeling It 4

\section{DEFINING THE PROBLEM}

1.1 Identifying the Quantities To Be Studied 6

1.2 Different Stages in "Reasonably" Simplifying a Typical Office Building 7

1.2.1 The Basecase Office Building $\quad 8$

1.2.2 The "Detailed" Building Geometry 9

1.2.3 The "Simplified" Building Geometry 9

1.2.4 The "CEC" Building Geometry 10

1.2.5 The One-Room Description - "SPOT" 11

2. THE THERMAL BUILDING SIMULATION PROGRAM DOE-2

2.1 Short History of DOE-2 12

2.2 Structure of DOE-2 12

2.3 Evaluation of DOE-2 Accuracy 14

2.3.1 Evaluation By Comparison With Measurements 14

2.3.2 Evaluation By Comparison With Results From Other Thermal Building Simulation Programs $\quad 15$

\section{THE SENSITIVITY STUDY}

3.1 Premises of the Study 17

3.2 Effects of Simplifying the Building Geometry on the Indoor Conditions 20

3.2.1 The Unoccupied, Non-Conditioned Building 20

3.2.2 The Unoccupied Building, Ventilated to Fulfill the Minimum Air Quality Standards 23

3.2.3 The Unoccupied, Fully Conditioned Building 25

3.2.4 The Occupied Building, Ventilated to Fulfill the Minimum Air Quality Standards 27

3.2.5 The Occupied, Fully Conditioned Building 28

3.2.6 The Effects of Climate on the Previous Results 30

3.2.7 The Effect of the Building Thermal Mass on the Previous Results 32 
3.3 Effects of Simplifying the Building Geometry on Sizing the HVAC System 33

4. CONCLUSIONS 37

References $\quad 38$

List of Figures $\quad 39$

Figures 1-24

Appendix 


\section{THE EFFECT OF SIMPLIFYING THE BUILDING DESCRIPTION ON THE NUMERICAL MODELLING OF ITS THERMAL PERFORMANCE}

\section{EXECUTIVE SUMMARY}

A thermal building simulation program is a numerical model that calculates the response of the building envelopes to weather and human activity, simulates dynamic heating and cooling loads, heating and cooling distribution systems, and models building equipment operation. The scope of the research described in this paper is to supply the users of such programs with information about the dangers and benefits of simplifying the input to their models. To achieve this purpose, the concept of starting the thermal simulation of a building with an already "inaccurate" building floor plan is put in perspective.

The Introduction describes the advantages of modeling the heat transfer mechanisms in a building. The programs that perform this type of modeling have, however, limitations. The user is therefore often put in the situation of simplifying the floor plans of the building under study, but not being able to able to check the effects that this approximation introduces in the results of the simulation. The idea of a sensitivity study aimed at solving this question is advanced.

Chapter 1 is a description of methods. The rationale behind studying an office building is exposed, and the building properties of interest in the study are derived. Chapter 1 also introduces the floor plans for the office building under study and the "reasonable" floor plans simplifications.

Chapter 2 presents DOE-2, the thermal building simulation program used in the sensitivity study. The evaluation of the accuracy of the DOE-2 program itself is also presented. 
Chapter 3 contains the sensitivity study. The complicated nature of the process of interpreting the temperature profile inside a space leads to the necessity of defining different building modes, with the different influences on the air temperature introduced gradually. The study compares the results from the model of the detailed building description with the results from the models of the same building having simplified floor plans. The process is repeated for each defined building mode. Other influences on the character of the conclusions might come from the climate of the building site, and also from the building materials. The same package of comparisons is made for a different building site, and also for a different building wall structure. In the last part of the study, the difference between the sizes of air conditioning systems in the different building models is analyzed.

In Chapter 4 the conclusion is reached that a study of the effects of simplifying the floor plans of a building is important mainly for defining the cases in which this approximation is acceptable. Different results are obtained for different air conditioning/load regimes of the building. The decision to modify the accurate floor plans of a building should consequently depend on the air conditioning/load regime of the building, and the purpose of the simulation.

\section{ACKNOWLEDGMENTS}

This research was supported by the Assistant Secretary for Conservation and Renewable Energy, Office of Building Technology, Building Systems Division of the U.S. Department of Energy under Contract No. DE-AC03-76SF00098. 


\section{INTRODUCTION}

\section{The Development Of Thermal Energy Simulation Programs - A Necessity}

Energy use in buildings in the U.S. has grown by $34 \%$ in the last 20 years, mostly due to population, household and office numbers increases, but also to service demand more air conditioning, more computers, larger houses. Today, residential and commercial buildings account for one-third of the U.S. energy consumption (31.6 TJ), at an an uual cost of $\$ 170$ billion [1]. The application of improved technology has moderated this growth: the implementation of energy efficient building shells, appliances and building designs has caused the decrease of energy intensity in residences (energy use per household per year) and stabilized energy intensity in the commercial sector (energy use per square meter per year). The potential of further building energy savings can easily be seen when comparing energy use scenarios. A "business as usual" scenario of building energy shows a continuous growth at a moderate pace, reaching roughly 44.3 TJ in 2015 . An alternative perspective, assuming that all energy efficient technologies with a positive net present value to the consumer are implemented, suggest that building energy use could actually decrease to about 29.5 TJ by 2015 (Figure 1). This corresponds to annual energy savings of $14.8 \mathrm{TJ}$ by 2015 , worth $\$ 80$ billion at today's energy prices. In this context, the study of building energy consumption is proven to be worthwhile.

Designing building energy efficient technologies requires new procedures and new tools for engineers and architects. Calculations of the response of the building envelopes to weather and human activity, simulations of dynamic heating and cooling loads, and of heating and cooling distribution systems, and modeling of equipment operation are needed. Thermal building simulation programs have been created to meet these requirements and to provide a starting point in building design and for building retrofitting analyses. Also, building energy standards already exist in California, and the compliance of 
a real building to these standards is tested by comparing the results of the base-case and real building simulations ${ }^{1}$.

\section{The Rationale Of Simplifying The Floor Plans Of A Building When Modeling It}

There are a number of reasons which may induce the program user to simplifying the floor plans of a building.

\section{Shortening the input file}

The building thermal simulation programs are based on the calculation of the building thermal loads ${ }^{2}$ (from air conditioning, people, equipment, exterior conditions) and the solving of a set of heat balance equations for the building. The larger the number of details needed to be provided, the larger the set of equations, and also the computer space requirements to store the information. Optimal management of computer disk space can become a good reason for which the user might prefer simple/short input files to detailed/long/space consuming ones.

\section{Decreasing the chances of error introduction}

The more complex the building, (design, zoning, schedules), the larger the volume of the input to the simulation programs, but also the greater the chances of introducing errors in the input.

The thermal building simulation programs usually allow for a number of equivalent methods for the building description, so users who have not developed a consistent strategy for the use of these methods may easily get confused by the options and make mistakes. The more complex the building, the more likely that mistakes are introduced in the input.

\footnotetext{
1 The California Energy Commission uses DOE-2 for this purpose.

2 A load is the amount of heat that needs to be added to, or removed from, a space (by the air conditioning system), so that certain indoor conditions be maintained inside the space.
} 
Shortening the simulation time

It is fairly obvious that the more complex a building, the longer the computer time needed for the simulation program to first establish, solve the system of equations corresponding to the building thermal flows, and then display the results in the form selected by the user.

Keeping within the program boundaries

Most of the simulation programs have certain limitations pertaining to the number of surfaces, spaces, or air conditioning systems that can be described in a building. A user might therefore be forced adopt a certain degree of detail for the description of the building in the input file, and therefore to simplify the architecture of the building.

A straightforward solution to these problems is to make "reasonable" simplifications of the real building, and reduce the amount of useful information provided to the program. The main problem with this approach is that, after having approximated the building with a simpler floor plan, the modeler usually does not check whether the results of the simple version differ from the results that would have obtained with a more accurate version of the building. The subject of the remaining of this paper is a study of the extent in which some selected "reasonable" simplifications to the floor plans affect the results of the simulation of a typical office building. 


\section{DEFINING THE PROBLEM}

The problem that this paper tries to solve is to determine the extent in which simplifying the building description affects the results of the thermal building simulation. To this end, the study of office buildings was considered more relevant than the study of residential buildings. There were a number of reasons for making this choice. First, office buildings, and in general, non-residential buildings are modeled more often than residences. This is due to the fact that the high costs of large building contracts make simulation worthwhile. Second, there are States in which a test for complying to standards is required by law in the design phase of a building (Title 24 in California), and modeling proved to be a good testing method. Third, large buildings have complicated structure, so the models corresponding to these buildings are more likely to require the simplification of the floor plans. And last, DOE-2, the thermal building simulation program used in this study, has predetermined hourly schedules for the internal activity over the entire simulation period. The fact that a typical office building can be imagined as being close to having invariable schedules gives the study a realistic starting point.

\subsection{Identifying the Quantities To Be Studied}

The choice of an office building suggests the most important information that needs to be extracted from a thermal simulation of the building. A first factor of interest in the case of an office building is the indoor comfort provided and maintained through air conditioning. In a typical Californian office building, the HVAC system is in use only a number of hours a day, namely the time when the employees are at work. After the employees have left in the evening, the HVAC system is turned off, which provides a different thermal regime inside the building over night. This change in thermal regime affects the operation of the HVAC system by (possibly) setting loads at startup that are different from the loads the equipment was designed to handlf.. A study of the effects of 
simplifying the building model on the indoor air temperature was therefore performed. By designing the simulations so that the different building thermal loads be introduced gradually, the effects of each load on the resulting indoor air temperature could be correctly identified. The results of this section of the study provide the situations in which different stages in the accuracy of the building floor plans can be used in modeling.

Another part of the study was aimed at determining the effects of the building location and of the materials in the building shell, on the conclusions reached before. To this end, the same temperature studies were made for a different Californian climate and for different building materials.

To provide adequate indoor comfort, the sizing of the heating, ventilation and air conditioning (HVAC) system in an office building has to be done (technically) according to the loads that it needs to remove. As stated before, the thermal building simulation programs are also used as a starting point in building design and equipment sizing. If the results of the simulation are erroneous, the actual decision for equipment sizing can be wrong, and the building might end up either under-conditioned, or having oversized equipment (in which case the costs of equipping the building are unnecessarily inflated). Consequently, the last part of the study focused on the effects of simplifying the building model on the results of equipment sizing it provides.

The building thermal simulation program used to achieve the sensitivity study was DOE-2. A short presentation of DOE-2 is offered in the next chapter.

\subsection{Different Stages in "Reasonably" Simplifying a Typical Office Building}

A sensitivity study to determine the effects of geometry simplifications on the results of the thermal simulation of an office building was carried out. There is a large probability that different modelers approach the problem of simplifying the building geometry in different ways. The main idea behind the strategy to "reasonably" simplify a 
building is that the resulting geometry(ies) maintain the character of the main thermal regimes inside the building. In what follows, such a strategy is presented.

The fact that real office buildings usually have a large number of stories leads to the modeling situation where the simulation is mostly focused on middle floors. In the case of a fairly high building ${ }^{3}$ having similar floor plans at each level, the approximation can be made that a given floor has the same thermal regime as the floors above and below it. This implies that the study4 of only one of the middle stories of a high building provides satisfactory information about the thermal loads and the space conditions inside the building. Backed by these observations, the present study only models one middle floor of an office building.

\subsubsection{The Basecase Office Building}

The basecase office building that was simulated is typical in the sense that the floor plans present office space along the facades of the building, and the space in the core of the building is reserved for other activities. Figure 2 shows the floor plan of the middle floor of an idealized 5 typical office building. There are 18 spaces designed as offices, 14 of which have each one wall with a window to the facade of the building (Middle-floor Facade Rooms MFR 1-14). The geometry also presents 4 corner rooms, each having two exterior walls (Middle-floor Corner Rooms MCR 1-4). In the core of the building, two hallways (Middle-floor Hallways MH 1,2), one conference room (Middle-floor Interior Room MIR 2) and two smaller meeting or compster rooms (Middle-floor Interior Rooms MIR 1,3) are modeled.

\footnotetext{
${ }^{3} 6$ stories or more.

4 The practical way to model such a case is based on considering the heat fluxes through the floor an the ceiling as insignificant, and hence to declare these surfaces as adiabatic.

5 The idealization stands in the rectangular shape of the building and in the symmetrical arrangement of the offices inside. The generality of the problem is not reduced however, since the heat transfer mechanisms in a building depend less on the shape of the spaces than they depend on the surface area of the walls.
} 
All office spaces are considered to have the same occupancy, the same lighting and electrical equipment per unit area. For the air conditioning of the building, three HVAC systems are simulated. The first system conditions the North and East facades, which have relatively low cooling loads in summer, and high heating loads in winter. The second system conditions the South and West facades, which have relatively high cooling loads in summer, and low heating loads in winter. The third system conditions the core of the building, which, due to the lack of exterior walls, has a different thermal regime than the facades.

\subsubsection{The "Detailed Building Geometry}

This first model of the building accurately follows the floor plan shown in Figure 2. The results obtained in this case constitute the basecase for the proposed study. The remark needs however to be made that, considering the nature of the study, and the fact that the building thermal simulation programs have intrinsic imbedded approximations, the results obtained in the case of the Detailed geometry might not necessarily be the most accurate. For the purpose of the study, the Detailed geometry was nevertheless considered an appropriate basecase.

\subsubsection{The "Simplified" Geometry}

The basic idea for simplifying the floor plan is almost straightforward. Due to the fact that all facade spaces have the same internal loads 6 , the same results are expected from the calculations for determining the interior conditions for these spaces. In the same line of reasoning as before, the heat fluxes through the interior walls that separate these spaces, and the heat storage in these walls, can be considered negligible in steady state. This allows the elimination of the interior walls. The reason for not eliminating the interior walls separating the facades from the corner rooms is that the heat regime of the latter is

\footnotetext{
6 The internal loads of this building are the heat fluxes from occupants, equipment and lights located inside the building.
} 
difierent. The comer rooms have two exterior walls instead of one, which provides a more important heat exchange with the exterior. Also, the only interior walls that the corner rooms have are the ones separating them from the facade spaces. Since there is significant difference in the thermal regime of the two types of spaces, it is expected that the heat transfer through these walls is not negligible. It is therefore necessary that these walls be kept. These considerations lead to a somewhat simpler geometrical design of the floor plan (Figure 3 ) and to a significantly shorter input for the simulation.

\subsubsection{The "CEC" Building Geometry}

The next step in simplifying the floor plan is to eliminate the "separate" description of each corner room. The observation needs to be made that each one of these spaces has its exterior walls facing different directions. The thermal loads due to the heat exchange with the exterior through the two windows are therefore different. To eliminate one of each pair of remaining interior walls, would mean to include in the load of each facade a component that actually belongs to a facade with a different orientation. This would certainly change the thermal regime of the facade space. The way to avoid this is to "divide" each corner room with a diagonal wall, which yields two half rooms having each an exterior wall. The elimination of the "old" interior walls leads to the incorporation of each half room in the facade that has the same orientation for the exterior wall. The thermal load of each added half corner room adds this way to the thermal load of the appropriate facade space, and compensates for the loss of the internal heat transfer through the wall that has been eliminated. In this step, the geometry of the building core may also be simplified by completely eliminating the interior walls.

The resulting floor geometry is shown in Figure 4. This geometry matches the High-Rise Office Basecase Building, designed by the California Energy Commission (CEC) for compliance to standard tests [2]. 


\subsubsection{The One-Room Description - "SPOT"}

There are situations in which the building designer is primarily interested in the interior conditions of the office spaces ${ }^{7}$. Further simplifications to the building geometry can be suggested in such a case. Since the interior loads of all the offices on the same facade are the same, the study of only one of them ${ }^{8}$ ought to be satisfactory for determining the "average" space conditions on that facade.

To apply this theory to the "typical" office building without deviating too much from the scope of this study, the remark is made again that in California climates, an important thermal load to an office building is the weather-driven cooling load. A designer would therefore be interested in studying an "isolated" office on the facade with the highest cooling loads, i.e. the one facing South. The location of the "isolated" facade office was chosen based on the idea of minimizing the effecis induced by the isolation process. To this end, the observation is made that the most representative office on the South facade would be the one which is least influenced by the more intense heat exchange with the corner offices. In the Detailed geometry, this office is located in the center of the South facade and is denoted by MFR10.

Figure 5 shows the MFR10 space isolated from the rest of the building. The resulting building approximation will be referred to by the name of "SPOT". The isolation is modeled by declaring the interior walls adiabatic, which leads to the situation of no heat transfer to adjacent spaces by conduction through these walls. To account for the fact that adiabatic walls do not allow heat transfer, but nevertheless store heat, the wall structure of the internal walls that would separate the office from the similar adjacent spaces was reduced to half.

\footnotetext{
7 This situation might arise if the contractor works on retrofitting the building, or in a stage where he needs to design the HVAC system for the facades.

8 The same approach is used as in the case of isolating a single floor in a building: the heat transfer through the interior walls is considered negligible, so these surfaces are declared adiabatic. The only remaining heat exchange process of such a space is with the exterior.
} 


\section{THE THERMAL BUILDING SIMULATION PROGRAM DOE-2}

\subsection{Short History of DOE-2}

In 1976 the U.S. Energy Research and Development Administration (ERDA) and the California Energy Commission (CEC) decided that existing building energy analysis programs were inadequate for the non-academic practitioner, and that the development of a new public-domain program should be undertaken [3]. A project was established among several national laboratories (Lawrence Berkeley Laboratory, Argonne National Laboratory and Los Alamos National Laboratory) and Consultants Computation Bureau, a private company. Project leadership was centered at LBL.

In 1977 the Cal-ERDA program was released. At that point, the joint CEC/ERDA sponsorship came to an end, ERDA being absorbed into the new U.S. Department of Energy (DOE). A slightly improved version of the program, developed with the support of the DOE Office of Buildings and Community Systems, DOE-1, was released in 1978. It became the first of a series of versions leading to a much more sophisticated program, called DOE-2.

DOE-2 has since been continuously reviewed and updated through the effort of the Simulation Research Group at LBL, and of several other associated researchers. The program is widely used not only as a tool in the design of buildings, but also in many energy conservation projects and in the development of energy conservation standards.

\subsection{Structure of DOE-2}

DOE-2 has five parts [4]: an interpreter for input translation into computer code, and four simulation subprograms. The simulation subprograms are executed in sequence, the output of one becoming the input to the next. Each of the subprograms also produces 
printed reports of the results of its calculations. The information flow in a DOE-2 simulation is presented in Figure 6.

The Building Description Language processor BDL analyzes the data supplied by the user and translates it into computer code. It also performs data assignments and retrieval and controls the operation of the other subprograms.

The loads simulation subprogram LOADS calculates peak and design loads and hourly space loads, imposed by ambient weather contitions, internal occupancy, lighting and equipment. It takes into consideration variations in the size, location, orientation, construction and materials of the building components and the shape of the building. The calculation of the loads is based on the approximation of dynamic steady-state conditions, meaning that each space is considered as being kept at a constant temperature, selected by the user.

The secondary ${ }^{9}$ HVAC components simulation subprogram SYSTEMS corrects the first approximation of energy demands of a building produced by LOADS. It does so by including outside air conditions, schedules for equipment operation, HVAC equipment control strategies, and the transient response of the building when neither the heating nor the cooling are required to maintain the temperature and humidity set points. SYSTEMS allows for the simulated HVAC components to be arranged in various user-selected configurations, and to be operated according to various temperature schedules.

The primary ${ }^{10}$ HVAC system simulation subprogram PLANT simulates the behavior of primary HVAC systems in satisfying the heating and cooling requirements of the secondary systems. It also takes into account the part-loads characteristics of the primary equipment and calculates the fuel and electrical demands of the building.

\footnotetext{
9 The secondary HVAC system is constituted by the fans, ducts, coils, economizers etc. that operate inside the building and provide the desired indoor conditions.

${ }^{10}$ The primary HVAC system is constituted by the boilers, chillers, Diesel engines, turbines etc. operated to provide the warm/cold air or water for the secondary HVAC system.
} 
The economic analysis subprogram ECONOMICS calculates energy consumption for the building and life-cycle costs for the HVAC systems. It can be used to evaluate energy consumption in a given period, to compare different building designs and different HVAC systems, or to calculate savings for retrofits to an existing building.

\subsection{Evaluation Of DOE-2 Accuracy}

Yarious studies have been made to evaluate ${ }^{11}$ the accuracy of the thermal building simulation program DOE-2. The studies are either analytical (back of the envelope calculations in the case of simple models), or describe comparisons of results both with measurements, and with results from other simulation programs (e.g. [5], [6]). The following will refer to an LBL study [7] that performs the last two tasks.

\subsubsection{Evaluation By Comparison With Measurements}

For the evaluation of DOE-2 by comparison with measurements, data were taken from measurements performed by the Oak Ridge National Laboratory's Buildings Envelopes Program in two different climates, Gaithesburg, MD and Tesuque Pueblo, NM. In each of the two climates, three test cells (i.e. buildings), having different wall materials, were built. The measurements pertained to the electricity consumption, to the working regime of the HVAC system, and to the indoor conditions (temperature, relative humidity) in the test cells. A DOE-2 simulation of the cells was made for the two climates.

The results natch the measured data within a $( \pm 20 \%)$ interval. The cause for the disparity was identified as a combination of factors lying on both measurement and simulation sides. On the data side, the measurements display anomalies like high lighting heat gains, or no sensible cooling. These are thought to originate from potentially incorrect maintenance of the sensors, and/or from accidental inconsistencies of the time at

11 The term "validation" was found inappropriate for simulation programs. The large number of imbedded assumptions and of parameters to check makes the work for performing a real validation not only impossible, but also futile. The term "evaluation" was therefore considered to reflect in a more appropriate way the activity of checking the results of a model. 
which the measurement was performed, with the time of the most representative building or space thermal loads. On the simulation side, sensitivity studies of the simulation program were made and the conclusion was reached that differences from the "real world" are consistently obtained due to the initial assumptions of the model. A simulation is therefore an idealistic estimate of the situation one is trying to replicate. Also, the human factor always present in the measured data, is lost in a simulation. The most important identified inadequacy of the DOE-2 program for the scope of this study was the inability to model conductive edge losses.

In conclusion, even if the simulation matches the measurements in the fairly large $( \pm 20 \%)$ interval, the DOE-2 model still provides a good estimate of the "real world".

\subsubsection{Evaluation By Comparison With Results From Other Thermal Building} Simulation Programs

The evaluation of the DOE-2 modeling by comparison with results from another thermal simulation program was the second scope of the same project. To this end, the same residential building was modeled using DOE-2 and BLAST ("Building Loads Analysis and System Thermodynamics", written by the Construction Engineering Research Laboratory, U.S. Department of the Army, Champaign, Illinois). The simulation set included varying of wall materials, location of insulation, and building site. There were systematic differences in the results, identified as originating from a number of conceptual differences in the two programs. Some of these differences are: different calculation methods for the reradiation of the roof surfaces to the sky, for the sensible cooling and heating rates, and for the natural ventilation inside the building, and different ways of modeling the thermal zones inside the building in this particular application.

The results from the two programs are however remarkably close where the thermal mass effects are concerned. This leads to the conclusion that a person using DOE- 
2 would draw the same conclusions from the results of a DOE model that could be drawn as a result of using a BLAST model. 


\section{THE SENSITIVITY STUDY}

The DOE-2-based sensitivity study was designed in two parts. The first part is the study of the effects of simplifying the building geometry on the indoor air temperature and the internal heat transfer mechanisms. The effects of changing the building location and the components of the building shell on the results above, are also included here. The second part is the study of the potential effects that simplifying the building geometry might have on the sizing of the HVAC equipment.

Both categories of results were obtained by running DOE-2 and modeling the same (interior and exterior) conditions for the different building geometries identified in Chapter 1. The DOE-2 input for the Detailed and SPOT geometries are given in the Appendix. The sizes of the two input packages are 41.8 kbytes for the Detailed geometry and 20.1 kbytes for SPOT. The computer time needed to perform the DOE-2 calculations corresponding to the two input packages is 7 minutes 25 seconds in the case of the Detailed geometry, and 53 seconds in the case of SPOT. The savings in both time and computer memory in the case of choosing the one-room geometry instead of the Detailed, are indisputable.

\subsection{Premises of the Study}

To model a building in DOE-2, specific building data needs to be supplied to the program. These data constitute information about the location of the building, study period, building shell materials, building occupancy, type of HVAC systems, and operation schedules. The sensitivity study was designed so that the specific information be the same in the DOE-2 input corresponding to the different geometries. As a result, the difference in simulation results could be interpreted as having only been caused by the difference in geometries. The base case specific information is provided below. 


\section{Building location}

The building is located in Red Bluff, California, at $40.2^{\circ} \mathrm{N}, 112.2^{\circ} \mathrm{W}$ and $104 \mathrm{~m}$ altitude. A DOE-2 "typical" weather file is obtained by making a time-series analysis of the climate of a given site. The "typical" monthly averages for solar radiation, temperature etc. are determined, and then real weather data for each month is selected that is closest to the determined averages.

\section{Study period}

The time period over which the space conditions were studied was set based on the day of the peak cooling load on the South facade. For the Red Bluff climate, the day is August 24. The chosen study period extends for a day before and a day after this date.

\section{Building materials}

The structure of the building shell is given in Figure 7. It thermally corresponds to a medium-heavy thermal mass building shell. The exterior walls have a U-value of 0.26 $\mathrm{W} / \mathrm{m}^{2} \mathrm{~K}$, and the average $\mathrm{U}$-value of the exterior walls and windows is $0.96 \mathrm{~W} / \mathrm{m}^{2} \mathrm{~K}$. The interior walls have a $U$-value of $2.39 \mathrm{~W} / \mathrm{m}^{2} \mathrm{~K}$. The floors and ceilings have a surface absorptance of 0.7 .

\section{Building occupancy, lighting and equipment}

For the purpose of the study, each office was considered as being occupied by 3 persons. There is one person in each printer (small meeting) room. Two persons are in each hallway, and 8 persons in the large conference room.

The spaces are lit using fluorescent lights. A one-step lighting control mechanism turns the lights off inside every space if the combination of daylight and electrical light exceeds the level of $500 \mathrm{~lx}$ in the center of the space.

Computers are considered as constituting the equipment of each office space, and the same equipment loads per unit area are simulated in each of these rooms. Larger loads 
are simulated in the meeting (printer) rooms, as well as in the conference room (projectors, experimental equipment etc.).

\section{Indoor conditions and HVAC systems}

The HVAC system is set in such a way that the temperature inside each space be kept at $23^{\circ} \mathrm{C}$, but allowed to fluctuate \pm 1 degree (throttling range is 2 degrees). The minimum temperature of the supply air is of $17^{\circ} \mathrm{C}$. In the case when the temperature of the recirculation and outside air mix becomes lower than $17^{\circ} \mathrm{C}$, a pre-heater is operated.

The systems that heat or cool the air are working only when the ventilation is working. In the absence of the air conditioning, infiltration is simulated in each space, at a level of $0.2 \mathrm{ach}^{12}$.

Three secondary HVAC systems are simulated, one for the North and East facades, one for the South and West facades and one for the core of the building. They are all Variable Air Volume ${ }^{13}$ (VAV) systems, with the cooling provided by a central chiller and the heating by thermostatically controlled baseboard heaters.

The primary HVAC system is composed of a domestic hot water heater, a hermetic reciprocating compression chiller with an air-cooled condenser, and an electrical boiler.

\section{Building occupancy and operation schedules}

The following occupancy and operation schedules were considered representative for a typical office building:

- air conditioning: 5 am to 6 p.m.

- lights on: 7 am to 6 p.m.

- occupants and equipment working inside the building: 8 am to 5 p.m.

12 ach stands for "air changes per hour". The ach quantity shows how many times in an hour the volume of air inside of a space is completely changed.

13 The working principle of the VAV systems is that the air rate is adapted at each moment so that the highest load of all the zones (spaces) conditioned by the same system be met. VAVs work therefore very rarely at full capacity, which saves fan and cooling power. 
- infiltration: over the time the air conditioning is turned off, i.e. 6 p.m. to 5 a.m. next day The schedules of the occupants, equipment and lights, and for the management of the systems are summarized in Figure 8.

The analysis of the temperature profile of a space is typically complicated. This is due to a fairly large number of simultaneous influences on the thermal regime of the building, which have different intensities. It is the reason for which the approach was taken that the interior loads be introduced gradually. The study started by comparing the results obtained for the different geometries in the case of an empty, non-conditioned building. Each later step consisted of a new internal influence on the temperature being added (ventilation, air conditioning, occupants, equipment and lights). The following building modes were simulated:

1. an unoccupied, non-conditioned building

2. an empty building, ventilated to fulfill the minimum air quality requirements

3. an empty building, fully conditioned to keep the temperature at a constant level

4. an occupied building, which is only ventilated to fulfill the minimum air quality requirements

5. an occupied, fully conditioned building

The influences of the building site and of the building thermal mass are also examined.

\subsection{Effects of Simplifying the Building Geometry on the Indoor Conditions}

\subsubsection{The Unoccupied, Non-Conditioned Building}

In this first step none of the internal building loads are taken into consideration. The only thermal load for the building is in this case the exterior load due to the weather (air temperature and solar radiation), and the only air change mechanism for the inside spaces is infiltration. The spaces studied are MFR10 in the Detailed and SPOT geometries, 
and the corresponding MFR3 spaces in the Simplified and CEC geometries. The study period is August 23-25 for the Red Bluff location.

The ambient air temperature over the time period of the study is shown in Figure 9, and the corresponding temperature profiles inside the studied spaces are shown in Figure 10.

As expected from the fact that the only thermal load of the building is the weather, the profiles correlate well with the diurnal swing of the exterior air temperature. This can be explained based on the fact that for both outside air, and building, radiation from the Sun is the main heat source. Consequently, the moments of both peaks depend only on, and are driven only by, solar radiation.

The high temperatures in Figure 10 are consistent with the fact that the building is not conditioned in a hot climate. The temperature profiles of the MFR10 space in the Detailed geometry and those of the corresponding spaces in the simplified geometries correlate well, the main difference being the daily amplitudes. To explain the cause of this difference, the intensities of the heat transfer mechanisms in each of the geometries were studied. The heat transferred to the adjacent spaces by conduction through the unit area of the interior walls (heat fluxes to adjacent spaces) are shown in Figures $11 \mathrm{a}-\mathrm{c}$. Figure $11 \mathrm{~d}$ shows weighed heat losses to the adjacent spaces in the different geometries. The plotted quantities are the total heat losses through internal walls in each case (flux multiplied by wall area), weighed by the floor area of each space. The figures can be interpreted as follows.

The MFR10 space in the Detailed geometry participates in heat transfer with the hallway and with two adjacent spaces similar to itself. As a result, the space in the Detailed geometry mainly transfers heat to the core of the building (Figure 11 a). Based on this result, and on the assumption that the storage effects are negligible, the elimination of the interior walls appears to be reasonable. 
The MFR3 space in the Simplified geometry is adjacent to the corner rooms MCR3 and MCR4, which, due to their second exterior wall, have a much larger interaction with the exterior. As a result, the space in the Simplified geometry participates in a more intense heat transfer to the adjacent corner spaces, and the overall weighed heat flux to the adjacent spaces is larger than that of the Detailed building (Figure $11 \mathrm{~b}$ ). This affects the daily amplitude of the temperature, which becomes roughly 2 degrees ${ }^{14}$ larger than in the Detailed building (see Figure 9).

The MFR3 space in the CEC geometry participates in heat transfer with the spaces on the other facades of the building. As a result of the lower air temperatures of these spaces, the heat fluxes through the side walls become comparable to the heat flux through the back wall (Fig. $11 \mathrm{c}$ ), and the overall weighed heat flux is even larger than in the case of the Simplified building. The daily amplitude of the temperature is also larger than that of the Detailed building.

The temperature profile in the SPOT geometry shows the largest disparity from the Detailed geometry, with roughly 5 degrees in average temperature. The overheating of the space is due to the adiabatic character of the interior walls, which allows thermal storage in the walls, but prevents any heat transfer to the rest of the building.

The results for this first building mode shows that if an unoccupied, nonconditioned building is modeled, simplifications of the building geometry lead to significant changes in the thermal behavior of the building. In the case of the typical office building, the one-room model with adiabatic interior walls is obviously inadequate for modeling the interior space conditions, because of the complete elimination of the heat transfer mechanisms through the interior walls. At the opposite end of the spectrum, the CEC geometry is inadequate because of the much more intense heat transfer through the interior walls. The space modeled in the Simplified geometry is the best approximation for

14 The 2 degrees difference represents $25 \%$ of the amplitude in the basecase, which is larger than the \pm 20 $\%$ interval found in the evaluation of DOE-2 against measurements (see Chapter 2). 
both the temperature profile, and the heat exchange mechanisms, even though it still displays more intense heat transfer than the Detailed geometry.

\subsubsection{The Unoccupied Building, Ventilated to Fulfill the Minimum Air Quality Standards}

This step introduces ventilation in the previously non-conditioned building. The air flow rate for ventilation was chosen based on the following two considerations. First, an important requirement for providing healthy working conditions inside real buildings is a certain rate of refreshing the air inside the building. For office buildings, this is equivalent to the fact that the designer must size and operate the HVAC system so that every office space is provided the rate of $10 \mathrm{y} / \mathrm{s} /$ person of outside air ${ }^{15}$. Second, the introduction of internal building activities that would contribute to the heat loads or as heat loads removal mechanisms, had to be consistent throughout the study. The next building mode will introduce heating/cooling of the air so that indoor air temperature be kept at a given level. In air conditioning, the recirculation of the air inside a building is a usual strategy for savings in neating/cooling energy. In the most economical situation, the next building mocie would be designed so that most of the air be recirculated, and the minimum rate of outside air would be that required in the ASHRAE standards. Consequently, consistency is achieved between steps if the air flow rates in the only-ventilated building are set at the level of the ASHRAE requirements.

The same consistency reasons were applied when adopting the fan schedule. The model was that of an occupied office building (Figure 8), with the ians working only during the working day. The model allows for infiltration over the time the fans are not working, and the infiltration rate is taken the same as in the case of the non-vented building, i.e., 0.2 volume air changes per hivur.

15 Standard imposed by the American Society of Heating, Refrigeration and Air-Conditioning Engineers (ASHRAE) [8]. 
Figure 12 shows the temperature profiles obtained inside the studied space in the different geometries. Due to ventilation, outside air is supplied to the spaces. Outside air is colder than the indoor air temperature of a non-vented building (compare Figure 9 and Figure 10), and the peak temperatures in this case are consequently lower than those obtained in the non-conditioned building. Although the indoor air temperature profiles still follow the outside air temperature profile, there are some disruptions in the slopes of the curves. These disruptions account for the changes in the fan operation, i.e. the moments when the ventilation starts, and respectively, stops. Figure 12 also shows that the temperature profiles in the different geometries are closer together than in the case of the non-vented building.

Figure 13 shows the weighed heat losses to the adjacent spaces, by conduction through the interior walls. The heat transfer to adjacent spaces through interior walls is, overall, reduced as compared to the case of the non-vented building. This results from the fact that outside air is supplied at equal rates in all spaces through ventilation, which removes a portion of each space load, and brings the temperature of adjacent spaces closer.

The facade office in the Simplified geometry shows a less intense heat transfer to the adjacent offices than the space in the Detailed geometry. This can be explained based on the fact that a number of interior walls were eliminated in the Simplified geometry. As compared to the case of the Detailed geometry where a portion of the radiation is absorbed by the interior walls, the equivalent heat is warming the air in the Simplified geometry, which intensifies the heat transfer to the adjacent spaces.

The CEC geometry shows, as in the case of the non-vented building, the largest heat transfer to the adjacent spaces. This is due, as in the case of the Simplified geometry, to the elimination of interior walls, which leads to additional warming of the inside air.

The one-room description of the office shows again the largest disparity ternperature-wise, due to its adiabatic interior walls that do not allow heat transfer to the 
adjacent spaces. As a result, the heat gain from the exterior mainly warms up the air, which becomes 2.5 degrees higher at peak than in the Detailed geometry.

This step shows that even though the temperature profiles are much closer than those corresponding to the non-conditioned building due to ventilation, the interior heat transfer is still larger in the alternative geometries as compared to the Detailed geometry. The Simplified geometry yields the closest temperature and heat loss profile, which makes it again the best approximation.

\subsubsection{The Unoccupied, Fully Conditioned Building}

In this step, working HVAC systems are modeled inside the building with different floor plan geometries. The working principle of the modeled VAV systems is that the air supply to each zone (space) is adapted at each moment, so that every zone conditioned by the same system, including the zone with highest peak load, be fully conditioned. In our case, this is done by varying the air flow rates of the system so that the temperature inside each zone be kept at $(23 \pm 1)^{\circ} \mathrm{C}$. The air-conditioning system of the building is working only during the working hours, like in the previous step. At night, infiltration is modeled at the same rate of 0.2 ach.

Figure 14 shows the temperature profiles in the different geometries, in the case of the fully conditioned building. The figure shows that over the time the building is conditioned, the temperature of the spaces is kept within the $(23 \pm 1)^{\circ} \mathrm{C}$ interval. The temperature varies however, and the shape of the curves is consistent with the weather conditions (the increase, and then drop, in solar radiation and outside air temperature). There is essentially no difference among the curves over the time the building is conditioned, because in each geometry, the air flow rates are set to adequately perform space conditioning. As soon as the fans are turned off, there is a sudden rise in temperature due to the fact that the heat gains of the spaces are not removed anymore through air conditioning. Over the night hours, when there are no more (external) heat 
gains, the temperature drops slowly, influenced by the drop in outside air temperature through the mechanisms of infiltration and long-wave radiation. When the fans are turned on again, colder air is suddenly supplied, so the temperature of the inside air drops rapidly. Figure 15 shows that the weighed heat losses through the interior walls in this case are even smaller than in the case of the vented building. Also, the discrepancies among the curves are smaller than in the case of the vented building, due to the controlled air temperature inside the building over the day. The figure shows that, as opposed to the previous cases in which heat was lost through interior walls over the whole day, in this case heat is gained in the morning, and then lost in the afternoon. This can be explained based on the fact that the main heat transfer occurs through the back wall. While the facade spaces cool down over night due to convection and radiation to the night sky, the only cooling mechanism of the core of the building is by heat transfer to the facades. The high heat capacity of the walls slows down this process, which makes the core of the building keep its temperature almost constant. When the fans start up in the morning, this temperature is higher than that of the facade spaces. Due to the sudden start of the air conditioning, the temperature drops, including in the core, but the difference in temperatures keeps the same character, which allows heat transfer from the core to the facades. Conversely, in the afternoon when the solar gain is high on the South facade, the temperature inside the facade spaces becomes higher than that of the core, and heat is transferred the other way.

The results of this step show that if the user is only interested in the temperature profile of a conditioned facade space, even the one-room description is a good approximation of the Detailed geometry. The one-room model is easier to design in DOE2 , and also requires less computer time to obtain results. If the entire building needs to be modeled and simplifications are imposed, the CEC geometry is a good approximation for the purpose of determining the temperature profiles inside. If, however, the interest is that 
the approximation yields results as close as possible to those of the Detailed geometry, the Simplified geometry is once more the one to be used.

\subsubsection{The Occupied Building, Ventilated to Fulfill the Minimum Air Quality Standards}

This step introduces the internal loads from occupants, equipment and lights to the vented building. The occupancy and equipment, lights, fan operation schedules are the same as in Figure 8. Infiltration is again modeled at the same rate over the time when the ventilation is turned off.

Figure 16 shows the temperature profiles in this case, and Figure 17, the weighed heat losses to the adjacent spaces through the interior walls. As compared to the case of the unoccupied vented building (Figure 12), the addition of internal loads causes a raise in interior temperature, the temperature becoming 6 degrees higher in average. The temperature profiles are discontinuous like in the previous case, the points of discontinuity corresponding to the presence or absence of internal loads and ventilation. Turning on the fans causes a drop in temperature due to colder outside air being supplied inside the building. Turning on the lights causes the temperature to drop in a less pronounced way, due to the fact that extra loads are added. Adding the loads from the occupants and equipment, simultaneous with a rise in temperature outdoors causes a raise in temperature due to extra loads that the (now warmer) supplied air cannot compensate. The removal of the loads from occupants, equipment and lights, with the fans still on, causes a drop in temperature. Turning off of the fans causes a temperature rise due to the fact that outside air is not forced inside the building anymore, but there still is heat stored in the internal walls. Over the night hours, the infiltration and long-wave radiation to the exterior causes a slow drop in temperature.

The examination of the heat fluxes leads to the conclusion that the extra internal loads due to heat gain from people, equipment and lights brings the space conditions closer in the adjacent spaces. The heat loss through the internal walls becomes less intense 
than in the case of the unoccupied, vented building. Both the Simplified and the CEC geometries display somewhat different heat transfer than the Detailed building, their trends diverging in the morning hours and converging in the afternoon. Due to the fact that the Simplified geometry displays a higher swing of the heat transfer curve, the CEC geometry appears to be a better approximation of the Detailed building, for heat transfer.

\subsubsection{The Occupied, Fully Conditioned Building}

This last case introduces the loads from occupants inside the fully conditioned building. The term "fully conditioned" refers again to the fact that the model sizes the air flow rates so that the air flow meet the highest load in the zones, while creating and keeping certain indoor conditions inside the building. By consequent, when comparing the results of this simulation with the results in the case of the unoccupied building, the spaces are not expected to have higher temperatures due to the added internal loads.

Figure 18 shows the temperature profiles in the different geometries in this case, and Figure 19, the weighed heat losses through the interior walls. The thermostat setpoint for the cooling system is $23^{\circ} \mathrm{C} \pm 1^{\circ} \mathrm{C}$.

The temperature profiles again display discontinuities, which correspond to the different loads added to the building. The temperature is kept within the throttling range over the time the air conditioning is working, and then is increasing slightly over the day, due to the load from the weather. There is no noticeable difference among the temperature profiles for the different geometries over the time the air conditioning is on, and very small differences over the time it is turned off. Also, the one-room description seems to yield the closest results to the Detailed building geometry, so the conclusion is reached that this very simple model can be successfully used in the study of the inside conditions of this building. The heat fluxes obtained in this case show that it is not really the case.

To interpret the large reduction of the heat transfer intensity through the interior walls as compared to the previous case, the same approach is taken as in the case of the 
cooled building. The building is conditioned according to its internal loads. The conditions in adjacent rooms become much closer than in the only-vented case, and the fluxes are reduced compared to the case of the only-vented building. The heat transfer to the spaces is again from the building core in the morning hours, and to the building core in the afternoon. Also, the difference between the curves for the Simplified geometry and the Detailed is again larger than that of the CEC geometry, which makes the CEC a closer approximation of the Detailed building, for heat transfer.

\section{Preliminary Conclusions}

The comparison of the space conditions in the different stages of simplifying the floor plans of a building, enables the user to observe the difference in temperature profiles and in heat transfer mechanisms introduced by altering the geometry. The results show that the magnitude of the heat transfer through the internal walls increases with the elimination of the internal structure, an approximation that was assumed as not affecting the results. The sensitivity study shows the magnitude of the changes in heat transfer intensity, as a result of the different loads introduced in the simulation.

The main conclusion reached is that the examination of only one parameter (the temperature) might be misleading when the decision of adopting a simpler building geometry is to be made. The results show that the Simplified geometry is preferable to the others if the temperature profiles have to be matched, while the CEC geometry is the best approximation if the user is interested in the heat transfer mechanisms in an occupied building. This is also a confirmation of the fact that, if this building were tested for compliance to Californian standards, the test, using the CEC geometry as imposed by the Californian Energy Commission, would yield results in good agreement with the basecase building, and would at the same time be performed in the most efficient time- and computer-wise way. The one-room approximation provides good results for the space 
temperature in some cases, but it does not give any information at all about the heat transfer mechanisms inside the building.

\subsubsection{The Effects of Climate on the Previous Results}

The study was aimed so far at determining the effects of floor plan simplifications on the results of a building thermal simulation. The results were however also influenced by the climate of the building site. Placing a non-conditioned office building in Red Bluff and studying the temperature profiles for a number of days in August resulted in temperature ranges inside the building that are far beyond comfort conditions. Ventilation and air conditioning were then introduced and the effects that each of them, as well as the effects of the loads from people and equipment on the interior conditions, were studied. The scope of this section is to determine what effect, if any, does the climate in which the building is simulated have on the conclusions reached so far. To this end, a different climate was simulated and the same steps were taken for the study of the building. The new climate was chosen to be that of San Diego, California. A description of the two climates follows [9].

Red Bluff $\left(40.2^{\circ} \mathrm{N}, 122.2^{\circ} \mathrm{W}, 104 \mathrm{~m}\right.$ altitude) is situated in the northern end of the Sacramento Valley. Mountains surround the city on three sides: the Coastal Range is located at about $45 \mathrm{~km}$ west, the Sierra Nevada at about $60 \mathrm{~km}$ east and the Cascade Range at about $75 \mathrm{~km}$ northeast and north. Precipitation is confined mostly to rain during winter and spring months. Temperatures reach their highest during the months of June through September, when daytime readings are very frequently over $35^{\circ} \mathrm{C}$. Nighttime temperature are however usually comfortable. Enthalpy and temperature of outdoor air exceed average return air conditions in a HVAC system for roughly three months. Due to a relatively stable humidity ratio over the course of the year, enthalpy scales directly with temperature. The yearly temperature profile in Red Bluff for a "representative year" is given in Figure $20 \mathrm{a}$. 
San Diego $\left(32.7^{\circ} \mathrm{N}, 117.2^{\circ} \mathrm{W}\right.$ and $4 \mathrm{~m}$ altitude) is located in the southwest corner of southern California. Weather is tempered by the Pacific ocean, resulting in cooler summers and warmer winters than usual at the same latitude. Dry easterly winds blow sometimes in the vicinity for several days at a time, causing temperatures to rise above $30^{\circ}$ C. Outdoor temperatures are therefore in the range of return temperatures most of the year (Figure $20 \mathrm{~b}$ ). A dominant characteristic is, as on the rest of the Pacific coast, the spring and summer nighttime and early morning cloudiness. Due to high humidity values, enthalpy limits are substantially exceeded during the summer months. The critical period during which the outside air conditions exceed return air conditions lasts for four months.

Calculations were conducted for the building in the San Diego climate, following the same strategy described for Red Bluff. The study period was centered on the day of the peak cooling load on the Southern facade, the day of September 19. As compared to the weather in Red Bluff at the time of the peak load, the San Diego temperatures are much lower (Figure 21). This leads to the conclusion that the peak loads in the two climates are induced by two different mechanisms. In Red Bluff, high outside air temperatures in August induce internal load buildup, with a peak in the period of the hottest summer days. In San Diego, the lower temperature-driven buildup is surpassed by the direct solar radiation load, which leads to a peak time close to the day of the Fall Equinox.

The results obtained in the case of the San Diego climate are similar to the ones in Red Bluff. To illustrate this, Figure 22 shows the temperature profiles for the four geometries in San Diego for the case of the occupied, fully conditioned building. A comparison with the corresponding Figure 18 shows that, all other factors being kept constant, the simulations yield similar results in the two climates. Over the time the HVAC system is working, the temperature is kept within the interval $\left(23^{\circ} \mathrm{C} \pm 1^{\circ} \mathrm{C}\right)$, but it swings over the night hours. The major difference between the results for the two climates is the 
amplitude of the temperature swing, which correlates with the amplitude of the outdoor air temperature swing at the radiation level given in each climate.

These results show that the building geometries have the same general behavior in the two different sites studied. The same conclusions are reached about the opportunities of simplifying the building geometries if the study is made in either of the two climates. The reader needs to be aware, however, that both simulated climates belong to the general Californian climate. If a conclusion needs to be reached for any other (non-Californian) climate, it is recommended that the same study be performed again, for the different building site.

\subsubsection{The Effect of the Building Thermal Mass on the Previous Results}

The last verification of the results of the sensitivity study, is done by examining the effects of changing the thermal mass of the building on the previous results. The thermal mass of the building can be altered by changing the materials of the wall component, as well as their thickness. The wall structure used in the previous models was shown in Figure 7, and can be described as a medium-heavy thermal structure. For the purpose of this section, the light thermal structure shown in Figure 23 was simulated. The parameters describing the thermal properties of the new wall structure are the following: the exterior walls have a $\mathrm{U}$-value of $0.27 \mathrm{~W} / \mathrm{m}^{2} \mathrm{~K}$, and the average $\mathrm{U}$-value of the exterior walls and windows is $1.1 \mathrm{~W} / \mathrm{m}^{2} \mathrm{~K}$. The interior walls have a $\mathrm{U}$-value of $0.37 \mathrm{~W} / \mathrm{m}^{2} \mathrm{~K}$. The ceilings and floors have a surface absorptance of 0.7 .

The same calculations as in the case of the medium-heavy type of building were performed for the Red Bluff climate. The peak cooling load was again obtained on August 24 for the South facade, which supports the assumption that the peak load is determined by internal load buildup, driven by high temperatures.

The case of the occupied, fully conditioned building was again chosen to illustrate the results. Figure 24 shows the temperature profiles obtained for the four geometries. 
The similarity with the results for the medium-heavy building is evident. Over the time when the air conditioning is working, the indoor air temperature is kept within the $\left(23^{\circ} \mathrm{C} \pm\right.$ $1^{\circ} \mathrm{C}$ ) range. The temperature rises as the air supply is turned off, and the internal loads are

not removed anymore. Then the temperature drops overnight, due to infiltration and infrared radiation to the night sky and the ground.

The difference in thermal mass accounts for the difference in the slopes of the temperature profiles. The temperature swing is more pronounced for the light building structure, both when the air conditioning is working, and when it is turned off. Over the night hours, the light building structure cools down more than the medium-heavy structure.

The character of the temperature profiles obtained in the cases of the two structures is nevertheless the same. This leads to the conclusion that the results of the sensitivity study are similar even if conducted for different wall structures.

\subsection{Effects of Simplifying the Building Geometry on Sixing the HVAC System}

The building thermal simulation programs are frequently used as a starting point for evaluating the size of the HVAC equipment needed for adequately conditioning the building. The results of such a DOE-2 application, modeling the same building geometries as before, are studied in this section. The scope is to determine what effect, if any, does the simplification of the floor plan geometry have on the suggested size of the HVAC system.

The DOE-2 output data to be examined is given by the sequence (see Figure 6)

1. building and space loads from LOADS

2. sizing of the supply air flow to each system and to each zone in SYSTEMS

3. building peak loads required by the HVAC systems in SYSTEMS from the central plant

4. sizing of the primary HVAC system necessary to meet these loads in PLANT

5. energy consumption of the primary HVAC system from PLANT 
The same HVAC systems were simulated as in the sensitivity study. Table 1 summarizes the simulation output for the four building geometries.

\section{Table 1: Simulation Output Parameters}

\section{LOADS}

Building Peak

Cooling Load[kW]

[\%] Difference

$\begin{array}{cccc}\text { Detailed } & \text { Simplified } & \text { CEC } & \text { SPOT } \\ 20.890 & 20.965 & 21.092 & \\ - & 0.4 & 1.0 & \\ & & & \\ 1.084 & 1.106 & 1.228 & 1.138 \\ - & 2.0 & 13.3 & 5.0\end{array}$

Facade Office Peak

Cooling Load[kW]

[\%] Difference

SYSTEMS

Supply Fan

SW System [ [/s]

[\%] Difference

Cooling Capacity [kW]

[\%] Difference

$\begin{array}{ccc}\text { Detalled } & \text { Simplified } & \text { CEC } \\ 1805 & 1815 & 1882 \\ - & 0.6 & 4.2 \\ 26.855 & 26.974 & 27.445 \\ - & 0.4 & 2.1\end{array}$

PLANT

Chiller Size[MW]

Cooling Tower Size [MW]

Detailed

55

Energy Consumption [MWh]

Space Cooling

[\%] Difference

HVAC Aux.

[\%] Difference

Lights

[\%] Difference

Miscellaneous
70

22.12

-

12.86

-

6.92

-

17.13

$\begin{array}{cc}\text { Simplified } & \text { CEC } \\ 56 & 55 \\ 71 & 70\end{array}$

22.18

0.2

20.69

13.03

1.3

12.37

3.8

6.76

6.76

2.3

17.13

17.13

These results can be interpreted as follows:

The building peak calculated in LOADS for the two simplified floor geometries are good approximations of the "accurate" building peak load. This shows that any building simplification may be used if the fixed temperature simulated for the entire building in the LOADS module is considered appropriate for the application.

The data for the space peak load refer to the MFR10 and its equivalents. They show that the values calculated in the cases of the different geometries differ as little as 
$2 \%$ in the case of the Simplified geometry and as much as $13 \%$ in the case of the CEC geometry. The larger load obtained after eliminating the interior walls in the Simplified geometry can be explained considering the approximations that DOE-2 introduces regarding the direct solar radiation that entering a space: $60 \%$ is distributed on the floor and $40 \%$ among the other walls. Since a number of interior walls has been eliminated from the office space in the Simplified geometry, a considerably larger fraction of the total direct radiation falls on the remaining internal walls, which warm up more than the interior walls in the Detailed geometry. Consequently, convection becomes more intense, and the space load increases in this geometry. The larger difference between the space peak load obtained in the CEC geometry and the Detailed geometry is due both to the effect of eliminating the interior walls, and to the extra exterior heat gains through the larger facade. The difference introduced by the one-space model is due to the adiabatic character of its interior walls, which prevents heat loss to the adjacent spaces and thus increases the heat load of the space.

The discrepancies in the sizing of the secondary system of the HVAC in the different geometries correlate with the discrepancies observed in the peak loads. The explanation is that, due to the character of the HVAC systems modeled, the sizing was done by the program according to the calculated peak load.

The difference in the primary HVAC sizes is minor. It is not correlated with the secondary systems size difference anymore, because in the case of primary systems, the DOE-2 sizing is done by selecting the existed (marketed) equipment size that can meet the secondary system demands.

The results of this section show that it is recommended to choose the floor plan geometry simplifications according to the scope of the simulation. The one-space model is a good approximation of the building if the scope of the study is the sizing of the HVAC equipment that would condition only that one space. The CEC geometry yields results that are close to the "accurate" ones if the user is only interested in the sizing of the equipment 
and is willing to neglect the side effects produced by considerably different space loads. The Simplified floor plan is the best approximation of the building. It is the only simpler studied building geometry that supplies all the results within a range of a few percent from the results of the Detailed geometry. 


\section{CONCLUSIONS}

- The simplification of floor plan geometry in thermal building simulation applications leads to results that differ from those obtained if the building geometry was described in detail.

- The size of the differences introduced depends on the thermal regime of the building. The more the interior conditions are controlled through air conditioning, the smaller the differen res introduced by floor plans simplifications. Depending on the application, situations might occur in which the differences are negligible and the building simulation can be safely performed using a simpler floor plan geometry.

- The character of the differences introduced does not depend on the building location in a given climate, or on the building thermal mass.

- A study of the effects of simplifying the building floor plans on the results of the simulations is recommended whenever simplifications are imposed. Such a study would result in determining the building thermal regimes in which the differences introduced are not significant.

- The decision of adopting simplified floor plans in the thermal simulation of buildings needs to be made according to is- scope of the simulation. A study like the one this paper proposes shows some important factors that might help in such a decision. 


\section{References:}

1. U.S. Congress, Office of Technology Assessment, Building Energy Efficiency, OTA-E518 (Washington, D.C.: U.S. Government Printing Office, May 1992), pp 3-4.

2. California Energy Commission, Compliance Options Approval Manual for the Building Energy Efficiency Standards, March 1988, p C-2.

3. Birdsall, B., Buhl, W.F., Ellington, K.L., Erdem, A.F., Winkelmann, F.C., Overview of the DOE-2 Building Energy Analysis Program, Version 2.1 D, LBL-17935, Rev.1 UC350 .

4. DOE-2 Basics, Simulation Research Group, Center for Building Science, Energy and Environment Division, Lawrence Berkeley Laboratory, Berkeley, CA 1991, p 1.19

5. SERI No. TR-253-265^, A Somparative Validation Study of the BLAST-3.0, SERIRES-1.0 and DOE-2.1A Using the Canadian Direct Gain Test Building, 1985

6. NTIS Order No. DE-84010570/LA, DOE-2: Comparison with Measured Data, Design and Operational Energy Studies in a New High-Rise Office Building, Vol.5

7. Birdsall, B. , A Comparison of DOE-2 Prediction with Thermal Mass Test Cell Measurements, LBL-18981, 1985

8. ASHRAE Standard 62-1989 (ISSN 1041-2336),Ventilation for Acceptable Ai, Quality, American Society of Heating, Refrigerating and Air-Conditioning Engineers, Inc., Atlanta, GA 1989, p 8

9. Local Climatological Data - Annual Summaries for 1980, NOAA National Oceanic and Atmospheric Administration, Environmental Data and Information Service, National Climate Center, Ashville, NC 1981 


\section{List of Figures:}

Figure 1 Building energy use: two future scenarios [1]

Figure 2 The Detailed description of the structure of a specific office building

Figure 3 The Simplified floor plan of the office building

Figure 4 The CEC equivalent of the office building floor plan

Figure 5 The one-space (SPOT) approximation of the office building

Figure 6 The DOE-2 program flow

Figure 7 The structure of a medium-heavy thermal mass wall

Figure 8 Internal activities of the office building

Figure 9 Outside air temperature in Red Bluff, August 23-25 of the typical year

Figure 10 Temperature profiles in the case of the unoccupied, non-conditioned building

Figure 11 a Heat fluxes from the space in the Detailed geometry

Figure $11 \mathrm{~b}$ Heat fluxes from the space in the Simplified geometry

Figure $11 \mathrm{c}$ Heat fluxes from the space in the CEC geometry

Figure $11 \mathrm{~d}$ Weighed heat losses from the space through interior walls in the different geometries

Figure 12 The temperature profiles in the case of the unoccupied, vented building

Figure 13 The weighed heat losses from the space through interior walls in the unoccupied, vented building

Figure 14 The temperature profiles in the case of the unoccupied, fully conditioned building

Figure 15 The weighed heat losses from the space through interior walls in the unoccupied, fully conditioned building

Figure 16 The temperature profiles in the case of the occupied, vented building

Figure 17 The weighed heat losses from the space through interior walls in the occupied, vented building

Figure 18 The temperature profiles in the case of the occupied, fully conditioned building 
Figure 19 The weighed heat losses from the space through interior walls in the occupied, fully conditioned building

Figure 20 a The outside air temperature in Red Bluff for the typical year [9]

Figure 20b The outside air temperature in San Diego for the typical year [9]

Figure 21 Outside air temperature in San Diego, September 18-20 of the typical year

Figure 22 The temperature profiles in the occupied, fully conditioned building located in San Diego

Figure 23 The wall structure in a light thermal mass building

Figure 24 The temperature profiles for a light thermal structure, in an occupied, fully conditioned building 


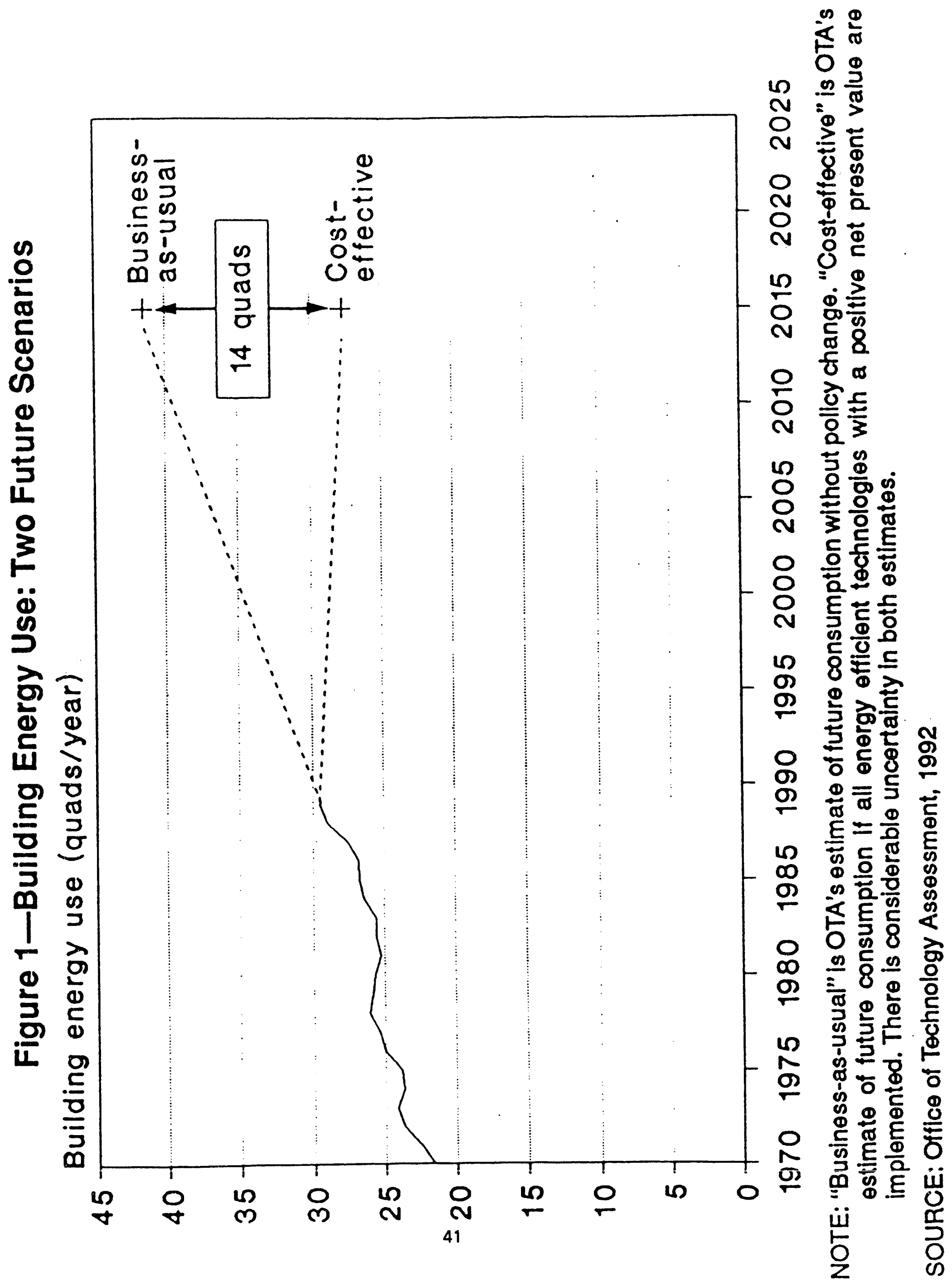




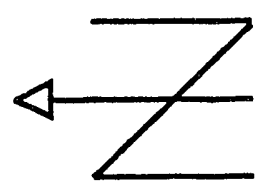

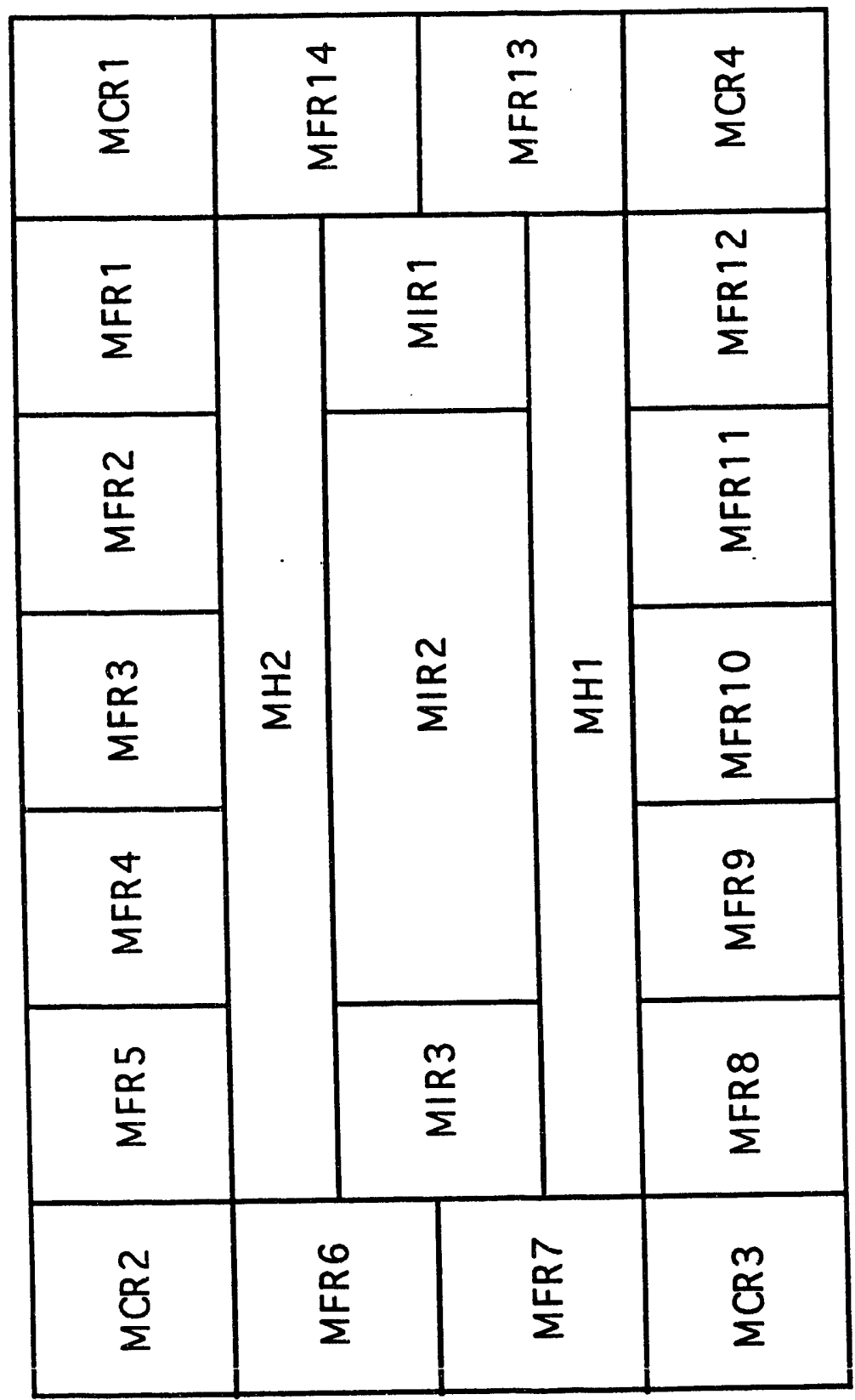

짐 

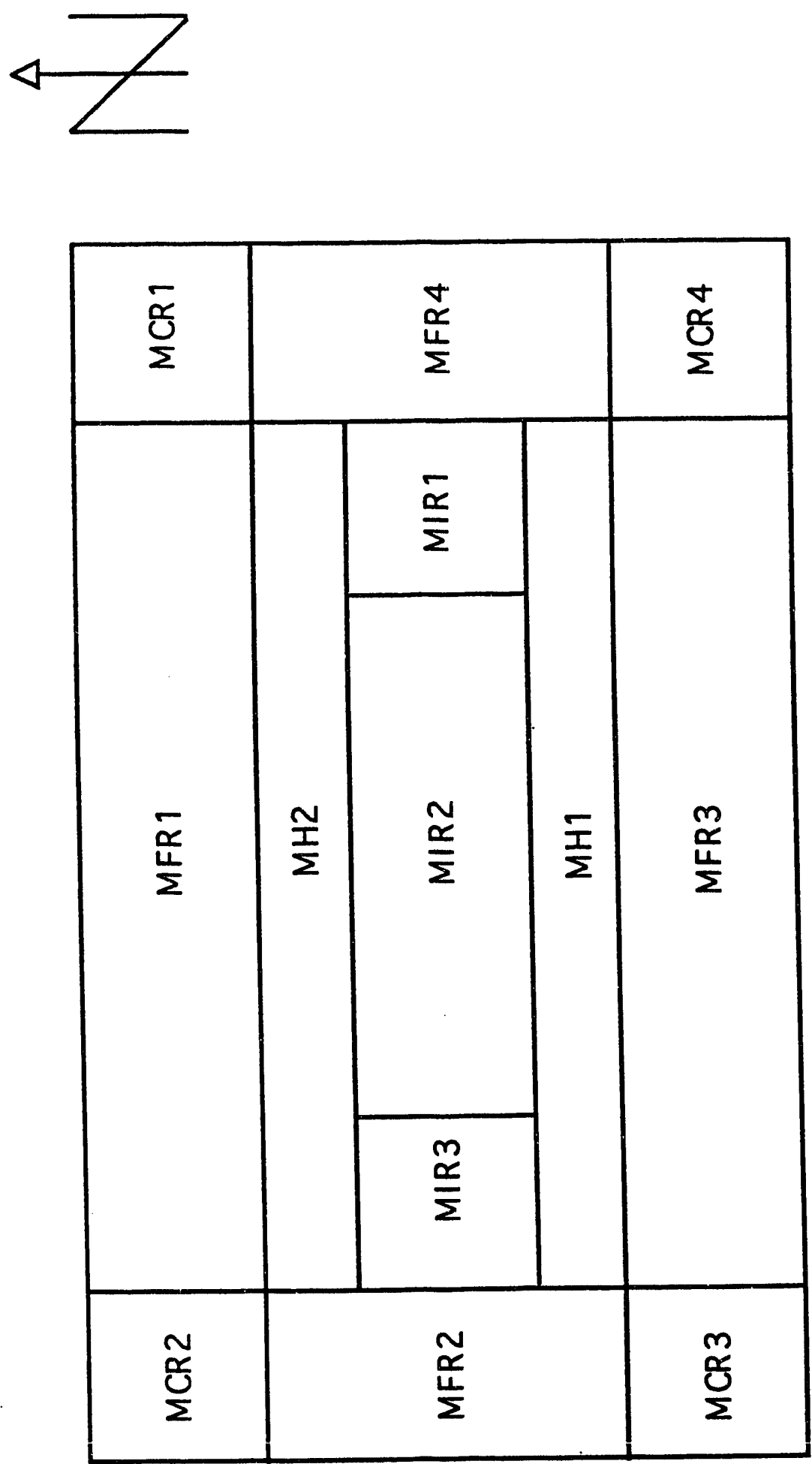

$\frac{0}{20}$ 

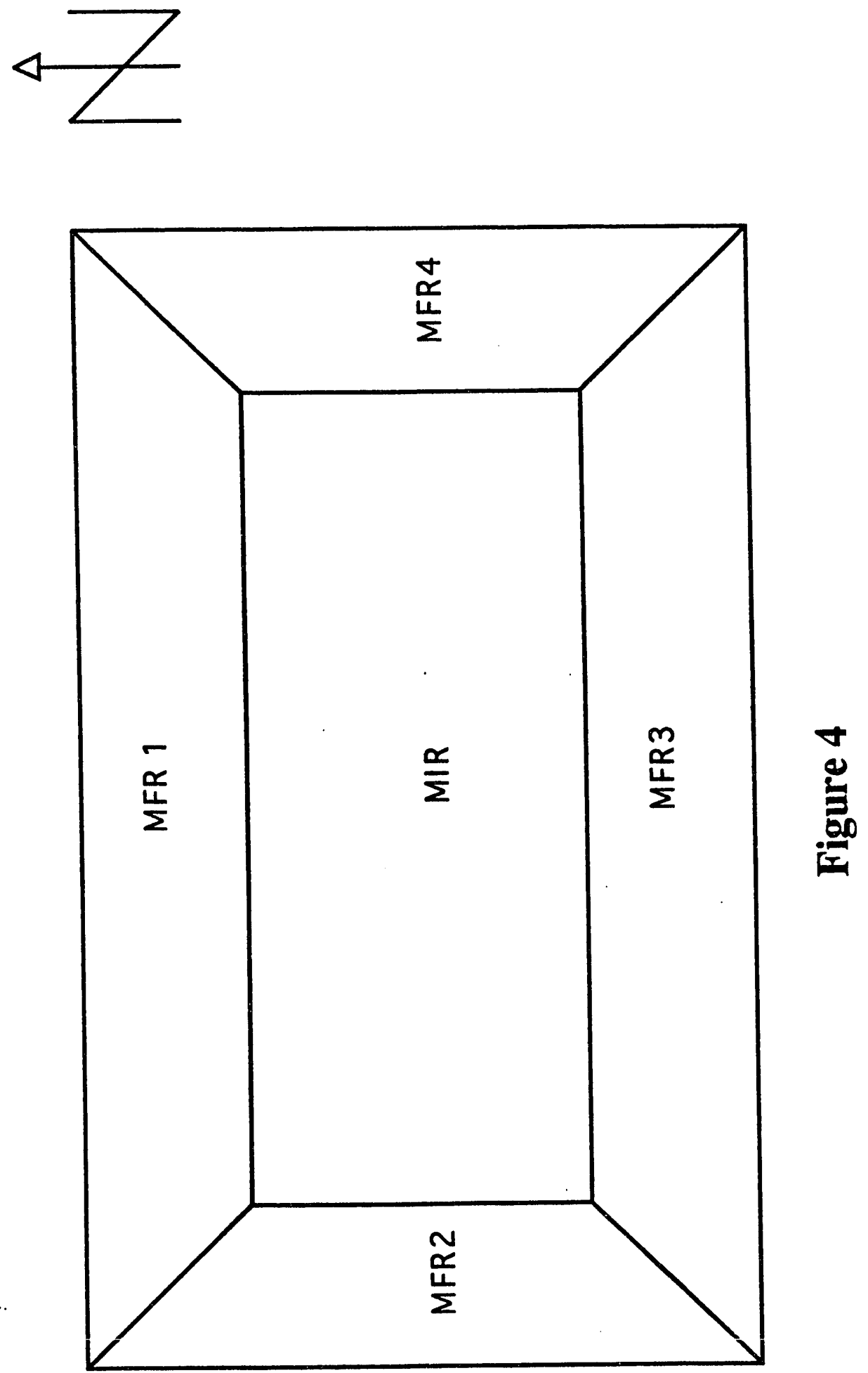

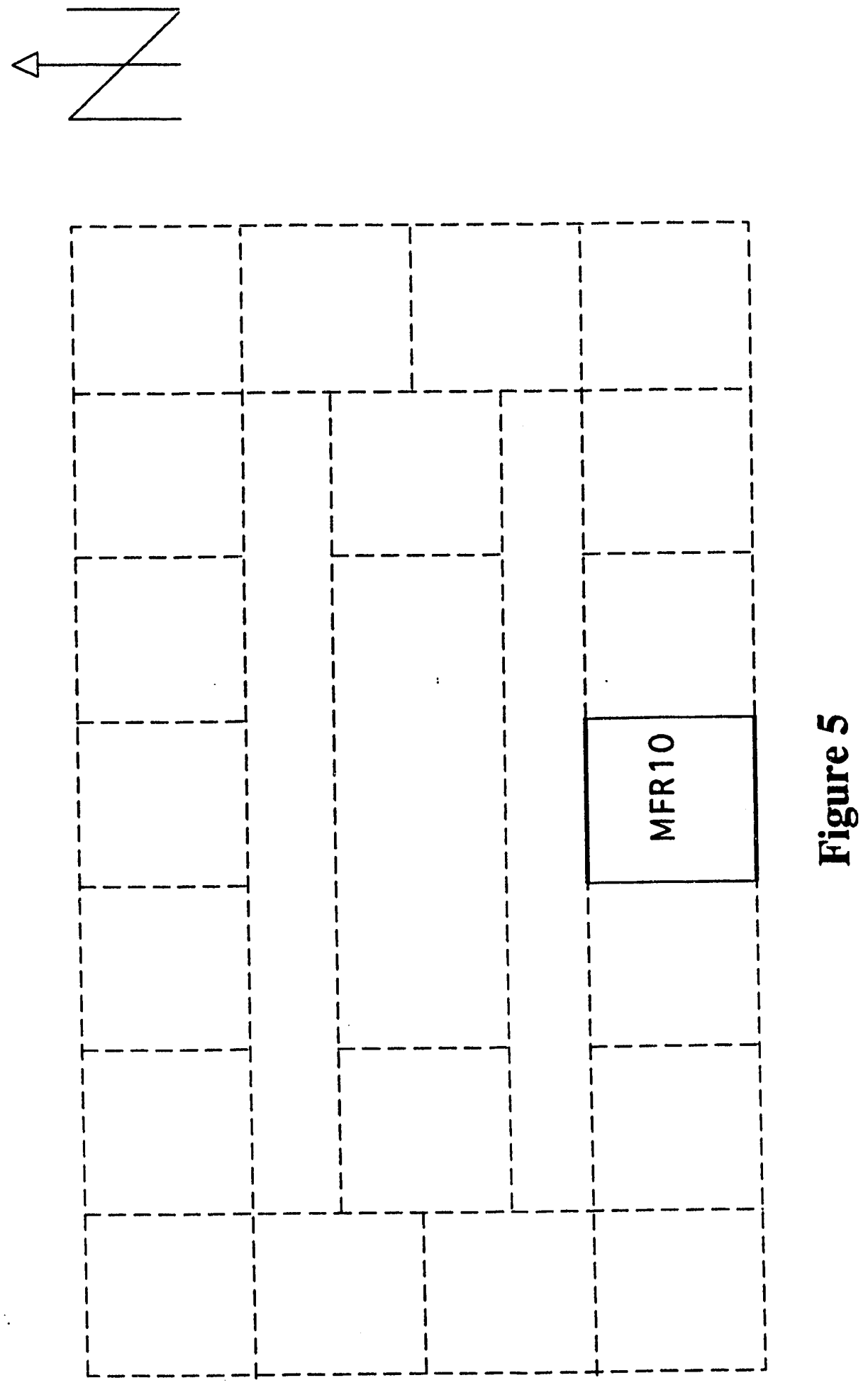

45 


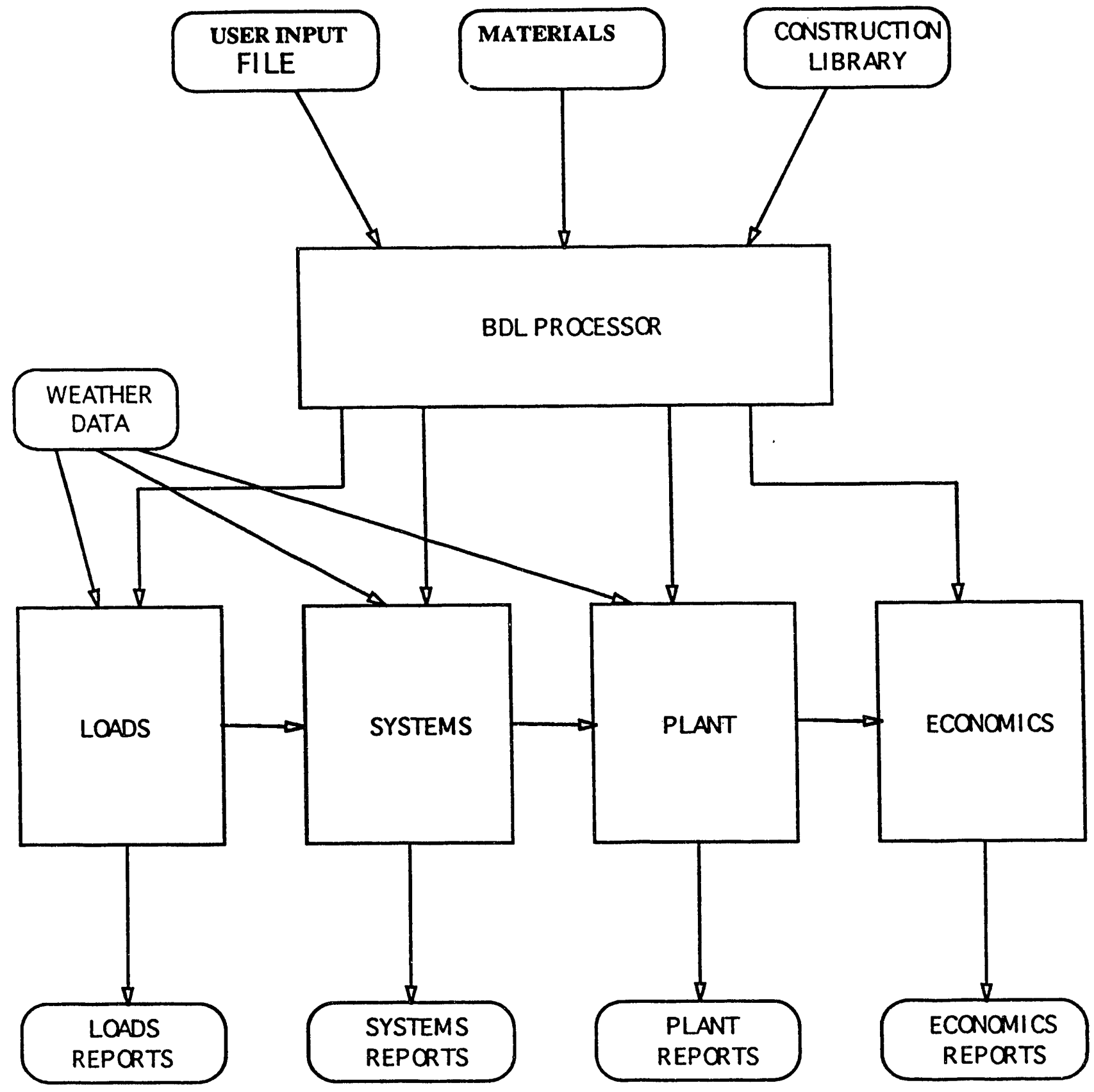

Figure 6 


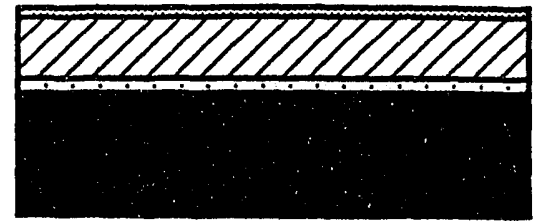

Floor Structure

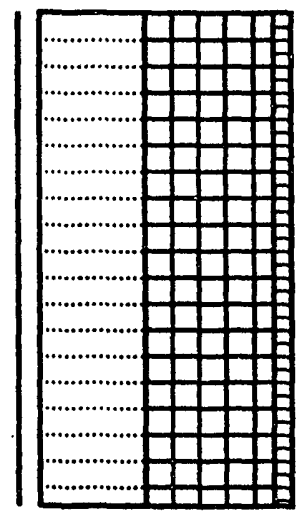

Vented Exterior Wall Structure

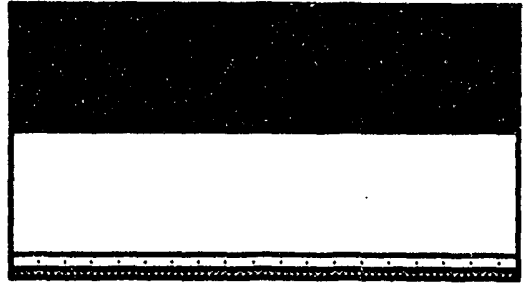

Ceiling Structure

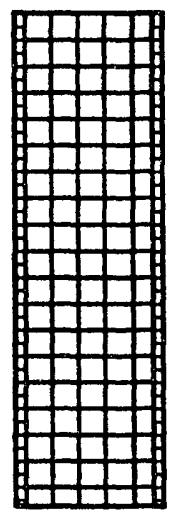

Interior Wall Structure

Material Legend :

Concrete

Mineral Board

E U-Floor

Felt Matress

$\square$ Air Space

Gypsum Board
Plaster

EI Red Masonry

….... Mineral Wool 


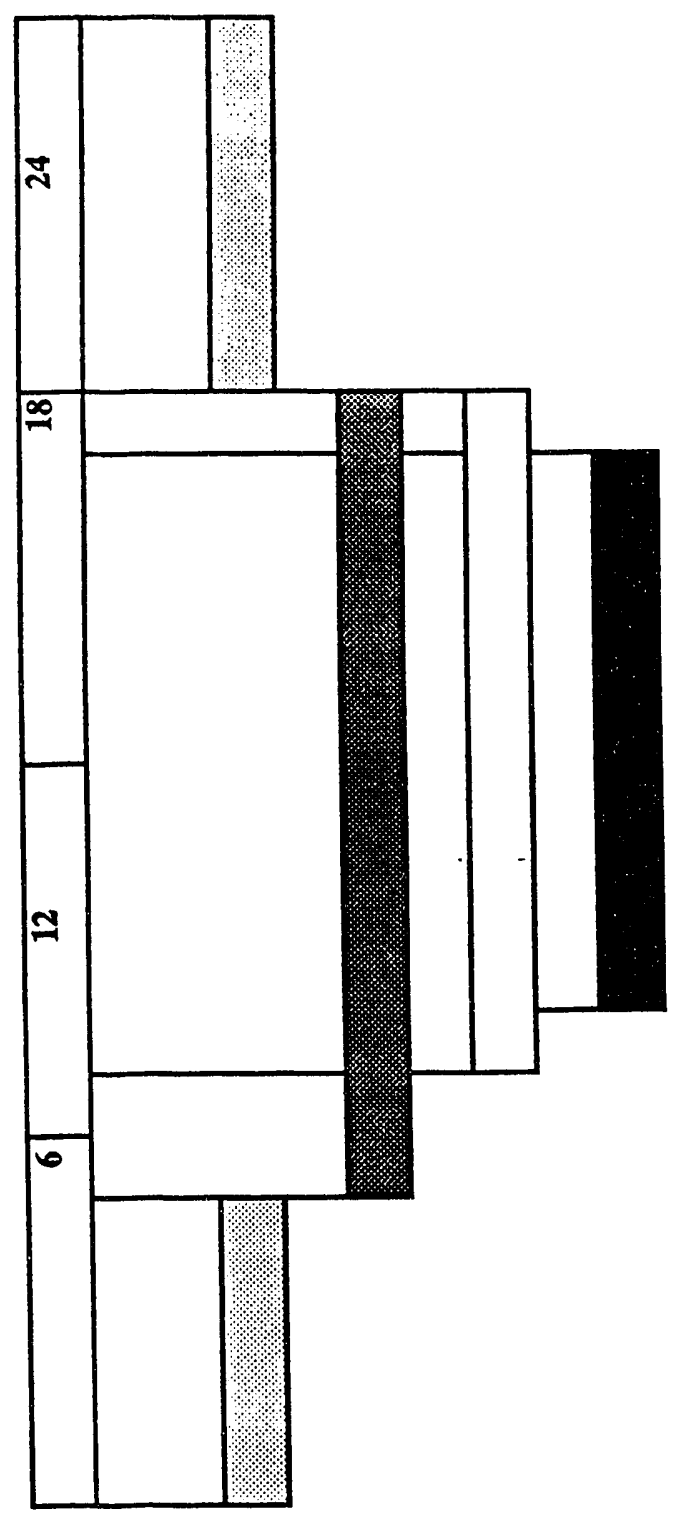

$\underset{\substack{0 \\ 0}}{\infty}$

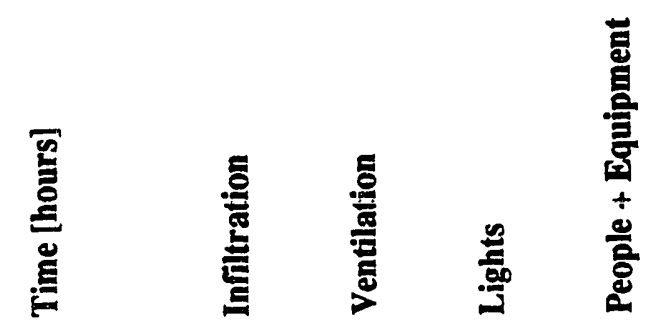

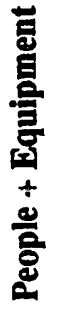




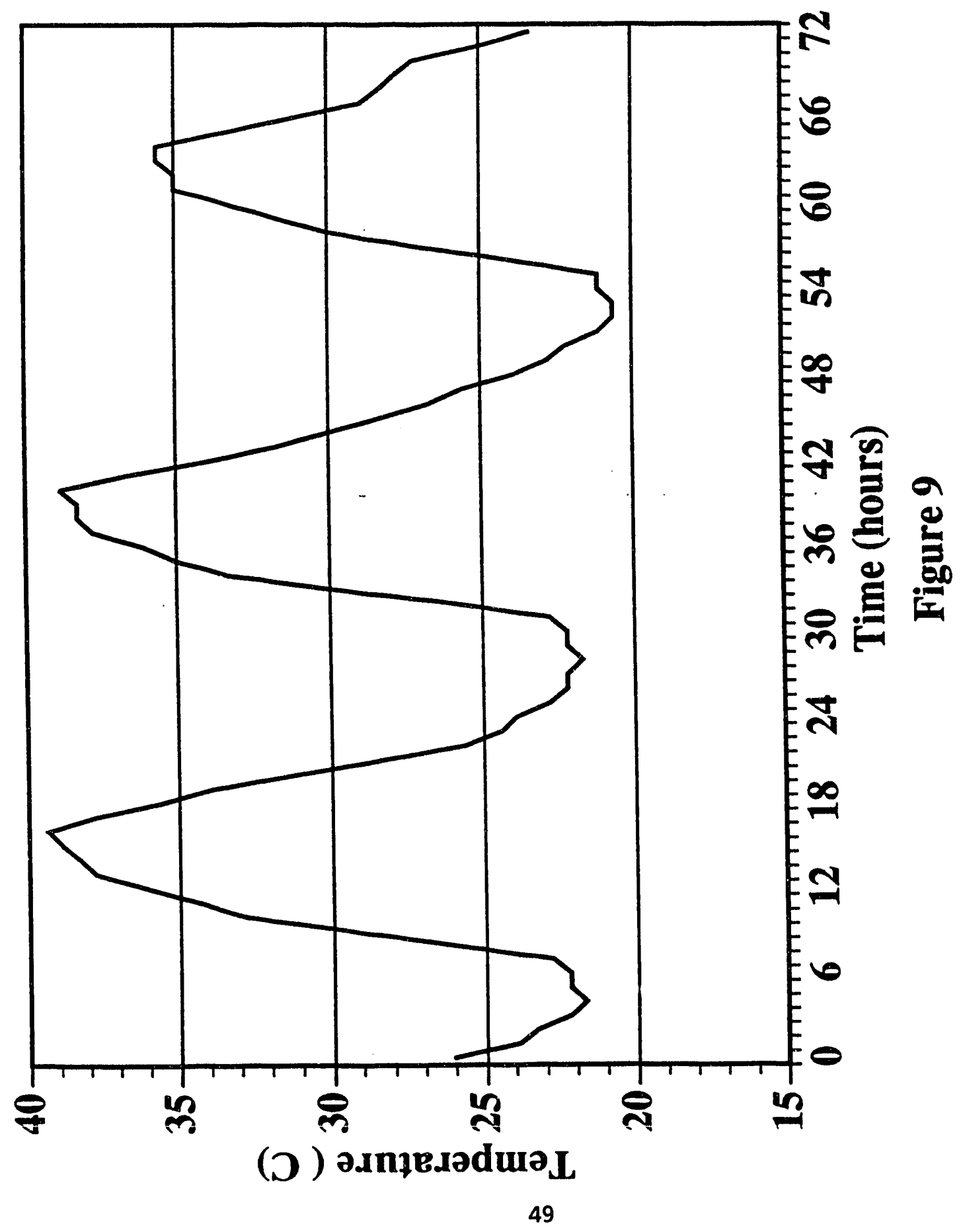




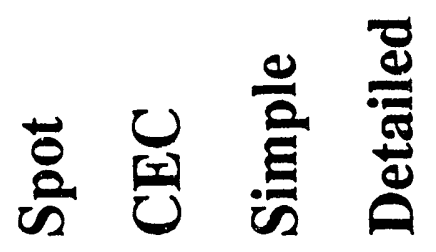

11

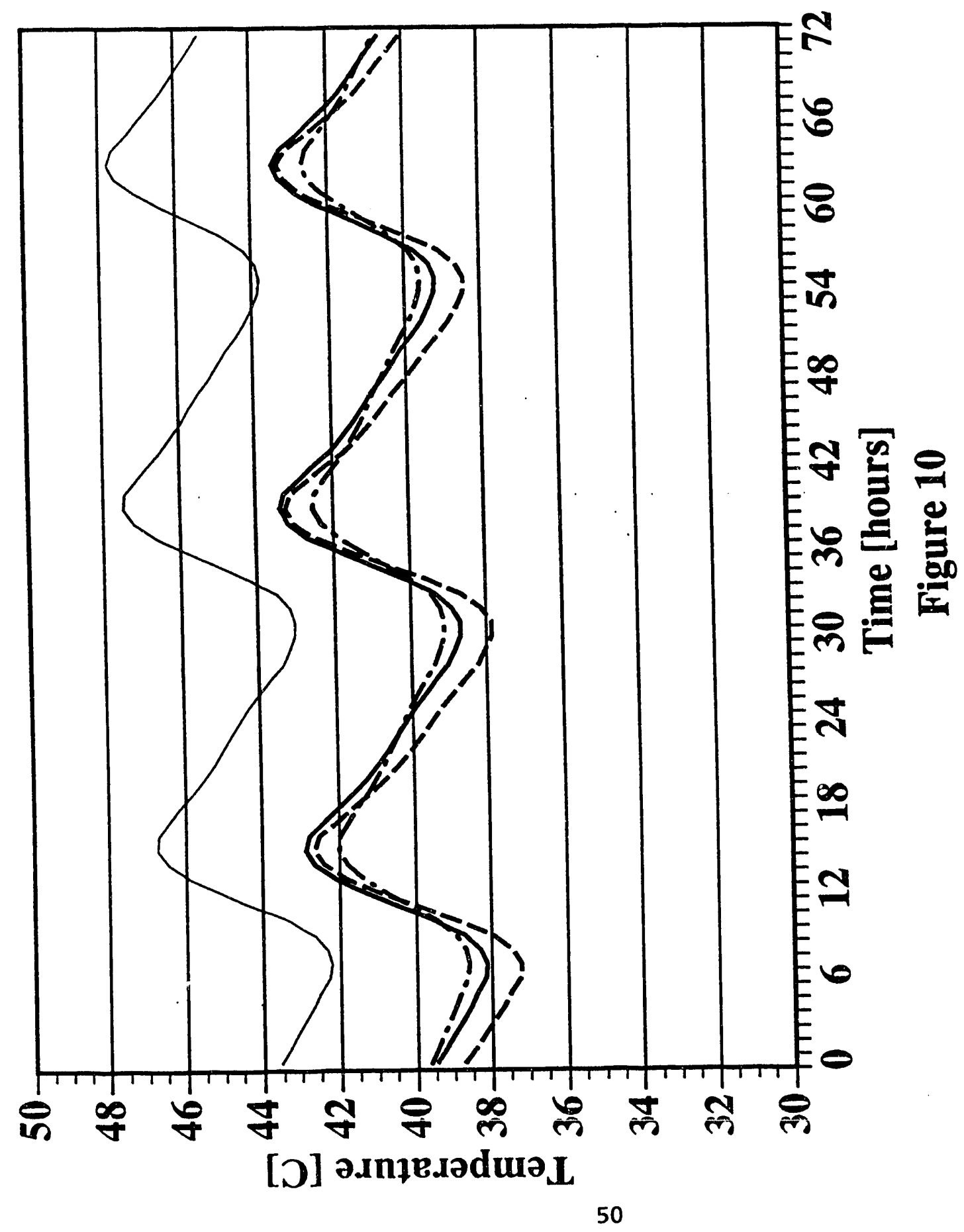



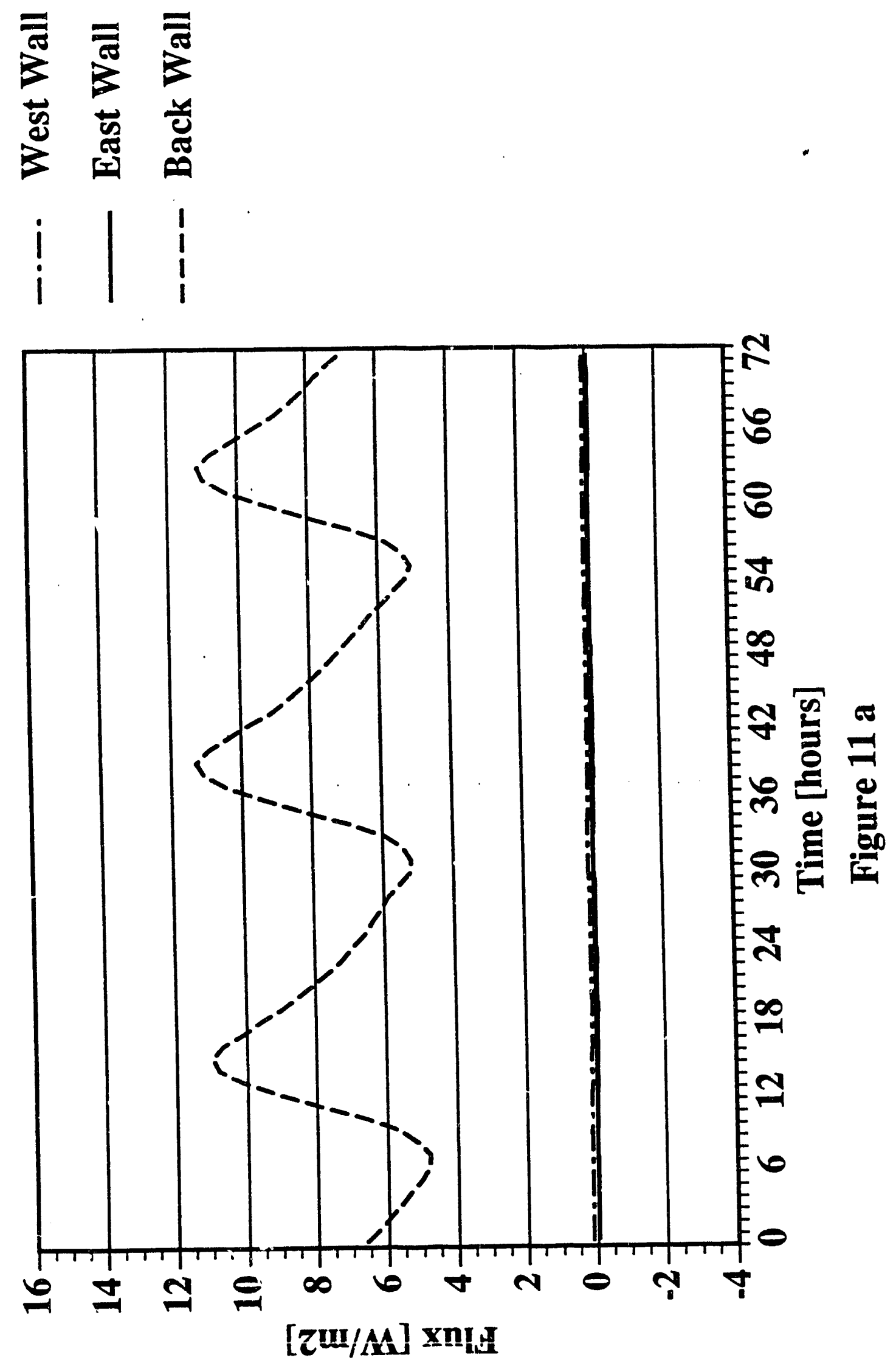

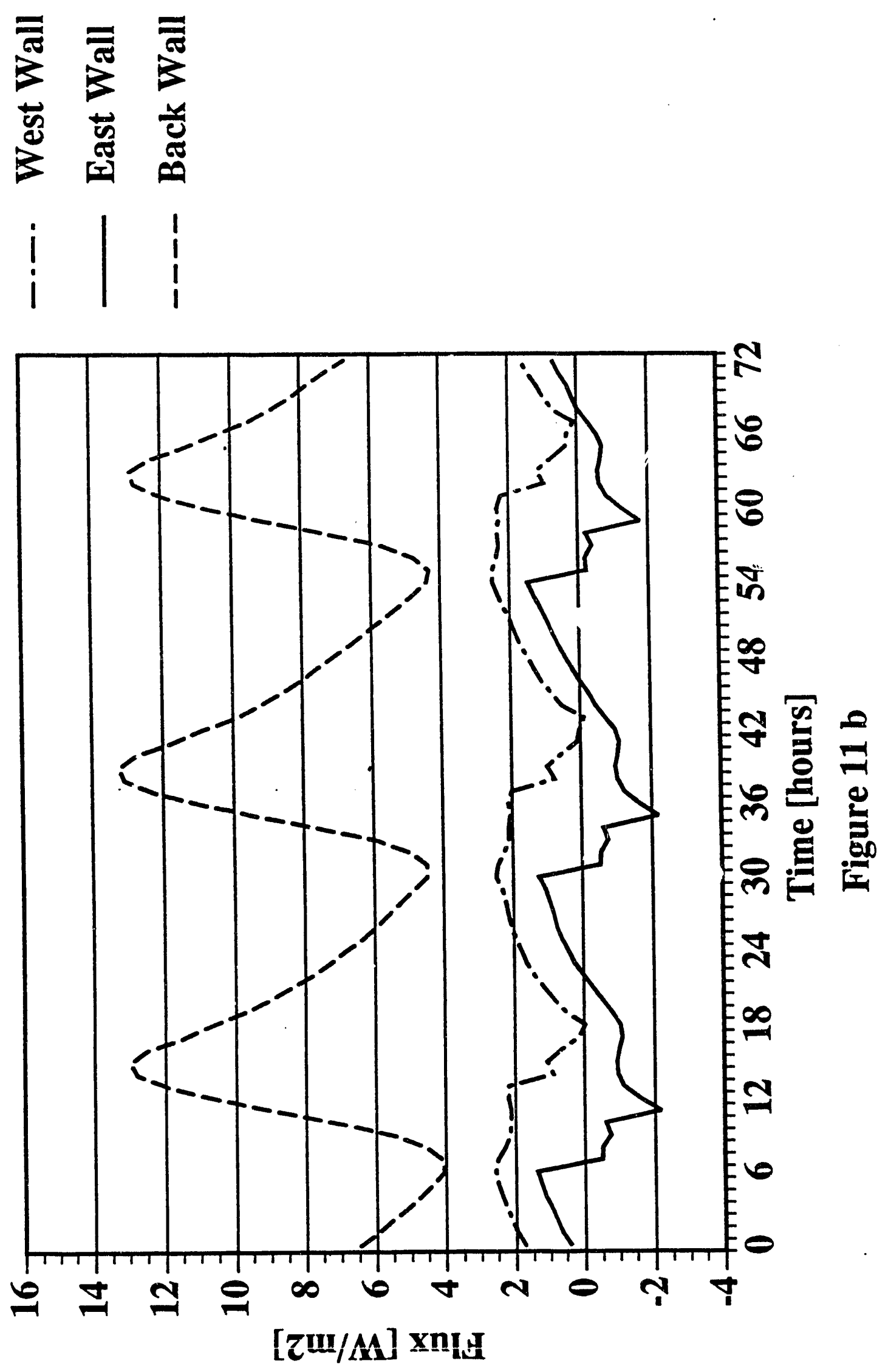

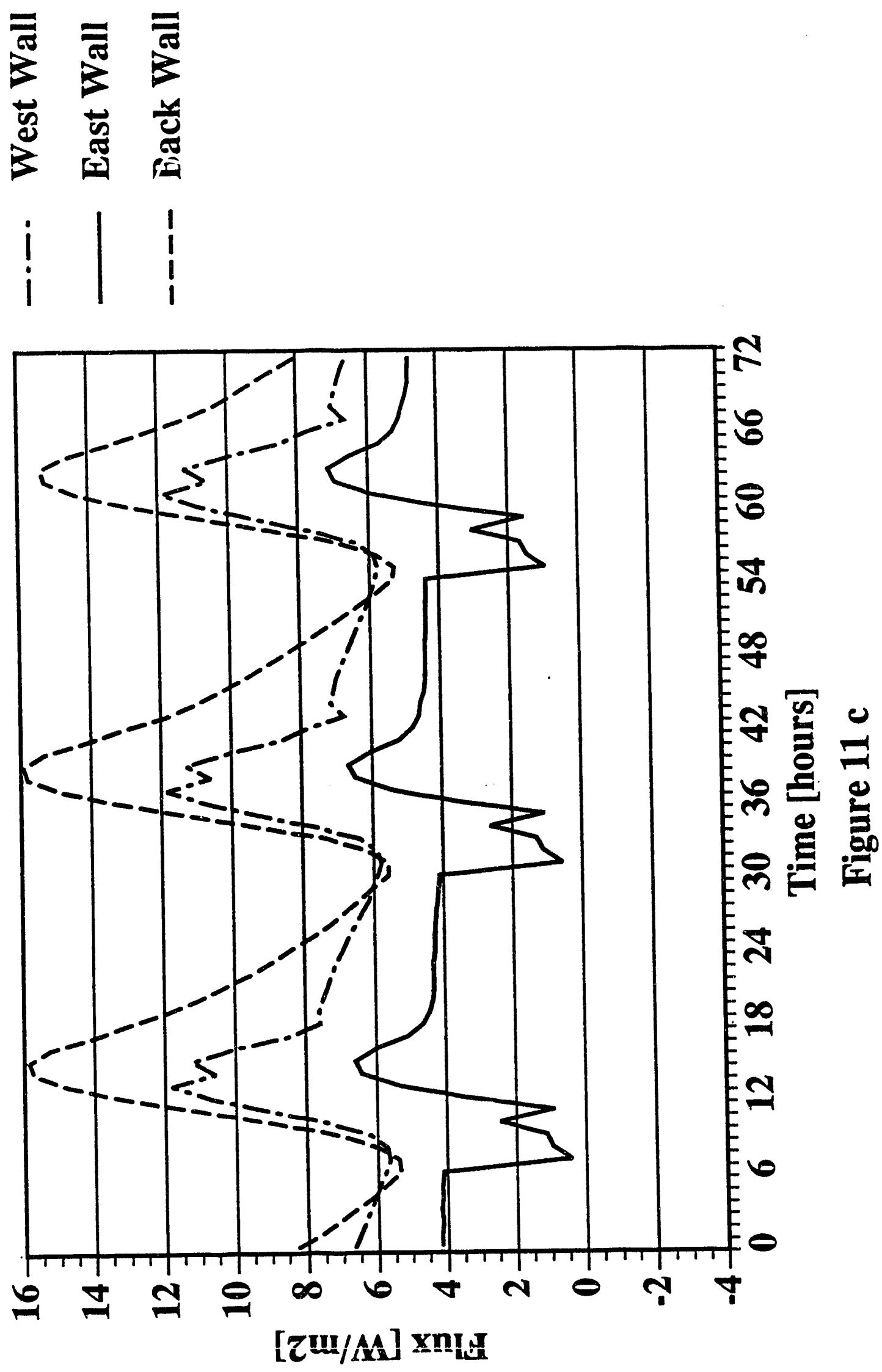


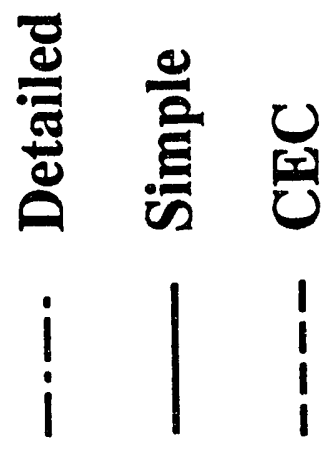

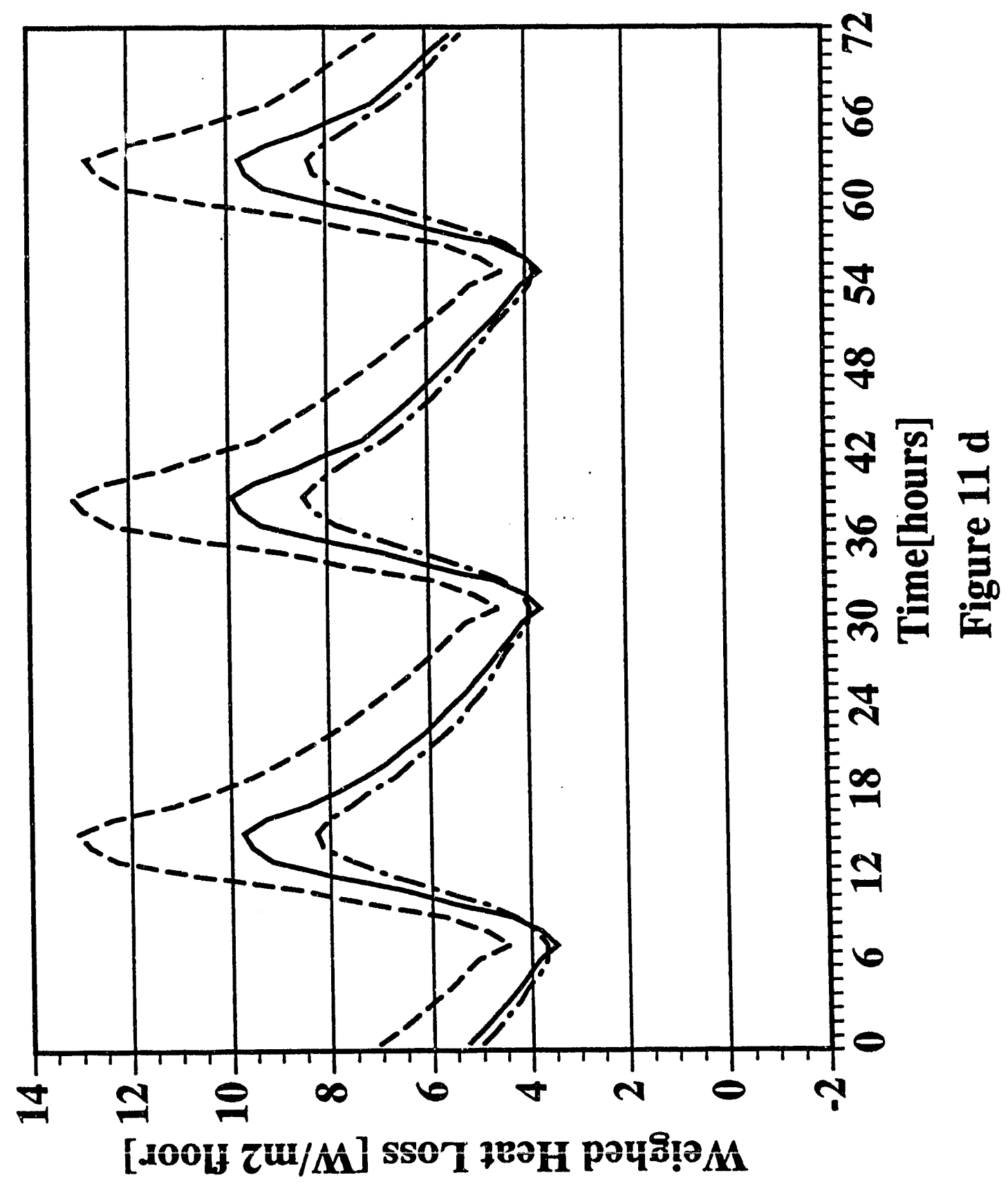




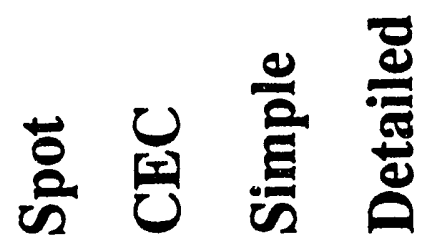

11

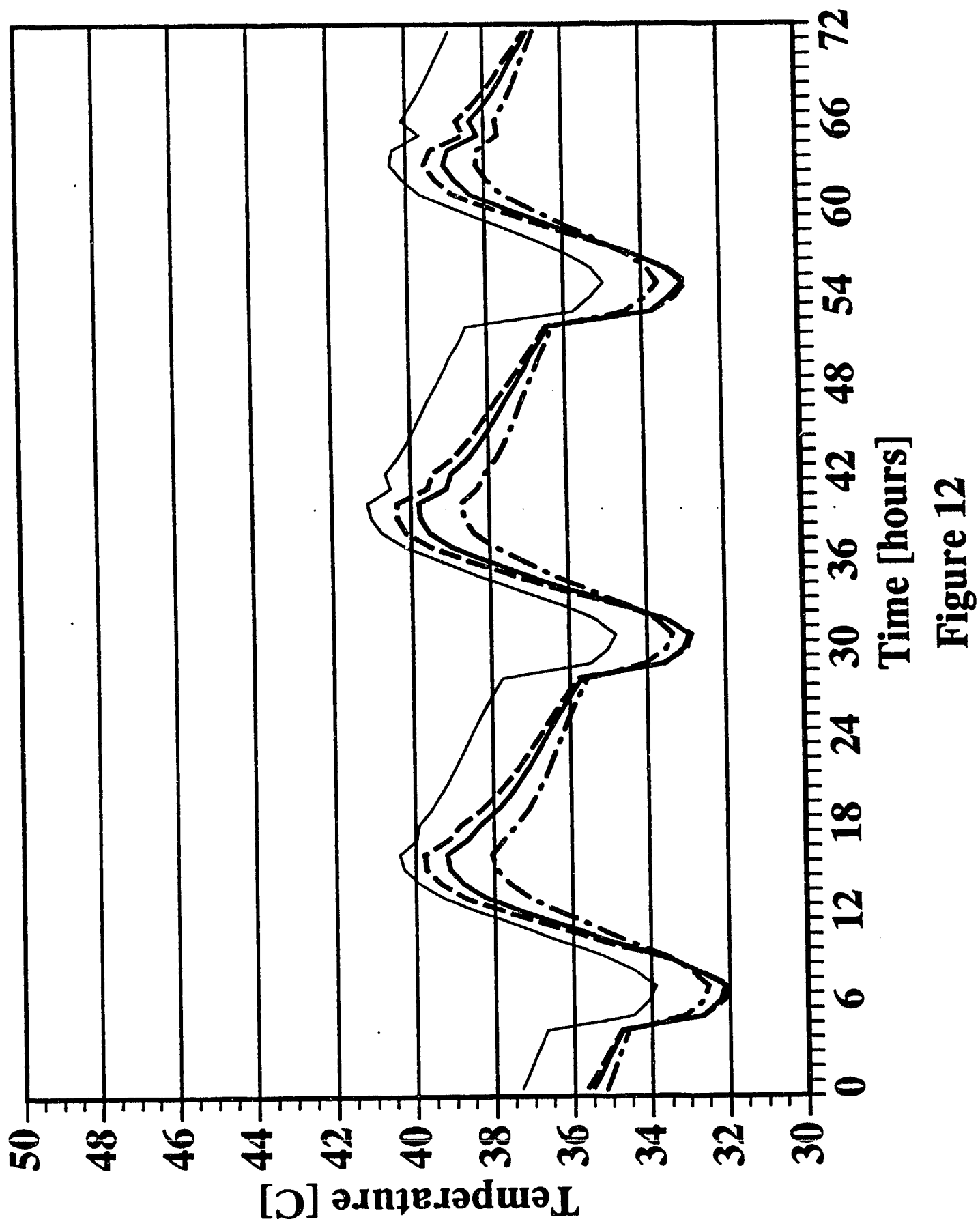




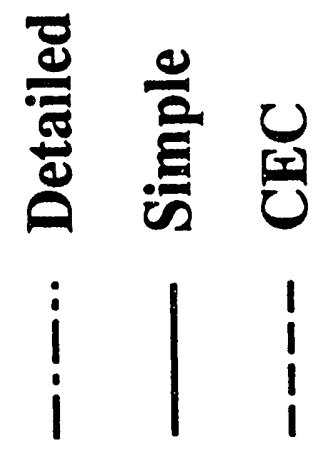

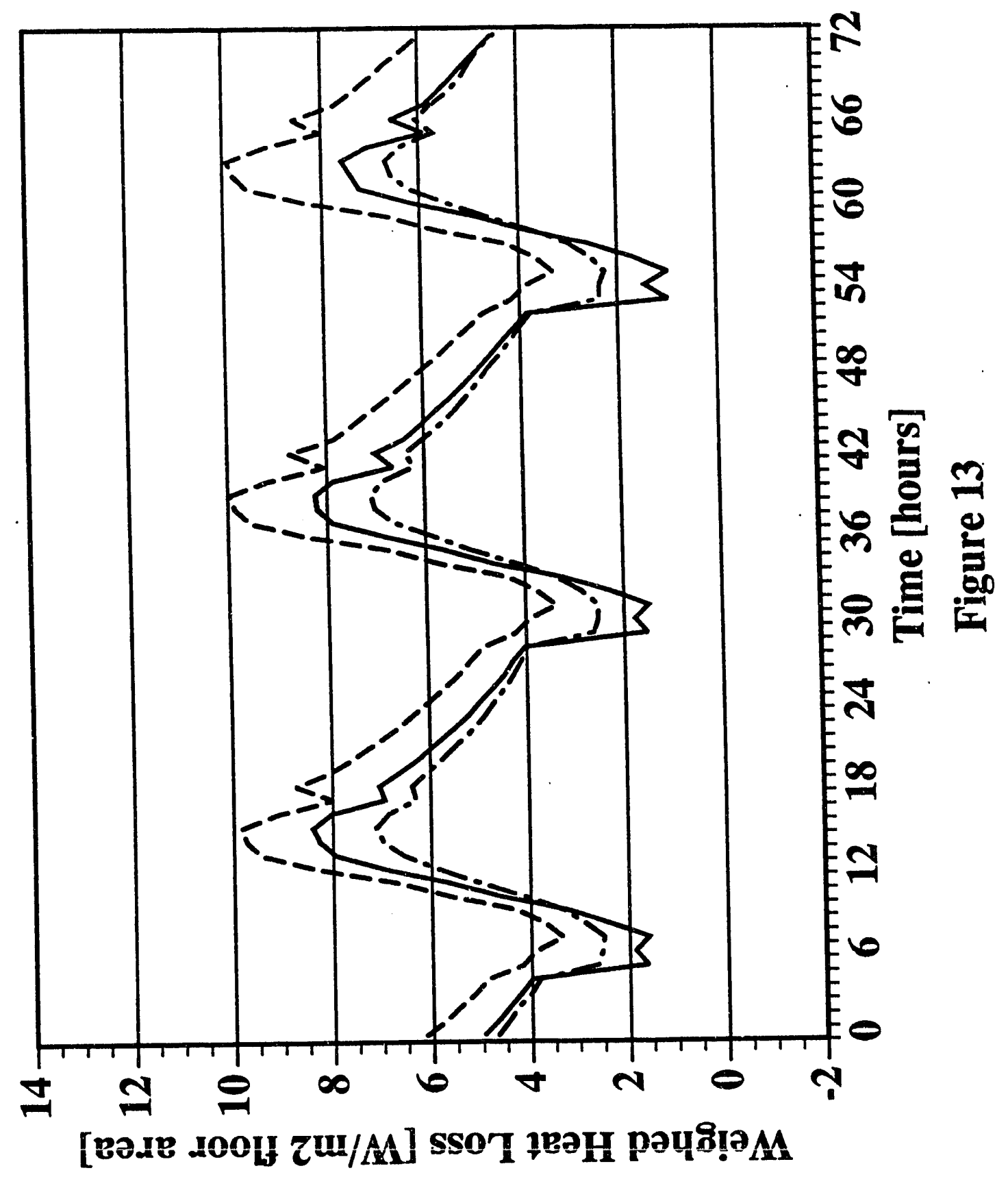




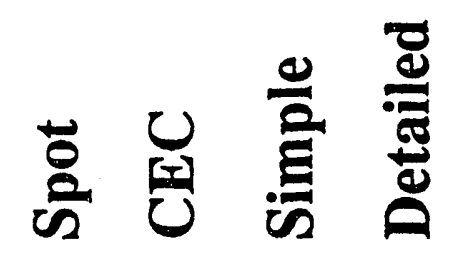

$\mid \begin{array}{ll}i & 1 \\ 1 & 1 \\ 1 & 1\end{array}$

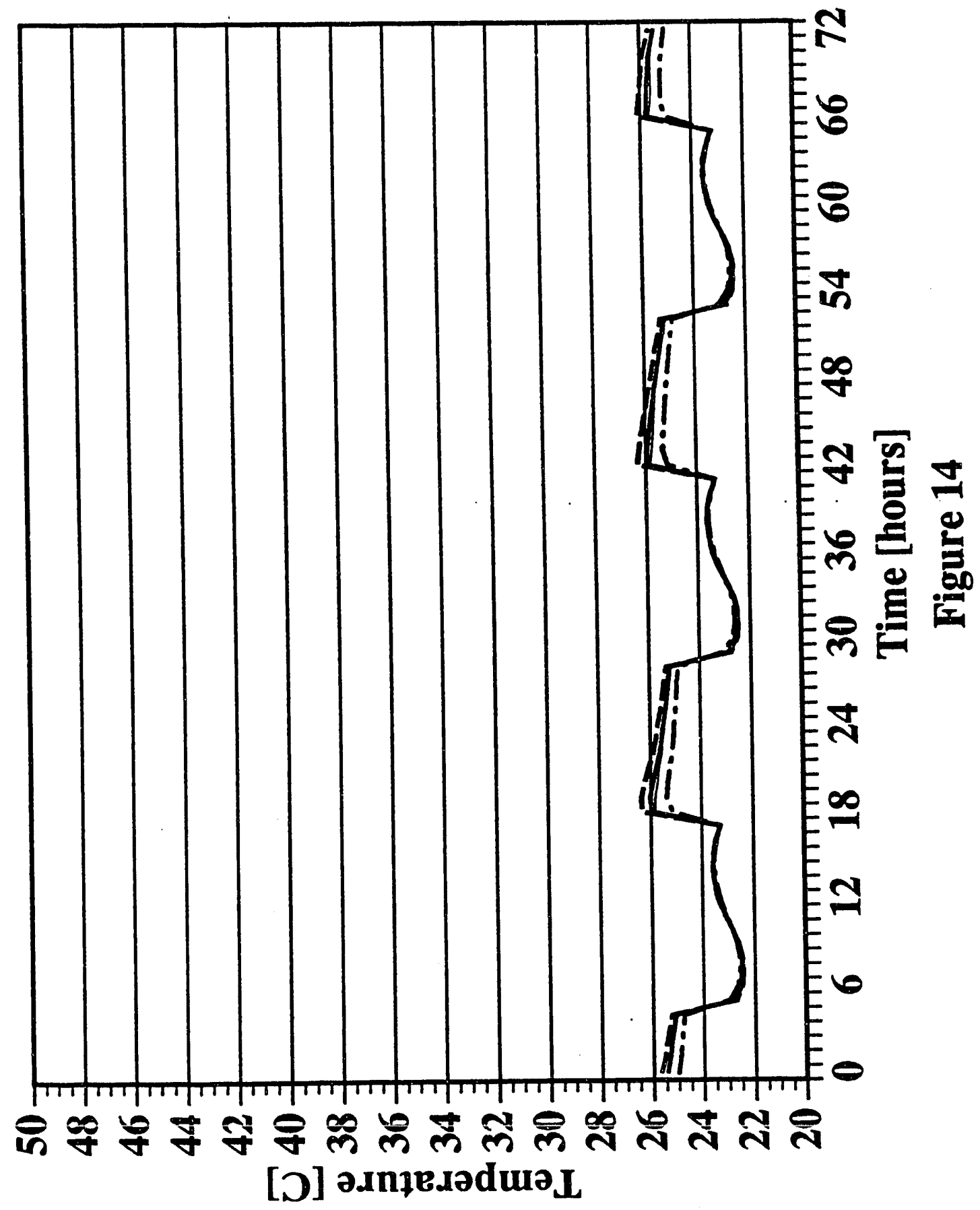




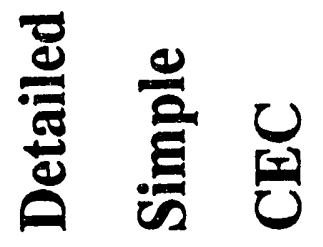

\begin{tabular}{l|l}
$i$ & 1 \\
$i$ & 1
\end{tabular}

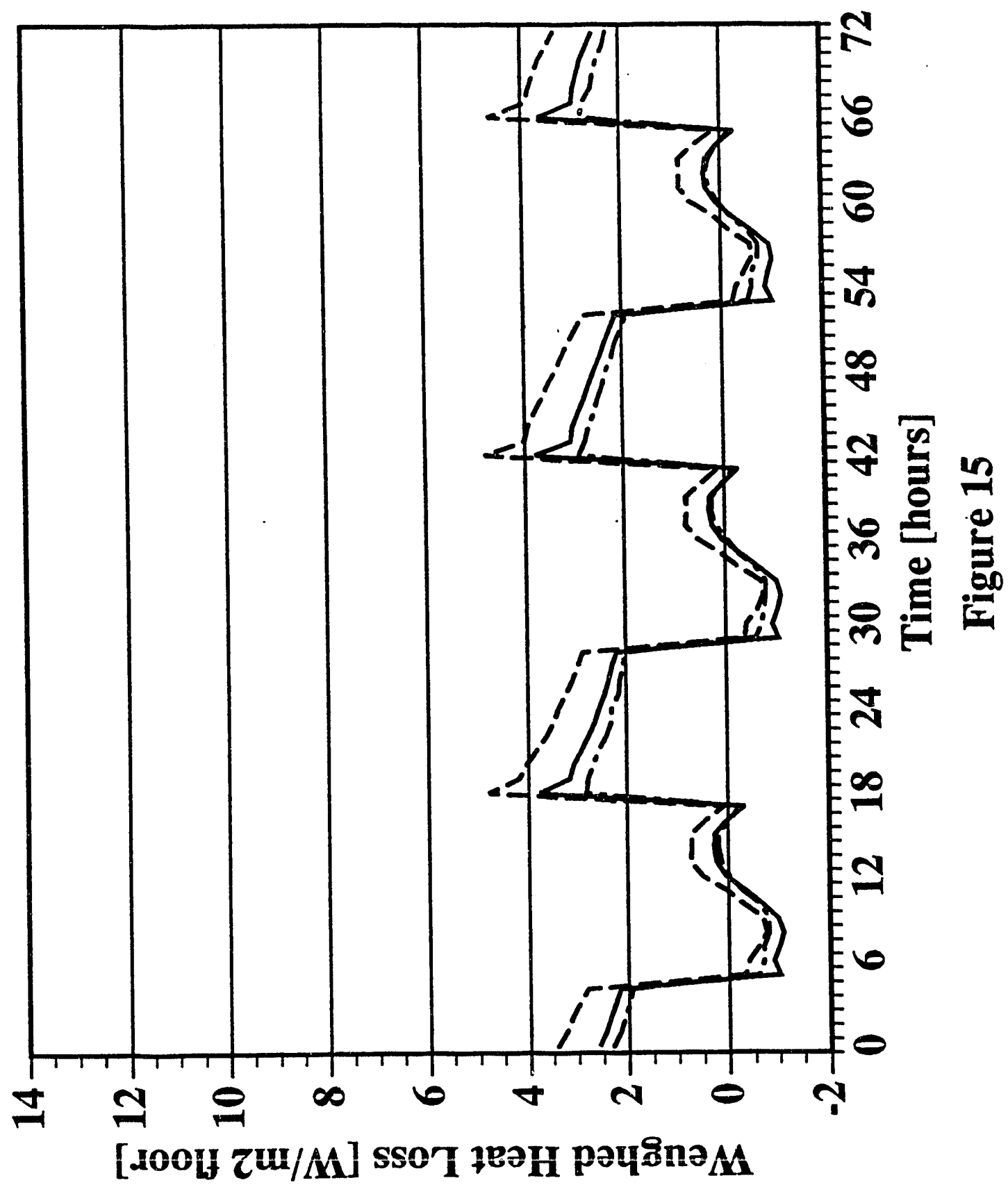




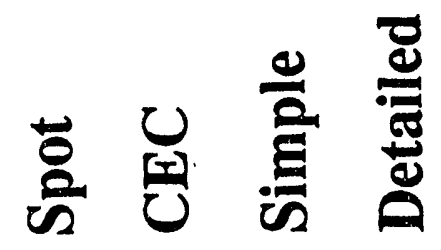

$\left|\begin{array}{ll}i & 1 \\ 1 \\ 1\end{array}\right|$

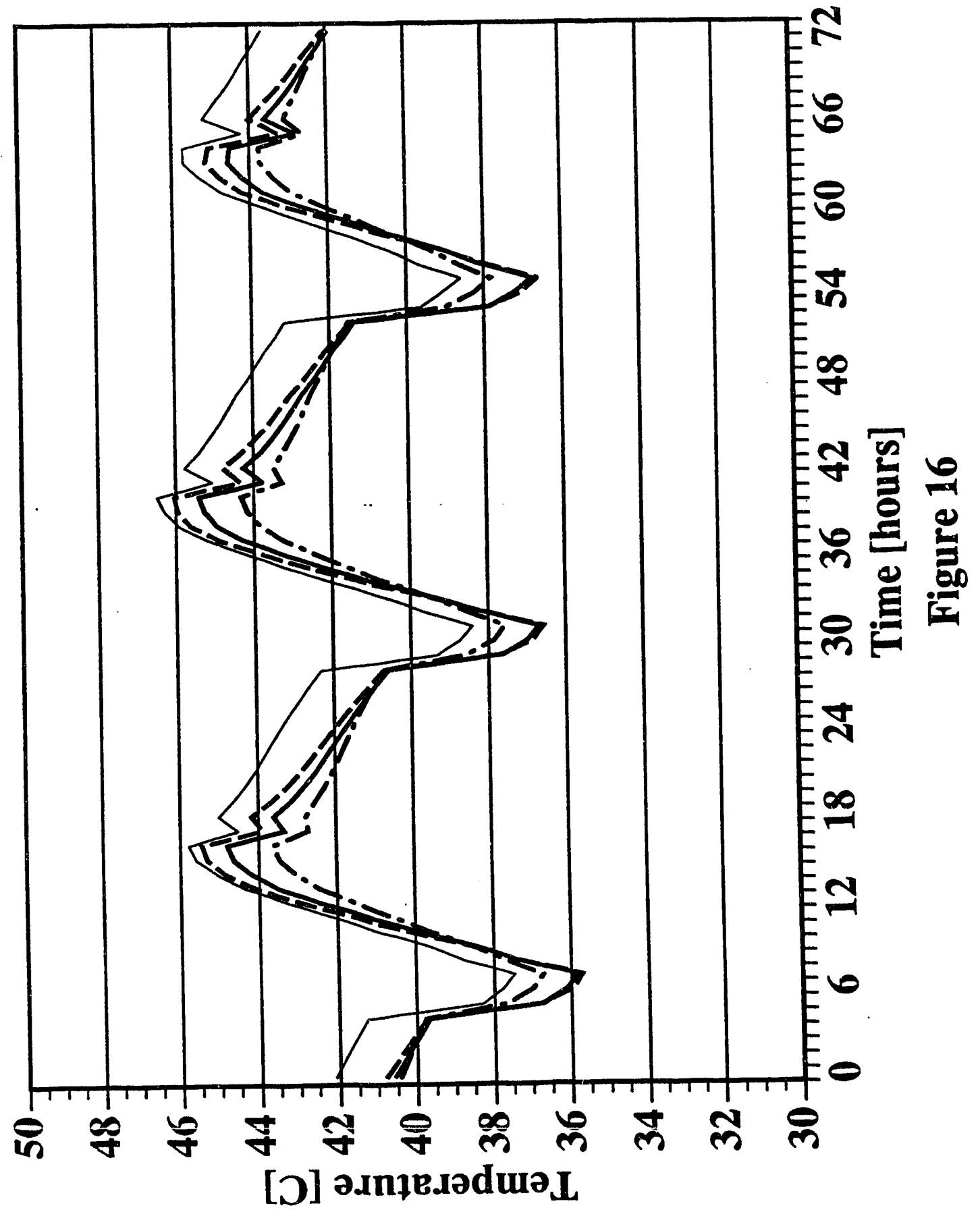




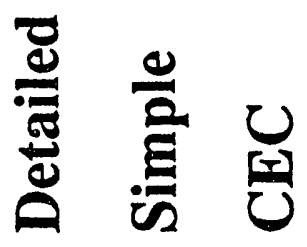

$i 1$

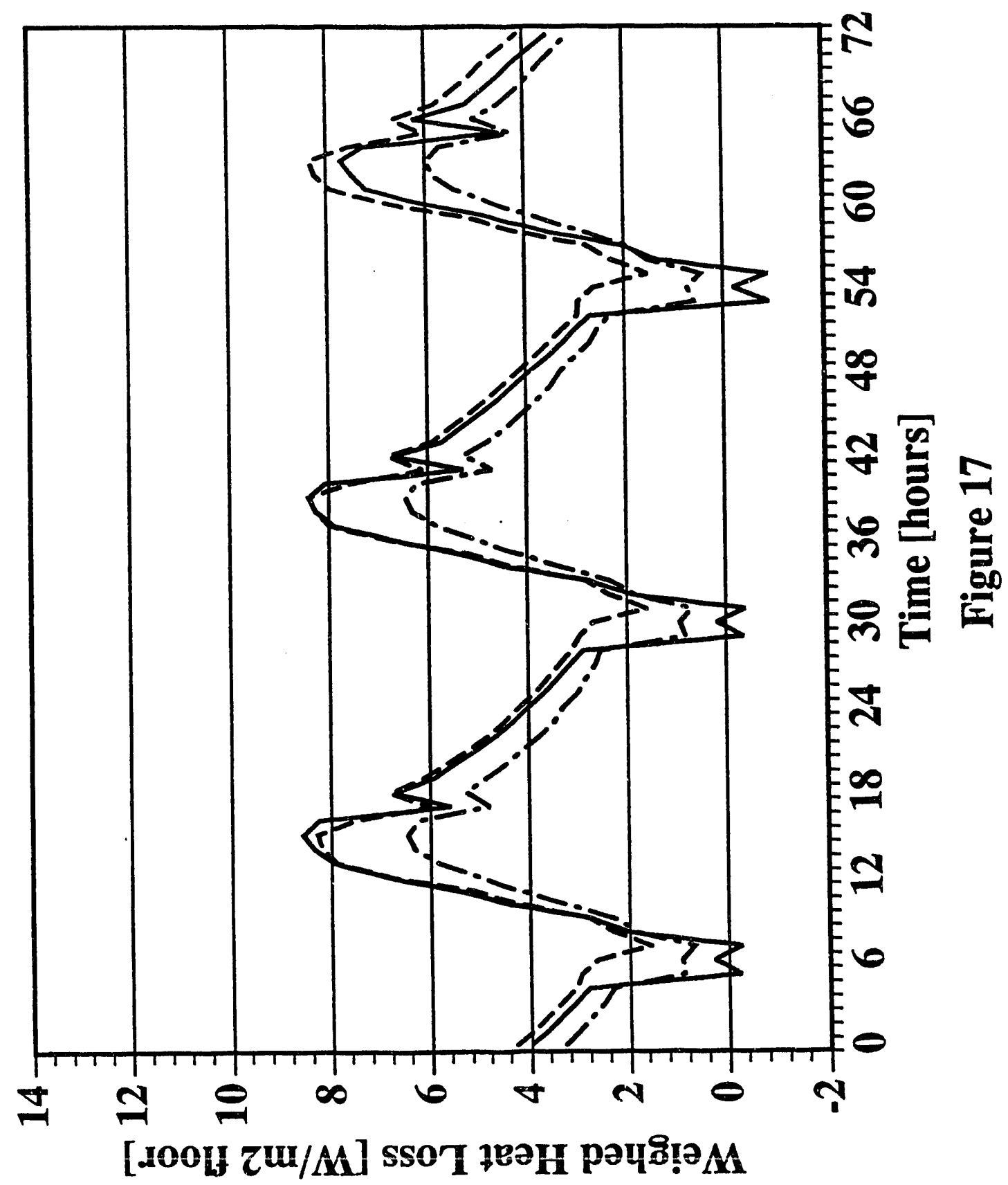




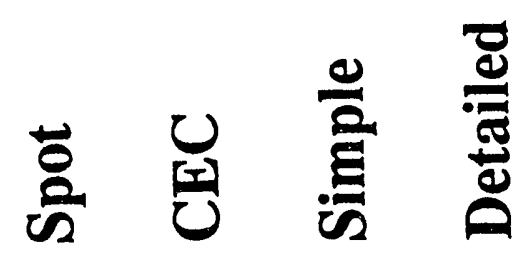
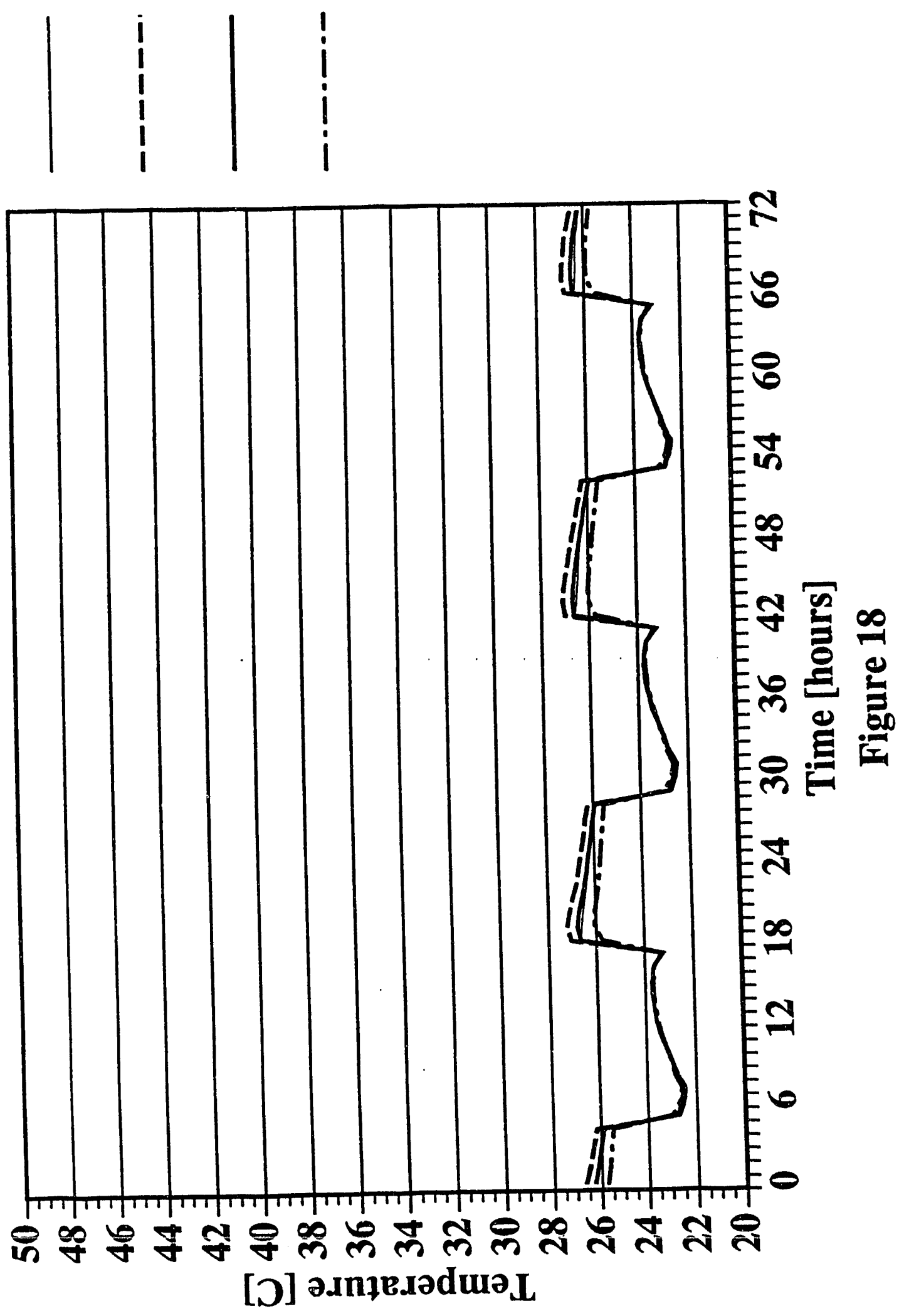


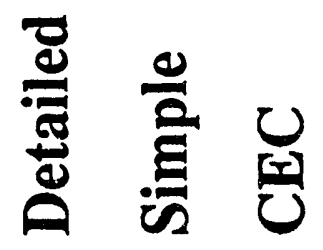

i

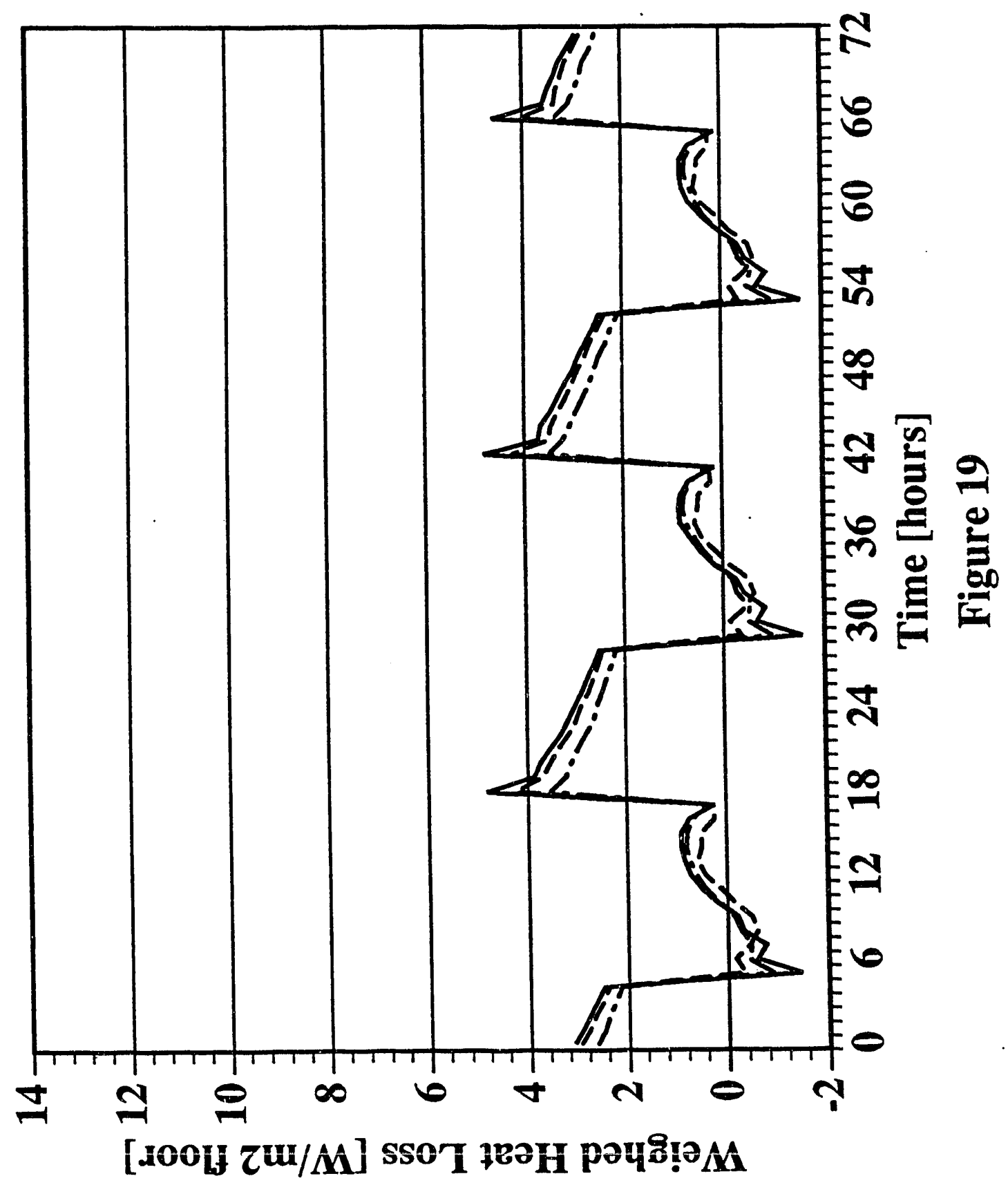




\section{Outdoor Temperature \\ Red Bluff}

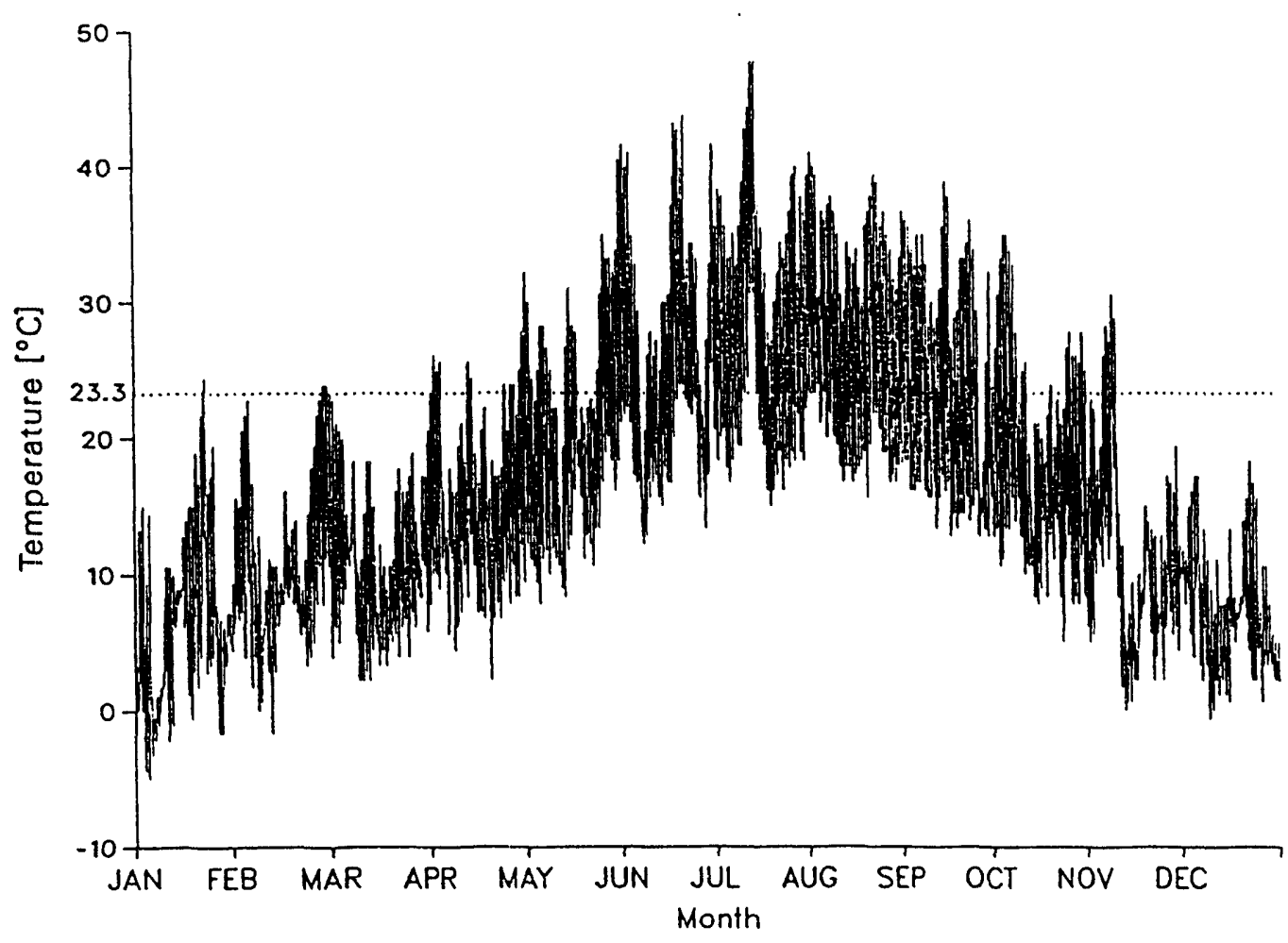

Outdoor, Temperature
San Diego

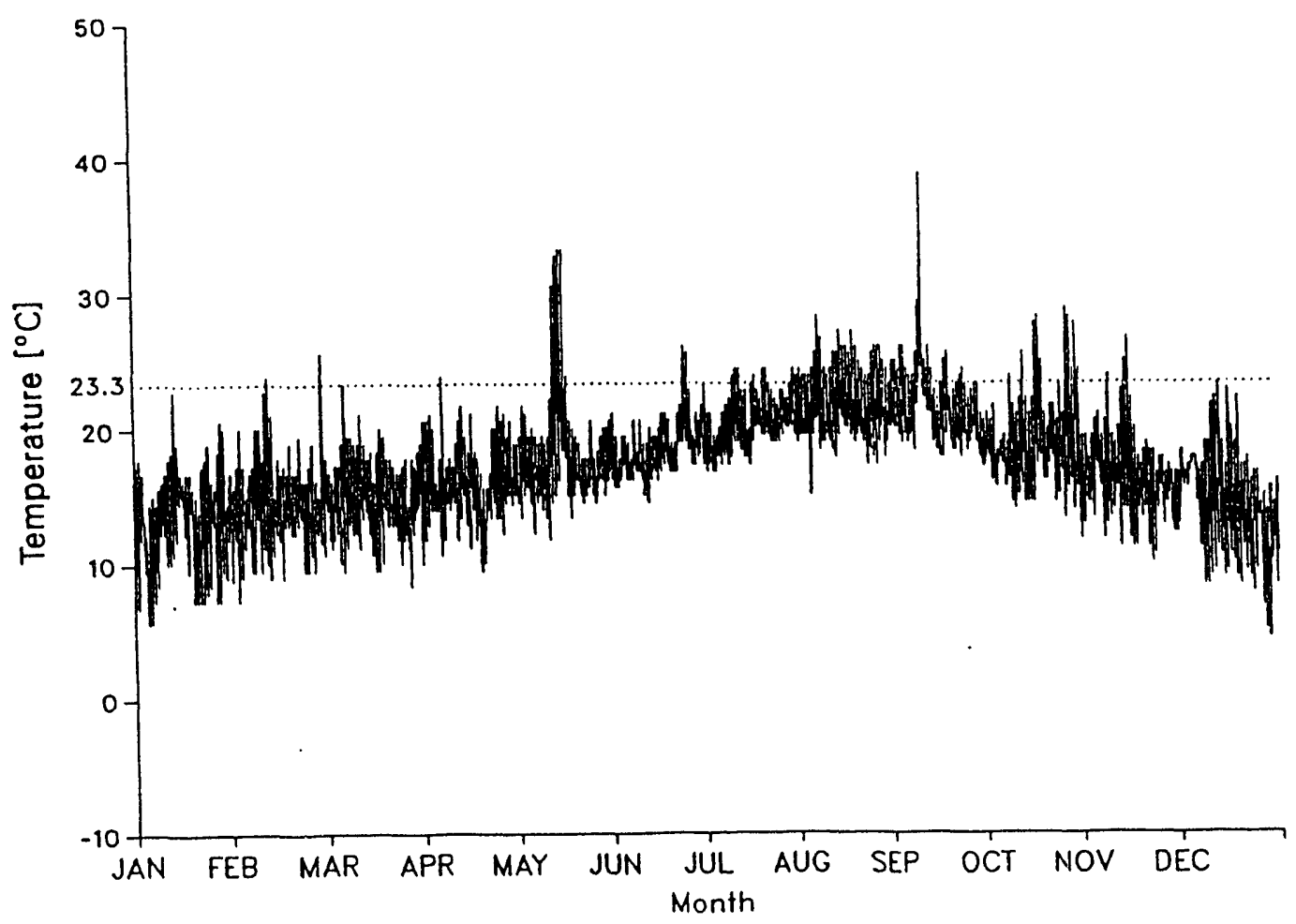




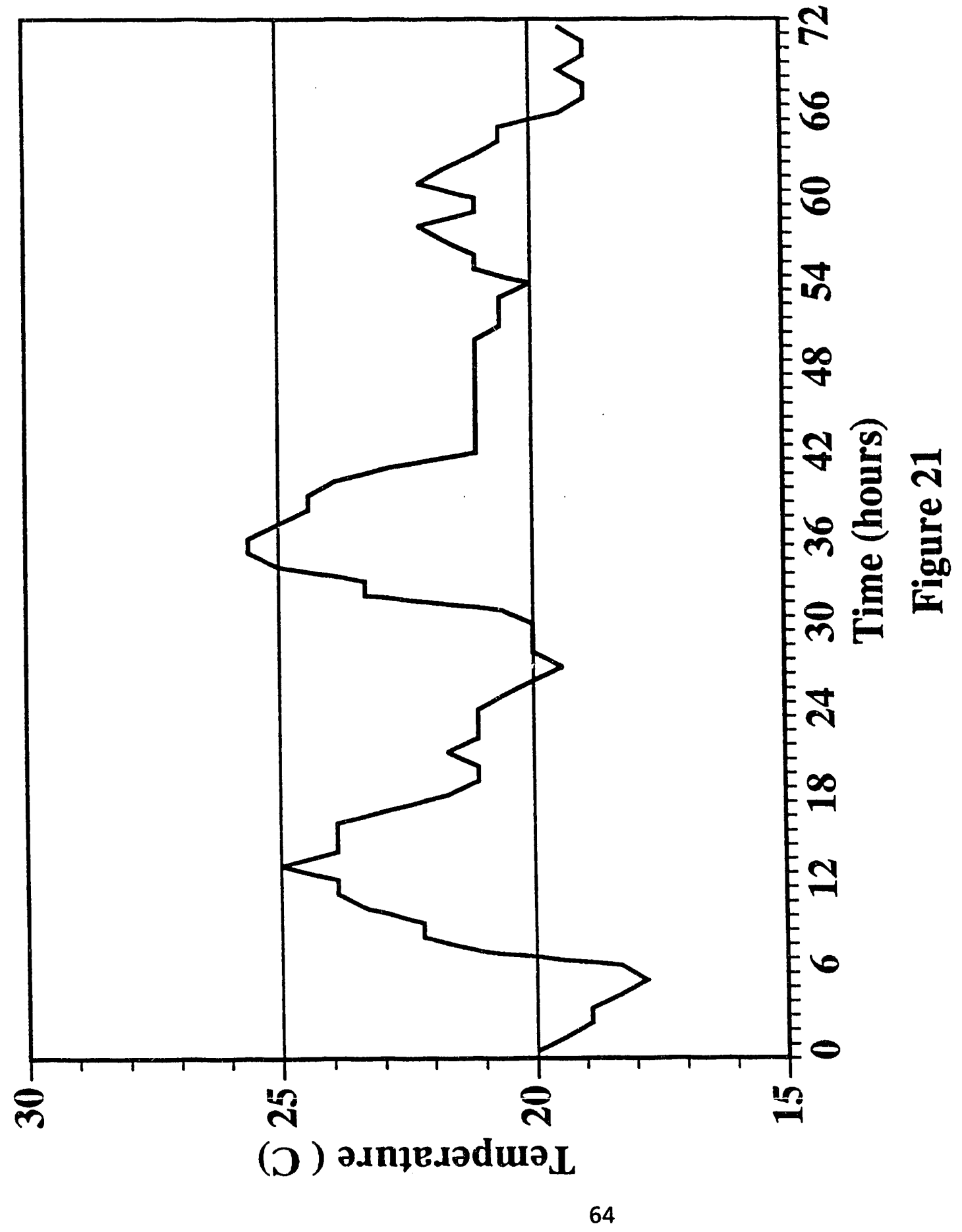




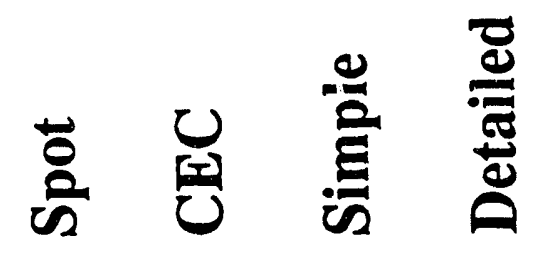

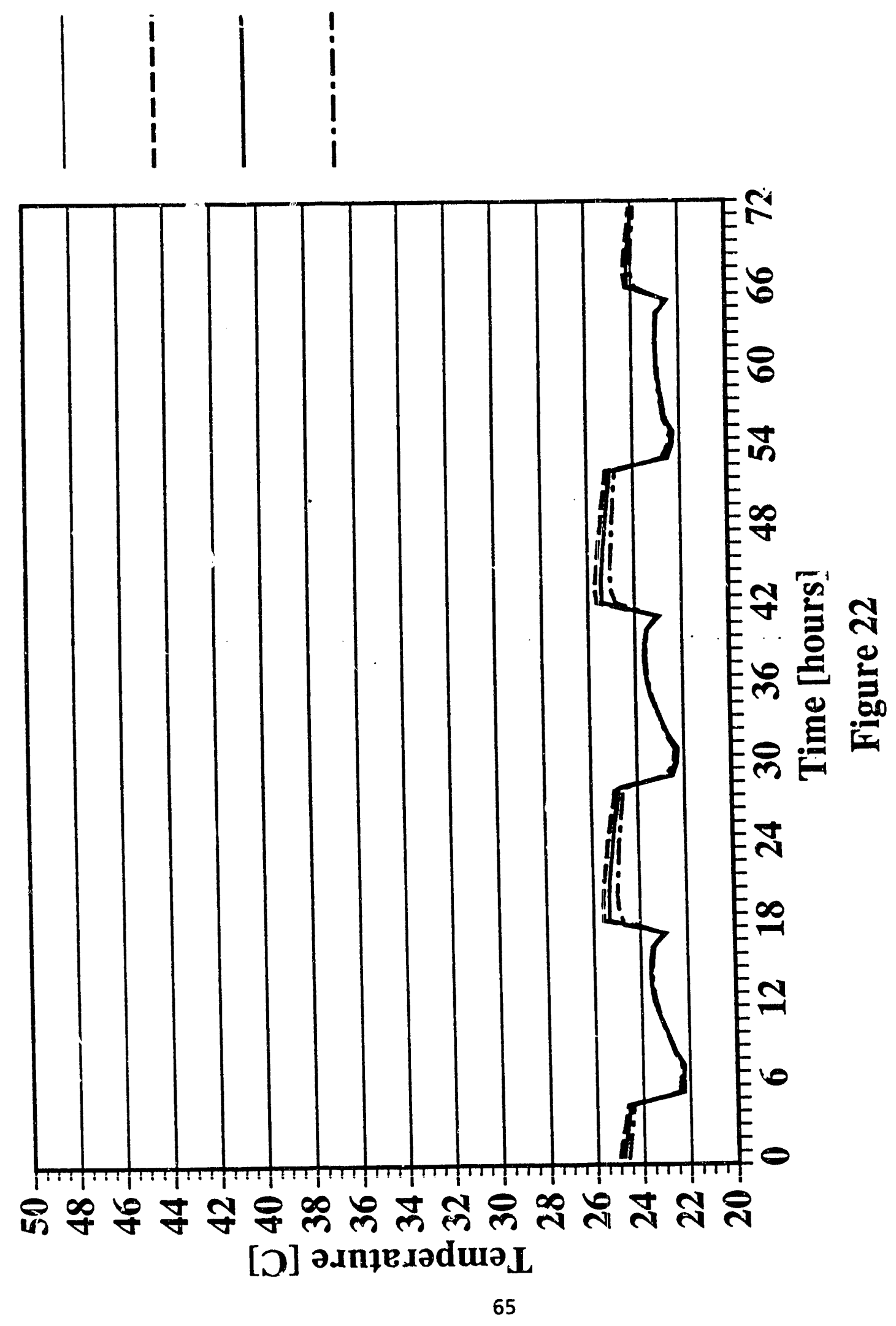




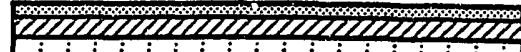

Floor Structure

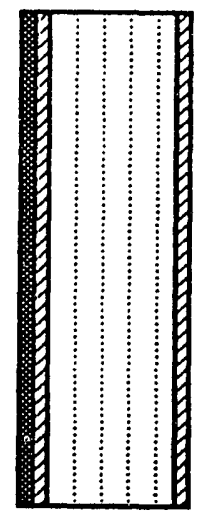

Exterior Wall Structure

Material Legend:

Mineral Wool

Particle Board

Carpet

\begin{tabular}{ll}
\hline Mineral Wool \\
Carticle Board \\
Carpet
\end{tabular}

Ceiling Structure

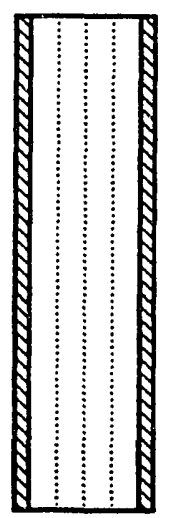

Interior Wall Structure $\square$ Air Space

Gypsum Board

Cement Plaster

Figure 23 


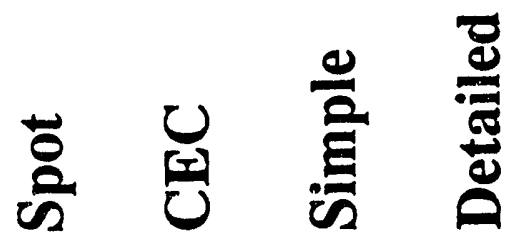
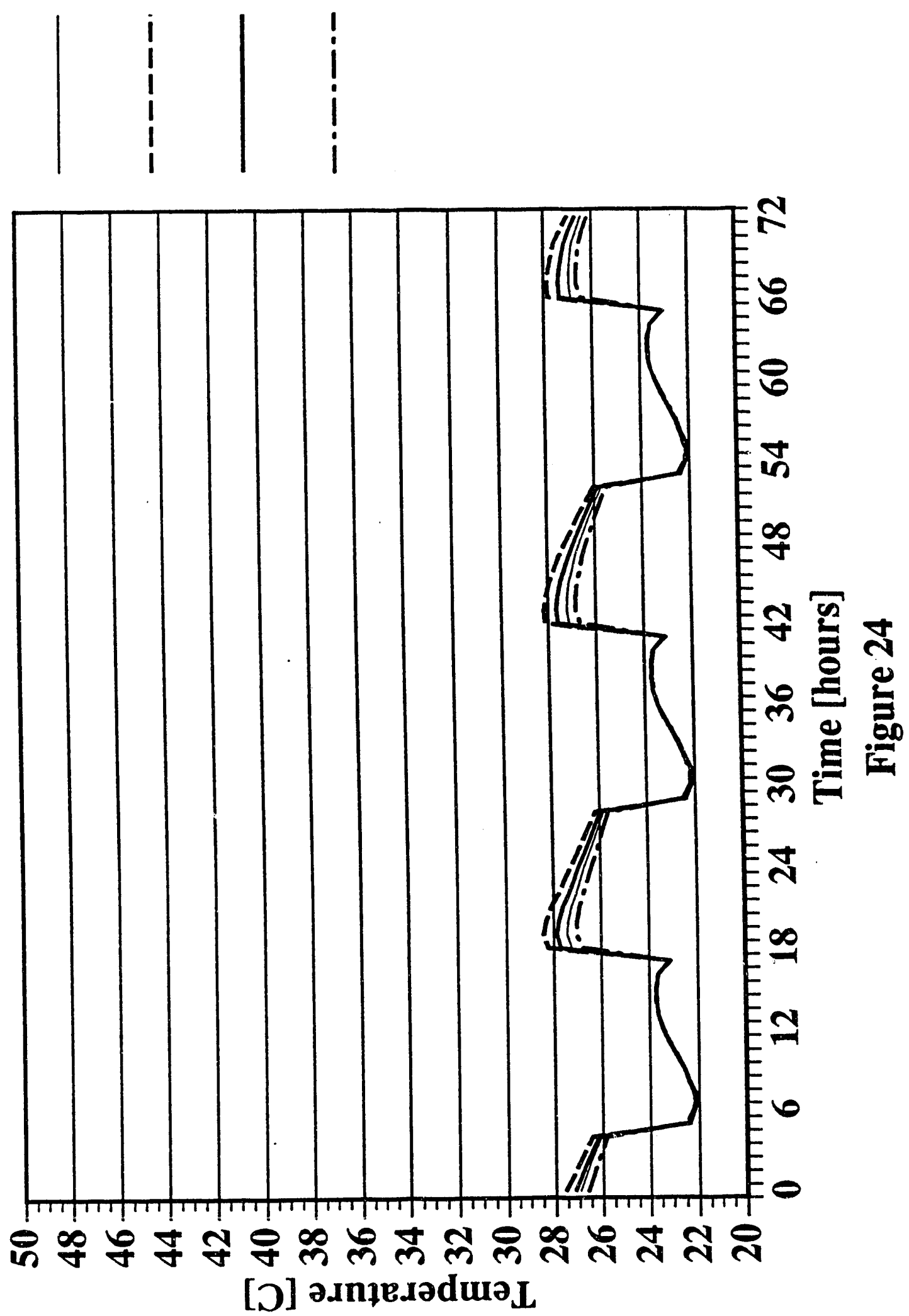


\section{Appendix}

The DOE-2 Program Input for the Simulation of the Detailed Geometry 
\$ INPUT FILE FOR THE INVESTIGATION OF THE INFLUENCE OF THE DESC- $\$$
$\$$
\$ RIPTION ON THE RESULT OF A SIMULATION WITH DOE-2
\$
\$ PREPARATION FOR PARAMETRIC RUNS ON THE STRUCTURE OF THE SHELL.
\$ WEATHER FILE = REDBLUFF.bIn

$\$$ LLLLLL $* * * * * * * * *$ LOADS GENERAL DATA INPUT $* * * * * * * * * *$ LLLLLLI $\$$

INPUT LOADS INPUT-UNITS $=$ METRIC OUTPUT-UNITS $=$ METRIC $\quad$.

ABORT WARNINGS

DIAGNOSTIC CAUTIONS, WIDE, ECHO, LIMITS, LIBRARY-CONTENTS

SINGLE-SPACED

TITLE

LINE-1 *EXHAUSTIVE DESCRIPTION OF THE MID FLOOR*

LINE-2 **

RUN-PERIOD

$\begin{array}{llllll}\text { JAN } 01 & 1984 & \text { THRU } & \text { DEC } & 31 & 1984\end{array}$

SET-DEFAULT

FOR WINDOW

SETBACK $=0.1$

PARAMETER

$\begin{array}{ll}\text { EWALL-PAR } & =\text { EWALL-M } \\ \text { IWALL-PAR } & =\text { IWALL-M } \\ \text { FLOOR-PAR } & =\text { FLOOR-M } \\ \text { CEIL-PAR } & =\text { CEIL-M } \\ \text { GLASS-PAR } & =2 I V-I R\end{array}$

BUILDING-LOCATION

$\begin{array}{llr}\text { LATITUDE } & =40.2 \\ \text { LONGITUDE } & =122.2 \\ \text { TIME-ZONE } & =8 \\ \text { ALTITUDE } & =140 \\ \text { DAYLIGHT-SAVINGS } & =\text { YES } \\ \text { HOLIDAY } & =\text { NO } \\ \text { AZIMUTH } & =270\end{array}$

\$ LLLLLL $* \star \star \star \star \star \star \star \star \star \star * \star$ MATER
CONCRETE $=$ MAT TH $=0.30$
REDMAS $=$ MAT TH $=0.15$
WHITEMAS $=$ MAT TH $=0.1$
EGGCRATE $=$ MAT TH $=0.15$
U-FLOOR = MAT TH $=0.05$
GYPSBRD $=$ MAT TH $=0.025$
PLASTER = MAT TH $=0.015$
CEMENTPLA $=$ MAT TH $=0.02$
MINWOOL1 = MAT TH $=0.04$
MINWOOL2 = MAT TH $=0.1$

Materials (DIN-NORM)

$\$ * * *$ RED BLUFF *** $\$$

AZIMUTH

$=270$

$\begin{array}{ll}\text { COND }=2.1 & \text { DENS }=2400 \\ \text { COND }=0.47 & \text { DENS }=1200 \\ \text { COND }=1.1 & \text { DENS }=2000 \\ \text { COND }=0.39 & \text { DENS }=305 \\ \text { COND }=0.47 & \text { DENS }=1400 \\ \text { COND }=0.4 & \text { DENS }=1000 \\ \text { COND }=0.7 & \text { DENS }=1400 \\ \text { COND }=1.4 & \text { DENS }=2000 \\ \text { COND }=0.036 & \text { DENS }=60 \\ \text { COND }=0.036 & \text { DENS }=90\end{array}$

$S-H=1050 \ldots$

$\mathrm{S}-\mathrm{H}=900 \ldots$

$S-H=900 \ldots$

$\mathrm{S}-\mathrm{H}=1100 \ldots$

$\mathrm{S}-\mathrm{H}=1100 \ldots$

$S-H=800 \ldots$

$\mathrm{S}-\mathrm{H}=900 \ldots$

$\mathrm{S}-\mathrm{H}=1100 \ldots$

$\mathrm{S}-\mathrm{H}=600 \ldots$ 


$\begin{array}{ll}\text { MINBRD1 } & =\text { MAT TH }=0.1 \\ \text { ACOUTILES } & =\text { MAT TH }=0.02 \\ \text { FELTMAT } & =\text { MAT TH }=0.005 \\ \text { BARCH } & =\text { MAT TH }=0.040 \\ \text { PLYWOOD }=\text { MAT TH }=0.04 \\ \text { PARTBRD }=\text { MAT TH }=0.04 \\ \text { PVC-LAYER }=\text { MAT TH }=0.004 \\ \text { ROOFMATE }=\text { MAT TH }=0.1 \\ \text { GRAVEL }=\text { MAT TH }=0.15 \\ \text { CARPET } & =\text { MAT RES }=0.0625 \\ \text { AIRLAYER } & =\text { MAT RES }=0.13 \\ \text { AIRSPACE } & =\text { MAT RES }=0.2 \\ \text { METAL } & =\text { MAT RES }=0.00002\end{array}$

$\begin{array}{ll}\text { COND }=0.04 & \text { DENS }=130 \\ \text { COND }=0.04 & \text { DENS }=130 \\ \text { COND }=0.047 & \text { DENS }=78 \\ \text { COND }=0.2 & \text { DENS }=800 \\ \text { COND }=0.15 & \text { DENS }=800 \\ \text { COND }=0.13 & \text { DENS }=700 \\ \text { COND }=0.23 & \text { DENS }=1300 \\ \text { COND }=0.035 & \text { DENS }=35 \\ \text { COND }=0.7 & \text { DENS }=1650\end{array}$

$S-H=600 \ldots$ $S-H=840 \ldots$ $\mathrm{S}-\mathrm{H}=880 \ldots$ $\mathrm{S}-\mathrm{H}=2200 \ldots$ $\mathrm{S}-\mathrm{H}=2520 \ldots$ $\mathrm{S}-\mathrm{H}=2700 \ldots$ $\mathrm{S}-\mathrm{H}=1470 \ldots$ $\mathrm{S}-\mathrm{H}=1000 \ldots$ $\mathrm{S}-\mathrm{H}=900 \ldots$

\$ THE KEYWORD OF EACH STRUCTURE IS COMPOSED OF THREE TERMS "1-2-3" BE \$ $\$$ LOW IS AN EXPLANATION OF THE PART 2 (ELEMENT OF THE SHELL) AND PART $3 \$$ $\$$ (CHARACTERISTICS OF THE ELEMENT IN TERM OF HEAT CAPACITY) $\$$

\$ PART 2: FLO $\rightarrow$ FLOOR

$\$$ CEI $\rightarrow$ CEILING

$\$$ IWA $\rightarrow$ INTERIOR WALL

$\$$ EWA $\rightarrow$ EXTERIOR WALI

$\$$ PART $3:$ EL $\rightarrow$ EXTRA-IIGHT

$\$$ I $\rightarrow$ LIGHT

$\$ \quad M \quad \rightarrow$ MEDIUM

$\$ \quad H \quad$ HEAVY

$\$$

$\$$

\$ - --- FLOOR STRUCTURE ---- \$

L-FLO-EL = LAYERS

MAT $=$ (ACOUTILES AIRSPACE CONCRETE AIRLAYER PARTBRD CARPET)

$\mathrm{TH}=\left(\begin{array}{llllll}0.02 & 0.15 & 0.30 & 0.03 & 0.04 & 0.01\end{array}\right)$

L-FLO-I = LAYERS

MAT $=$ (MINWOOL2 PARTBRD CARPET)

$\mathrm{TH}=\left(\begin{array}{lll}0.025 & 0.02 & 0.01\end{array}\right)$

L-FLO-M = LAYERS

MAT $=$ (CONCRETE MINBRD1 U-FLOOR FELTMAT)

$\mathrm{TH}=\left(\begin{array}{llll}0.15 & 0.015 & 0.08 & 0.005\end{array}\right)$

\$ - - CEILING STRUCTURE ---- \$

L-CEI-EL = LAYERS

MAT $=$ (CARPET PARTBRD AIRLAYER CONCRETE AIRSPACE ACOUTILES)

$\mathrm{TH}=\left(\begin{array}{llllll}0.01 & 0.04 & 0.03 & 0.30 & 0.27 & 0.02\end{array}\right.$

L-CEI-L = LAYERS

MAT $=$ (MINWOOL2 AIRSPACE GYPSBRD)

$\mathrm{TH}=\left(\begin{array}{lll}0.025 & 0.12 & 0.016\end{array}\right)$

$L-C E I-M=$ LAYERS 
MAT $=\left(\begin{array}{llcc}\text { CONCRETE } & \text { AIRSPACE } & \text { MINBRD1 } & \text { GYPSBRD }\end{array}\right)$
TH $=\left(\begin{array}{cccc}0.15 & 0.15 & 0.02 & 0.018\end{array}\right)$

$\$$

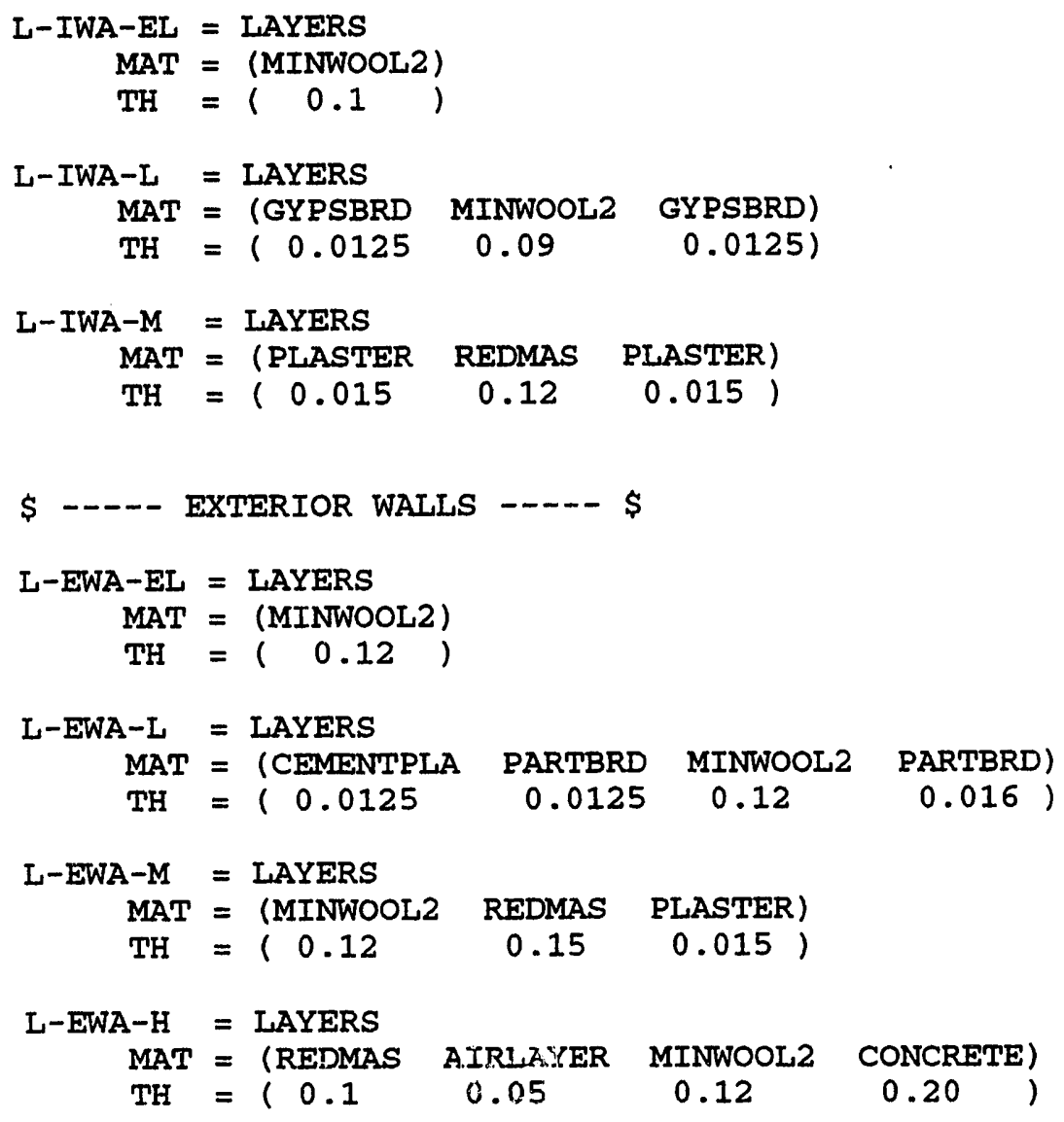

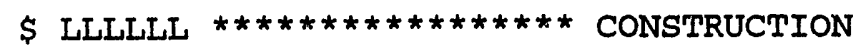

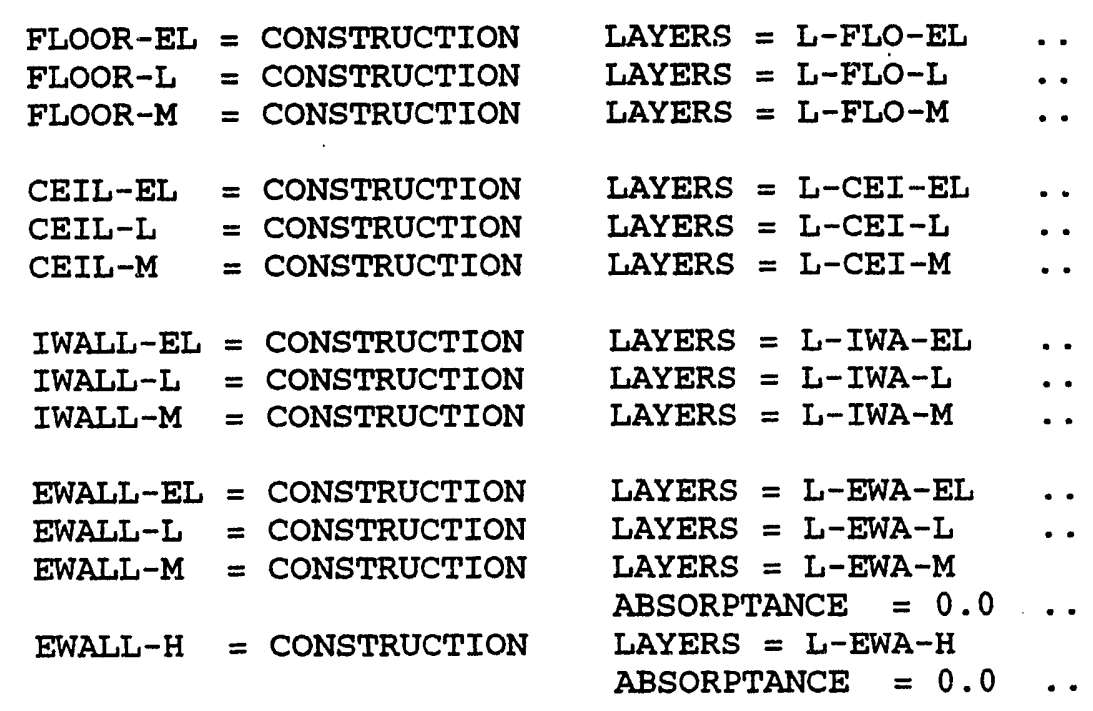


\$ transmitted by the glass, NOT solar radiation). All over the year $\$$

$\$$ the transmitted solar radiation through the BLINDS is $25 \%$.

$\begin{array}{llllll}\text { BLINDS-TRANS-H } & =S C H & \text { THRU DEC } 31(A L L) & (1,24)(.25) & \ldots \\ \text { BLINDS-TRANS-V } & =S C H & \text { THRU DEC } 31 \text { (ALL) } & (1,24)(.60)\end{array}$

\$ LLLLLL

SPACE-CONDITIONS

$* * * * * * * * * * *$ LLLLLLL

OFFICE
TEMPERATURE
PEOPLE-SCHEDULE
NUMBER-OF-PEOPLE
PEOPLE-HEAT-GAIN
LIGHTING-TYPE
LIGHTING-W/AREA
LIGHTING-SCHEDULE
LIGHT-TO-SPACE
LIGHT-TO-RETURN
EQUIP-SCHEDULE
EQUIPMENT-W/AREA
INF-SCHEDULE
INF-METHOD
AIR-CHANGES/HR
FURNITURE-TYPE
FURN-FRACTION
FURN-WEIGHT
FLOOR-WEIGHT
DAYLIGHTING

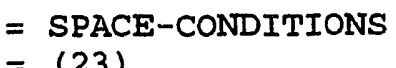

$=(23)$

$=$ EQUIP-ON

$=3$

$=130$

= SUS-FLUOR

$=10$

LIGHT-ON

$=1.0$

$=0.0$

$=$ EQUIP-ON

$=12$

$=$ INFILTRATION-ON

$=$ AIR-CHANGE

$=0.2$

$=$ LIGHT

$=0.3$

$=25$.

$=0$.

- YES

LIGHT-REF-POINT1 $=(3.0,2.0,0.8)$

LIGHT-SET-POINT1 $=500$

ZONE-FRACTION1 $=0.5$

LIGHT-REF-POINT2 $=(1.0,2.0,0.8)$

LIGHT-SET-POINT2 $=500$

ZONE-FRACTION2 $=0.5$

LIGHT-CTRL-TYPE1 = STEPPED

LIGHT-CTRL-TYPE2 = STEPPED

LIGHT-CTRL-STEPS $=1$

PRINTER-ROOM
TEMPERATURE
NUMBER-OF-PEOPLE
LIGHTING-W/ AREA
EQUIPMENT-W/AREA
AIR-CHANGES / HR
DAYIIGHTING

= SPACE-CONDITIONS

LIKE OFFICE

$=(23)$

$=1$

$=10$

$=35$

$=0$.

$=$ NO

= SPACE-COINDITIONS

LIKE OFFICE

$=(23)$

$=8$

$=15$

$=5$ 


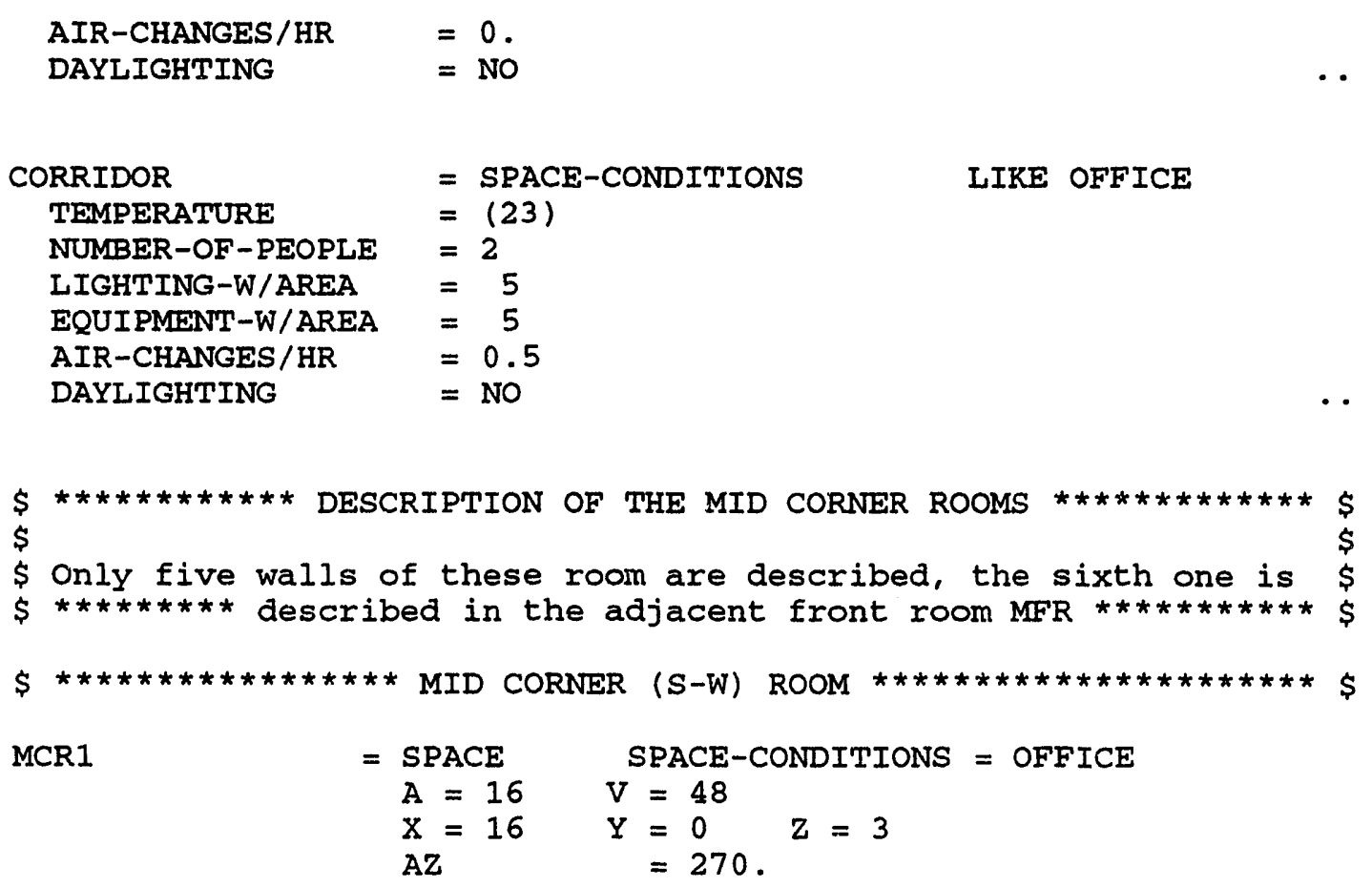

$\$$ The $Y$-Axis of the room shows in the direction of the west $\$$

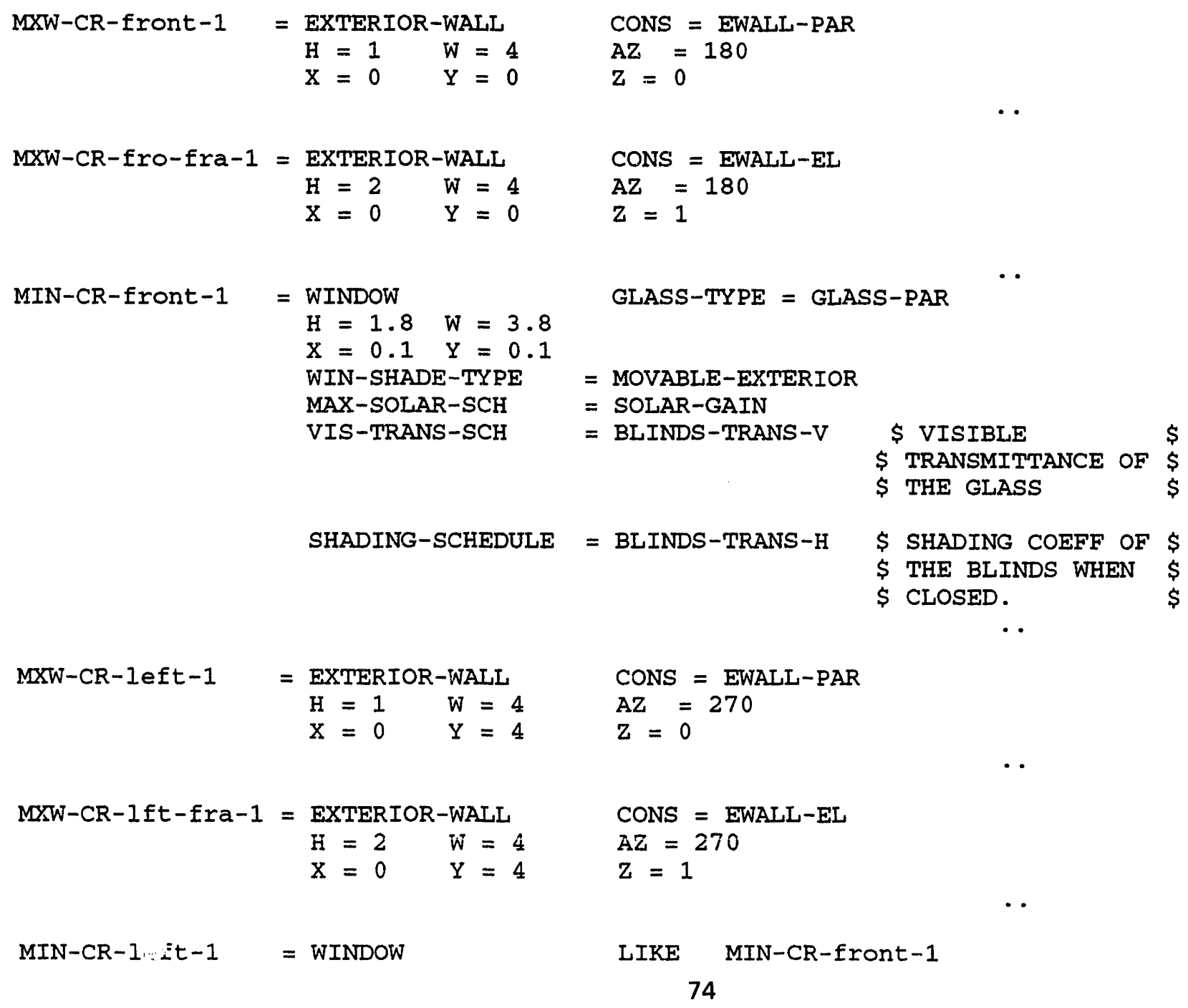




\begin{tabular}{|c|c|c|c|}
\hline \multirow[t]{2}{*}{ MNW-CR-back-1 } & \multicolumn{2}{|c|}{$=$ INTPERIOR-WALL } & \\
\hline & & $\begin{array}{ll}H=3 & W=4 \\
X=4 & Y=4 \\
\text { NEXT-TO }=\text { MFR14 }\end{array}$ & $\begin{array}{l}\text { INT-WALL-TYPE = STANDARD } \\
\mathrm{AZ}=0 \\
\mathrm{Z}=0\end{array}$ \\
\hline MLO-CR-in-1 & $=$ & $\begin{array}{l}\text { INTERIOR-WALL } \\
A=16 \\
X=4 \quad Y=0 \\
A Z=0\end{array}$ & $\begin{array}{l}\text { CONS = FLOOR-PAR } \\
\text { INT-WALL-TYPE = ADIABATIC } \\
Z=0 \\
\text { TILT = } 180\end{array}$ \\
\hline$M C E-C R-i n-1$ & $=$ & $\begin{array}{l}\text { INTERIOR-WALL } \\
A=16 \\
X=0 \quad Y=0 \\
A Z=180\end{array}$ & $\begin{array}{l}\text { CONS = CEIL-PAR } \\
\text { INT-WALI-TYPE = ADIABATIC } \\
\mathrm{Z}=3 \\
\mathrm{TILT}=0\end{array}$ \\
\hline
\end{tabular}

MCR2

$\begin{array}{llr}=\text { SPACE } & \text { LIKE } & \text { MCRI } \\ X=16 & Y=28 & Z=3 \\ A Z=180 . & & \end{array}$

$\$$ The $\mathrm{Y}$-Axis of the room shows in the direction of the South $\$$

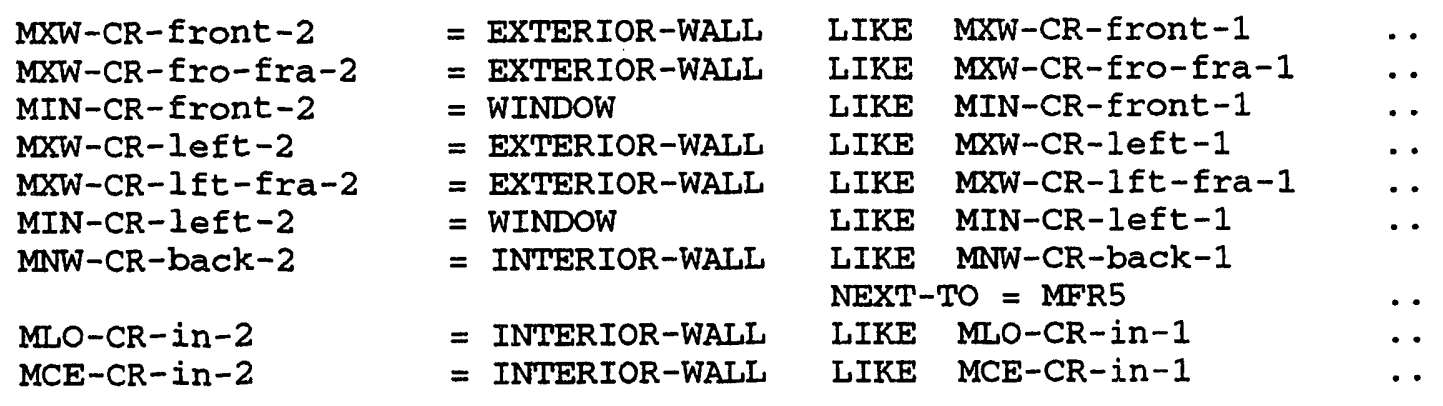

MCR3

$$
\begin{array}{lrc}
=\text { SPACE } & \text { LIKE } & \text { MCRI } \\
X=0 & Y=28 & Z=3 \\
A Z=90 . & &
\end{array}
$$

\begin{tabular}{|c|c|c|c|c|}
\hline$M D W-C R-$ front -3 & = EXTERIOR-WALI & LIKE & $M X W-C R-$ front -1 & $\cdots$ \\
\hline $\mathrm{MXW}-\mathrm{CR}$-fro-fra-3 & $=$ EXTERIOR-WALL & LIKE & $\mathrm{MXW}-\mathrm{CR}-\mathrm{fro}-\mathrm{fra}-1$ & \\
\hline MIN-CR-front-3 & $=$ WINDOW & LIKE & MIN-CR-front-1 & \\
\hline$M X W-C R-1$ eft-3 & $=$ EXTERIOR-WALL & LIKE & $M X W-C R-1$ eft -1 & \\
\hline $\mathrm{MXW}-\mathrm{CR}-1$ ft-fra -3 & = EXTERIOR-WALL & LIKE & $M X W-C R-1$ ft-fra-1 & - \\
\hline MIN-CR-1eft-3 & $=$ WINDOW & LIKE & $M I N-C R-1$ eft-1 & - \\
\hline MNW-CR-back-3 & $=$ INTERIOR-WALL & LIKE & MNW-CR-back-1 & \\
\hline & & NEXT- & $\Gamma O=$ MFR7 & \\
\hline MLO-CR-in-3 & $=$ INTERIOR-WALL & LIKE & MLO-CR-in-1 & \\
\hline$M C E-C R-i n-3$ & $=$ INTERIOR-WALL & LIKE & $M C E-C R-i n-1$ & \\
\hline
\end{tabular}

\$ The Y-Axis of the room shows in the direction of the East $\$$ 
MCR4

$$
\begin{array}{lll}
=\text { SPACE } & \text { LIKE } & \text { MCRI } \\
X=0 & Y=0 & Z=3 \\
A Z=0 . & &
\end{array}
$$

\begin{tabular}{|c|c|c|c|}
\hline$M X W-C R-$ front -4 & $=$ EXTERIOR-WALL & LIKE & $\mathrm{MXW}-\mathrm{CR}$-front-1 \\
\hline$M X W-C R-f r o-f r a-4$ & $=$ EXTERIOR-WALL & LIKE & $\mathrm{MXW}-\mathrm{CR}$-fro-fra-1 \\
\hline MIN-CR-front -4 & $=$ WINDOW & LIKE & MIN-CR-front-1 \\
\hline$M X W-C R-1 e f t-4$ & $=$ EXTERIOR-WALL & LIKE & MXW-CR-left-1 \\
\hline$M X W-C R-I f t-f r a-4$ & $=$ EXTERIOR-WALI & LIKE & MXW-CR-1ft-fra-1 \\
\hline$M I N-C R-1$ eft-4 & $=$ WINDOW & LIKE & MIN-CR-left-1 \\
\hline \multirow[t]{2}{*}{ MNW-CR-back-4 } & $=$ INTERIOR-WALL & LIKE & MNW-CR-back-1 \\
\hline & & \multicolumn{2}{|c|}{ NEXT-TO $=$ MFR 12} \\
\hline$M L O-C R-i n-4$ & $=$ INTERIOR-WALL & LIKE & $M L O-C R-i n-1$ \\
\hline$M C E-C R-i n-4$ & $=$ INTERIOR-WALL & LIKE & $M C E-C R-i n-1$ \\
\hline
\end{tabular}

$\$$ The $Y$-Axis of the room shows in the direction of the North \$

$\$ \operatorname{LLILLLL~} * * * * * * * * * * * * * * *$ MFr $\# 1 . .14 * * * * * * * * * * * * * * * * \operatorname{LLLLLLI~} \$$

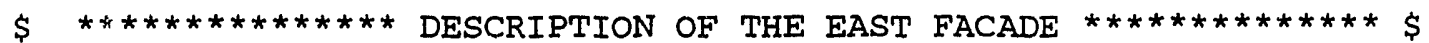

MFR1 = SPACE SPACE-CONDITIONS = OFFICE

$$
\begin{aligned}
& \mathrm{A}=16 \quad \mathrm{~V}=48 \\
& X=16 \quad Y=4 \quad Z=3 \\
& \mathrm{AZ}=270
\end{aligned}
$$

\$ The Y-Axis of the room shows in the direction of the West

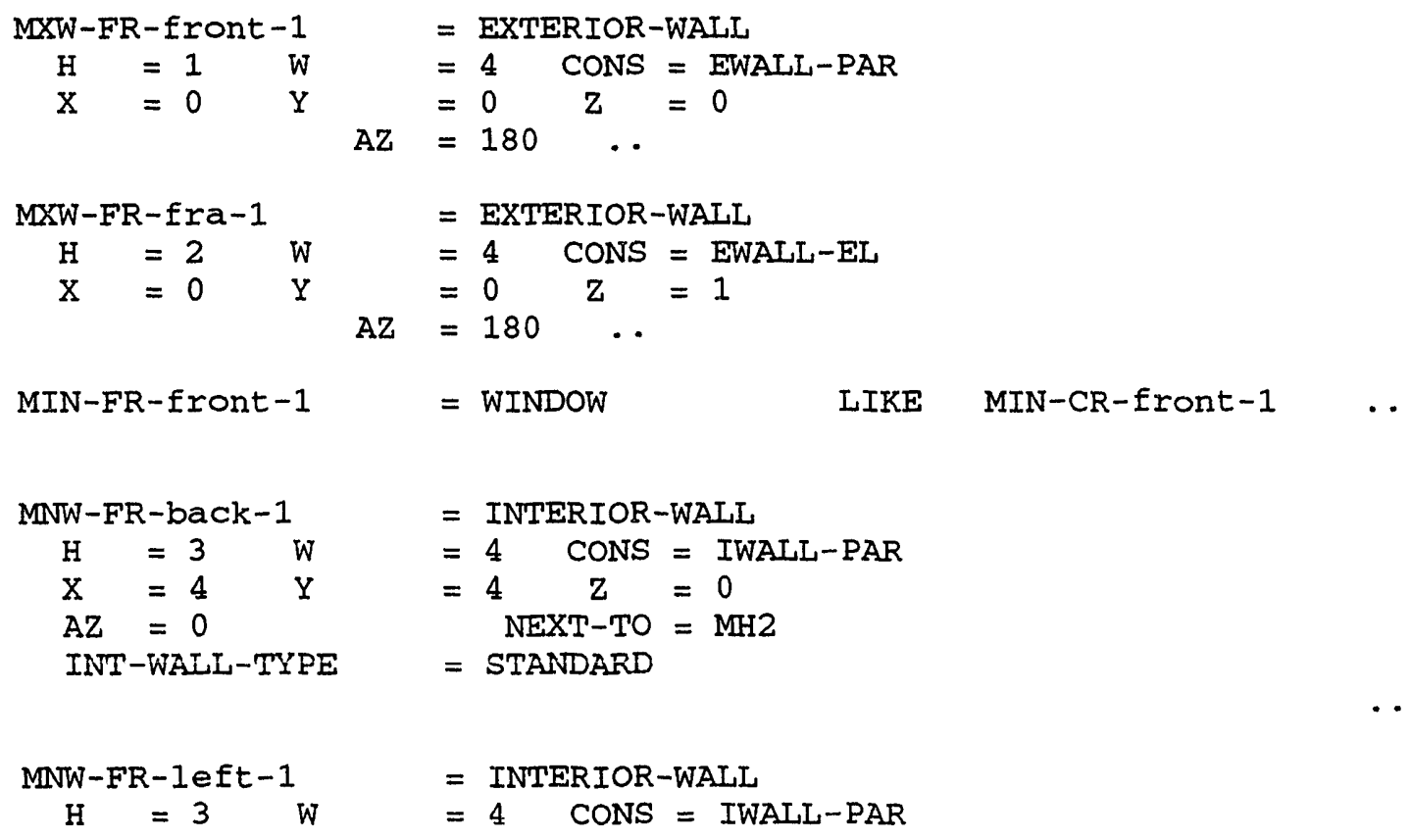




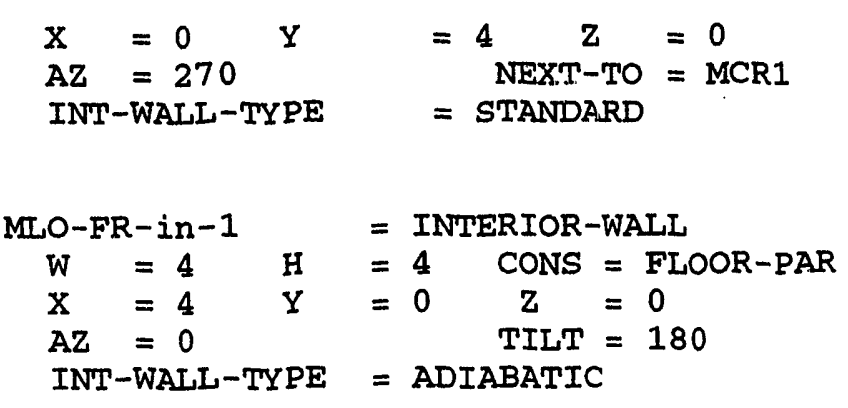

\$ with the keyword ADIABATIC,

$\$$ NEXT-TO is not used

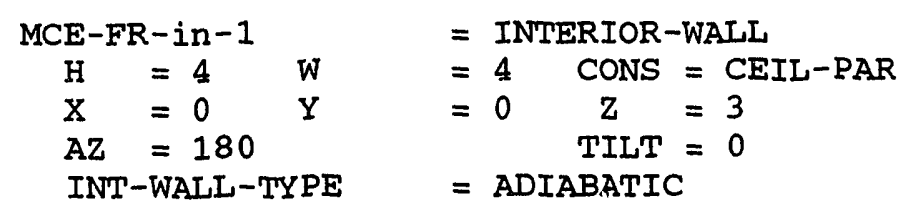

MFR2

$=$ SPACE LIKE MFRI

$Y=8$

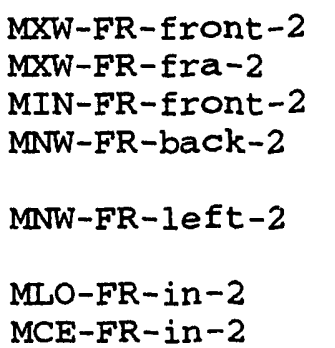

= EXTERIOR-WALL

= EXTERIOR-WALL

$=$ WINDOW

= INTERIOR-WALL

= INTERIOR-WALL

= INTERIOR-WALL

= INTERIOR-WALL
LIKE

LIKE MXW-FR-fra-1

LIKE MIN-FR-front-1

LIKE MNW-FR-back-1

NEXT - TO $=$ MH2

LIKE MNW-FR-left-1

NEXT-TO $=$ MFRI

LIKE MLO-FR-in-1

LIKE MCE-FR-in-1

\begin{tabular}{|c|c|c|c|c|c|}
\hline MFR3 & $=$ SPACE & $\stackrel{\text { MFR1 }}{Y}=$ & $=12$ & & \\
\hline MXW-FR-front -3 & $=$ & EXTERIOR-WALL & LIKE & MXX-FR-front-1 & .. \\
\hline$M X W-F R-f r a-3$ & $=$ & EXTERIOR-WALL & LIKE & MXW-FR-fra-1 & $\ldots$ \\
\hline MIN-FR-front-3 & $=$ & WINDOW & LIKE & MIN-FR-front-1 & .. \\
\hline $\mathrm{MNW}-\mathrm{FR}-\mathrm{back}-3$ & $=$ & INTERIOR-WALL & $\begin{array}{l}\text { LIKE } \\
\text { NEXT-O }\end{array}$ & $\begin{array}{l}\text { MNW-FR-back-1 } \\
\text { TO = MH2 }\end{array}$ & .. \\
\hline$M N W-F R-l e f t-3$ & $=$ & INTERIOR-WALL & $\begin{array}{l}\text { LIKE } \\
\text { NEXT- }\end{array}$ & $\begin{array}{l}\text { MNW-FR-left } 1 \\
\text { TO = MFR2 }\end{array}$ & . \\
\hline MLO-FR-in-3 & $=$ & INTERIOR-WALL & LIKE & MLO-FR-in-1 & . \\
\hline MCE-FR-in-3 & $=$ & INTERIOR-WALI & LIKE & MCE-FR-in-1 & $\cdots$ \\
\hline MFR4 & $=S P A C E$ & $\begin{array}{r}\text { MFR1 } \\
Y\end{array}$ & 16 & & \\
\hline$M X W-F R-$ front -4 & & EXTERIOR-WALL & LIKE & MXW-FR-front-1 & .. \\
\hline MXW-FR-fra-4 & & EXTERIOR-WALL & LIKE & MXW-FR-fra-1 & $\ldots$ \\
\hline MIN-FR-Eront-4 & $=$ & WINDOW & LIKE & MIN-FR-front-1 & $\ldots$ \\
\hline MNW-FR-back-4 & $=$ & INTERIOR-WALL & $\begin{array}{l}\text { LIKE } \\
\text { NEXT- }\end{array}$ & $\begin{array}{l}\text { MNW-FR-back-1 } \\
\text { mo = MH2 }\end{array}$ & \\
\hline MNW-FR-1eft-4 & $=$ & INTERIOR-WALL & $\begin{array}{l}\text { LIKE } \\
\text { NEXT- }\end{array}$ & $\begin{array}{l}\text { MNW-FR-left-1 } \\
\text { TO = MFR3 }\end{array}$ & $\bullet$ \\
\hline MLO-FR-in-4 & & INTERIOR-WAIL & LIKE & MLO-FR-in-1 & . \\
\hline MCE-FR-in-4 & $=$ & INTERIOR-WALL & LIKE & MCE-FR-in-1 & .. \\
\hline
\end{tabular}




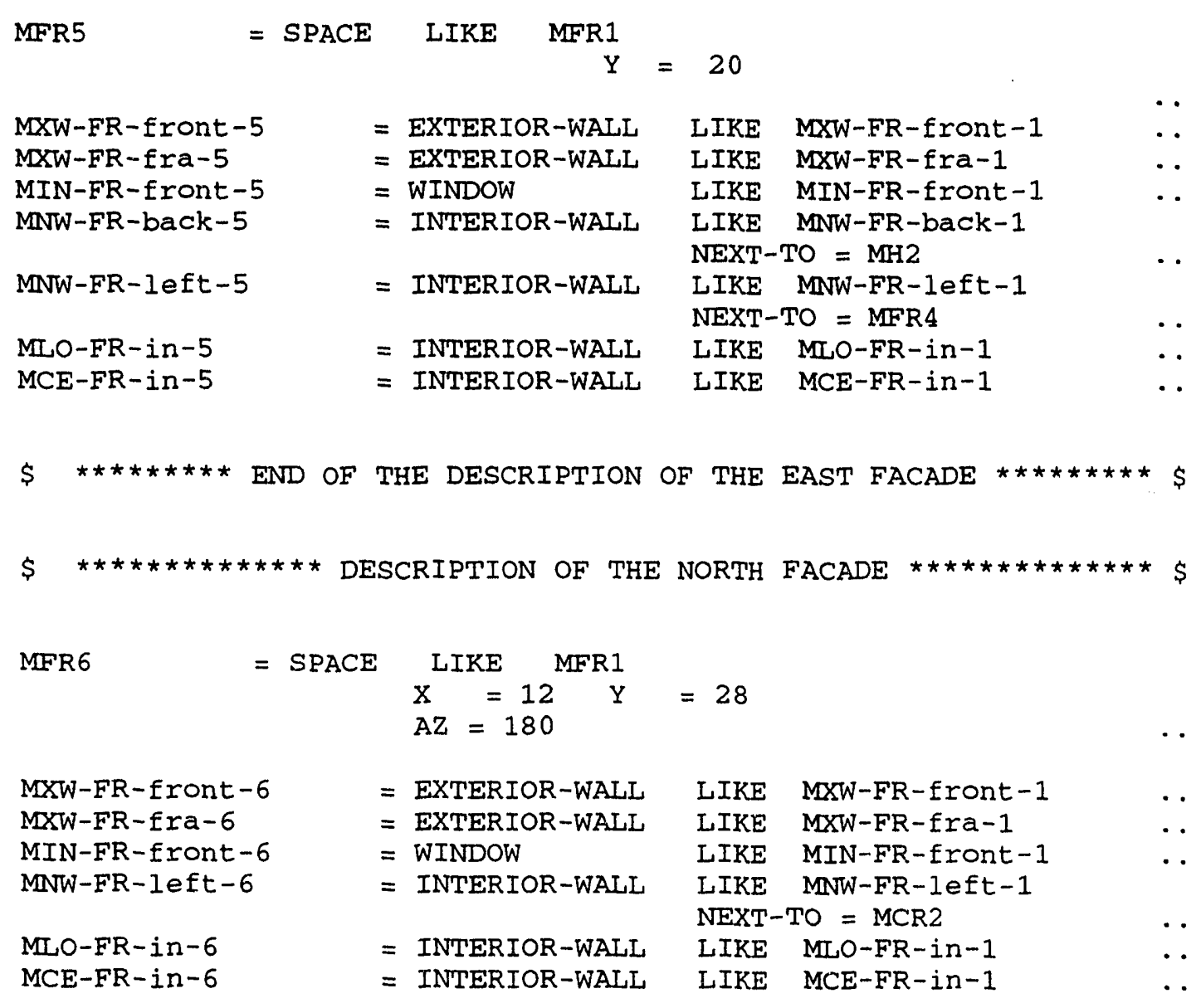

\begin{tabular}{|c|c|c|c|c|c|}
\hline \multirow[t]{2}{*}{ MFR7 } & \multirow[t]{2}{*}{ SPACE } & \multirow{2}{*}{$x^{\text {LIKE }}$} & & & \\
\hline & & & & & \\
\hline MXW-FR-Eront-7 & $=$ & EXTERIOR-WALL & LIKE & MXW-FR-front-1 & . \\
\hline$M X W-F R-f r a-7$ & $=$ & EXTERIOR-WALL & LIKE & MXW-FR-fra-1 & . \\
\hline MIN-FR-front-7 & $=$ & WINDOW & LIKE & MIN-FR-front-1 & . \\
\hline MNW-FR-1eft -7 & $=$ & INTERIOR-WALL & LIKE & MNW-FR-1eft-1 & \\
\hline & & & NEXT & TO $=$ MFR6 & \\
\hline MLO-FR-in-7 & $=$ & INTERIOR-WALL & LIKE & MLO-FR-in-1 & . \\
\hline MCE-FR-in-7 & $=$ & INTERIOR-WALL & LIKE & $M C E-F R-i n-1$ & . \\
\hline
\end{tabular}

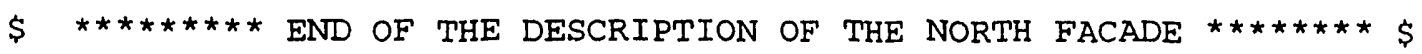

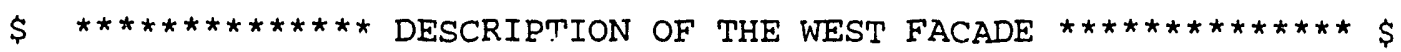

\begin{tabular}{|c|c|c|c|c|c|}
\hline \multirow[t]{3}{*}{ MFR8 } & \multirow[t]{3}{*}{$=$ SPACE } & LIKE MFR 1 & \multirow{3}{*}{$=24$} & & \\
\hline & & \multirow{2}{*}{$\begin{array}{l}X=0 \\
A Z=90\end{array}$} & & & \\
\hline & & & & & $\cdots$ \\
\hline MXW-FR-front - 8 & $=$ & EXTERIOR-WALL & LIKE & MXW-FR-front -1 & $\cdots$ \\
\hline$M X W-F R-f r a-8$ & $=$ & EXTERIOR-WALL & LIKE & MXW-FR-fra-1 & $\cdots$ \\
\hline$M I N-F R-$ front -8 & $=$ & WINDOW & LIKE & MIN-FR-tront-1 & $\ldots$ \\
\hline MNW-FR-back-8 & $=$ & INTERIOR-WALL & LIKE & $M N W-F R-b a c k-1$ & \\
\hline & & & \multicolumn{2}{|c|}{$\mathrm{NEXT}-\mathrm{TO}=\mathrm{MH} 1$} & \\
\hline$M N W-F R-1$ eft-8 & $=$ & INTERIOR-WALL & $\begin{array}{l}\text { LIKE } \\
\text { NEXT }\end{array}$ & $\begin{array}{l}\mathrm{MNW}-\mathrm{FR}-1 \text { eft }-1 \\
\mathrm{TO}=\mathrm{MCR} 3\end{array}$ & \\
\hline
\end{tabular}


MLO-FR-in-8
MCE-FR-in-8

= INTERIOR-WAILL

$=$ INTERIOR-WALL
LIKE MLO-FR-in-1

LIKE MCE-FR-in-1

MFR9

= SPACE LIKE MFR8

$Y=20$

MXW-FR-front-9
MXW-FR-fra-9
MIN-FR-front-9
MNW-FR-back-9
MNW-FR-left-9
MLO-FR-in-9
MCE-FR-in-9

$=$ EXTERIOR-WALL

= EXTERIOR-WALL

= WINDOW

$=$ INTEP.IOR-WALL

= INTERIOR-WALL

= INTERIOR-WALI

$=$ INTERIOR-WAII
LIKE

LIKE

LIKE

LIKE MNW-FR-back-1

NEXT-TO = MH.1

IIKE MNW-FR-Ieft-1

NEXT-TO = MFR8

LIKE MUO-FR-in-1

LIKE MCE-FR-in-1

MFR10

$=$ SPACE IIKE MFR8

$=16$

\begin{abstract}
MXW-FR-front -10
MXW-FR-Era-10

MIN-FR-front-10

MNW-FR-back-10

MNW-FR-1eft-10

MLO-FR-in-10

MCE-FR-in-10

MFR11
\end{abstract}

= EXTERIOR-WALL

= EXTTIRIOR-WALL

$=W I I$ JOW

$=$ IN $\perp$ ERIOR-WALI

$=$ INTERIOR-WALL

= INTERIOR-WALL

= INTERIOR-WALL
LIKE

IIKE

LIKE

LIKE MNW-FR-back-1

NEXT-TO $=$ MH1

LIKE MNW-FR-1eft-1

NEXT-TO = MFR.9

LIKE MLO-FR-in-1

LIKE MCE-FR-in-1
$=$ SPACE

MFR8

$Y=12$

$$
\begin{aligned}
& =\text { EXTERIOR-WALL } \\
& =\text { EXTERIOR-WALL } \\
& =\text { WINDOW } \\
& =\text { INTERIOR-WALL } \\
& =\text { INTERIOR-WALL } \\
& =\text { INTERIOR-WALL } \\
& =\text { INTERIOR-WALL }
\end{aligned}
$$

$\begin{array}{llc}\text { MFR12 SPACE } & \text { LIKE } & \text { MFR8 } \\ & Y=8\end{array}$

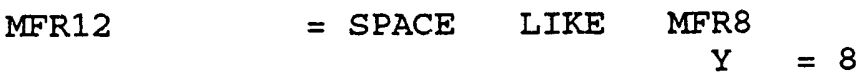

LIKE MXW-FR-front-1 …

LIKE MXW-FR-fra-1

LIKE MIN-FR-Eront-1

LIKE MNW-FR-Joack-1

$\mathrm{NEXT}-\mathrm{TO}=\mathrm{MH} 1$

LIKE MNW-FR-Left-1

NEXT-TO = MFR I. 0

LIKE MLO-FR-in-1

LIKE MCE-FR-in-1
-

.

-.

-

-

-

.

-
MXW-FR-front -12

MXW-FR-fra-12

MIN-FR-front-12

MNW-FR-back-12

$M N W-F \cdot$ - left -12

MLC-FR-in-12

MCE-FR-in-12
$=$ EXTERIOR-WALL

= EXTERIOK-WALI

$=$ WINDOW

= INTERIOR-WALI

$=$ INTERIOR-WALL

= INTERIOR-WALL

= INIER.IOR-WALL
LIKE MXW-FR-front-1 LIKE MXW-FR-fra-1

LIKE MIN-FR-f.ront-1 LIKE MNW-FR-back-1

NEXT-TO $=$ MH1

LIKE MNW-FR- left-1

NEXT-TO = MFR 11

LIKE MLO-FR-in-1

LIKE MCE-FR-in-1 
MF'R13

$$
\begin{array}{ccc}
\text { SPACE } & \text { LIKE } & \text { MFR1 } \\
& \mathrm{X}=4 & \mathrm{Y}=0 \\
\mathrm{AZ}= & = &
\end{array}
$$

MXW-FR-front-13

MXW-FR- fra-13

MIN-FR-front-13

MNW-FR-Ieft-13

MLO-FR-in-13

MCE-FR-in-13
$=$ EXTERIOR-WALL

= EXTERIOR-WALL

$=$ WINDOW

= INTERIOR-WAIL

$=$ INTERIOR-WALL

$=$ INTERIOR-WALL
IIKE

LIKE

LIKE

MIKE $M N-F R-1$ eft-1

NEXT-TO $=$ MCR4

LIKE MLO-FR-in-1

LIKE MCE-FR-in-1

MFR14

$$
\begin{array}{ccc}
\text { SPACE } & \text { LIKE } & \text { MFR13 } \\
& \mathrm{X}=8 & \mathrm{Y}=0
\end{array}
$$

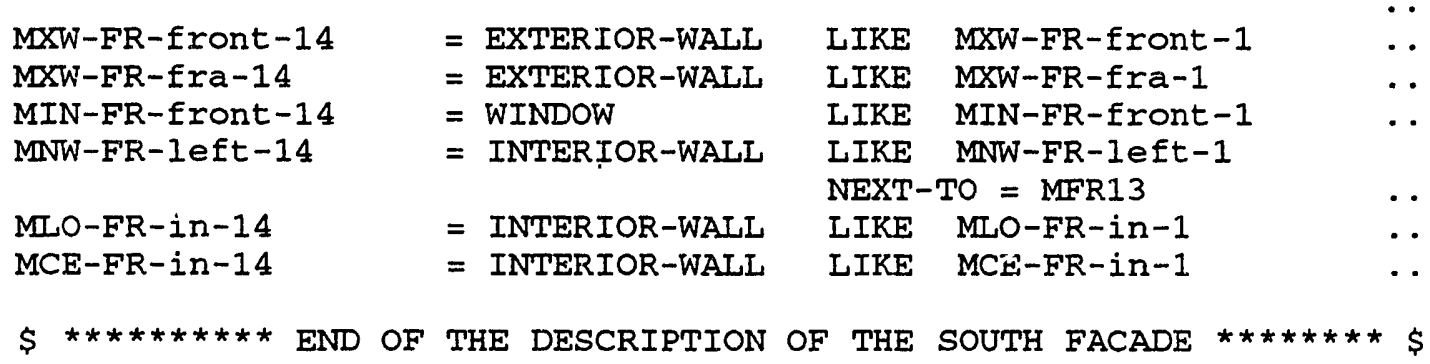

MIN-IR-S-a-1 = INTERIOR-WALL

$\mathrm{H}=3 \quad \mathrm{~W}=2$ CONS $=$ IWAILI-PAR

$\mathrm{X}=0 \quad \mathrm{Y}=0 \quad \mathrm{AZ}=180$

INT-WALL-TYPE = STANDARD NEXT-TO $=$ MFR13

MNW-IR-S-b-1 = INTERIOR-WALL

$\mathrm{H}=3 \quad \mathrm{~W}=2$ CONS $=$ IWALL-PAR

$\mathrm{X}=2 \mathrm{Y}=0 \mathrm{AZ}=18 \mathrm{C}$

INT-WALL-TYPE = STANDARD NEXT-TO $=$ MFR14

MIN-IR-W-1 = INTERIOR-WALL

$\mathrm{H}=3 \quad \mathrm{~W}=4$ CONS $=$ IWALL-PAR

$\mathrm{X}=0 \quad \mathrm{Y}=4 \quad \mathrm{AZ}=270$

INT-WALI-TYPE = STANDARD NEXT-TO $=$ MH1 

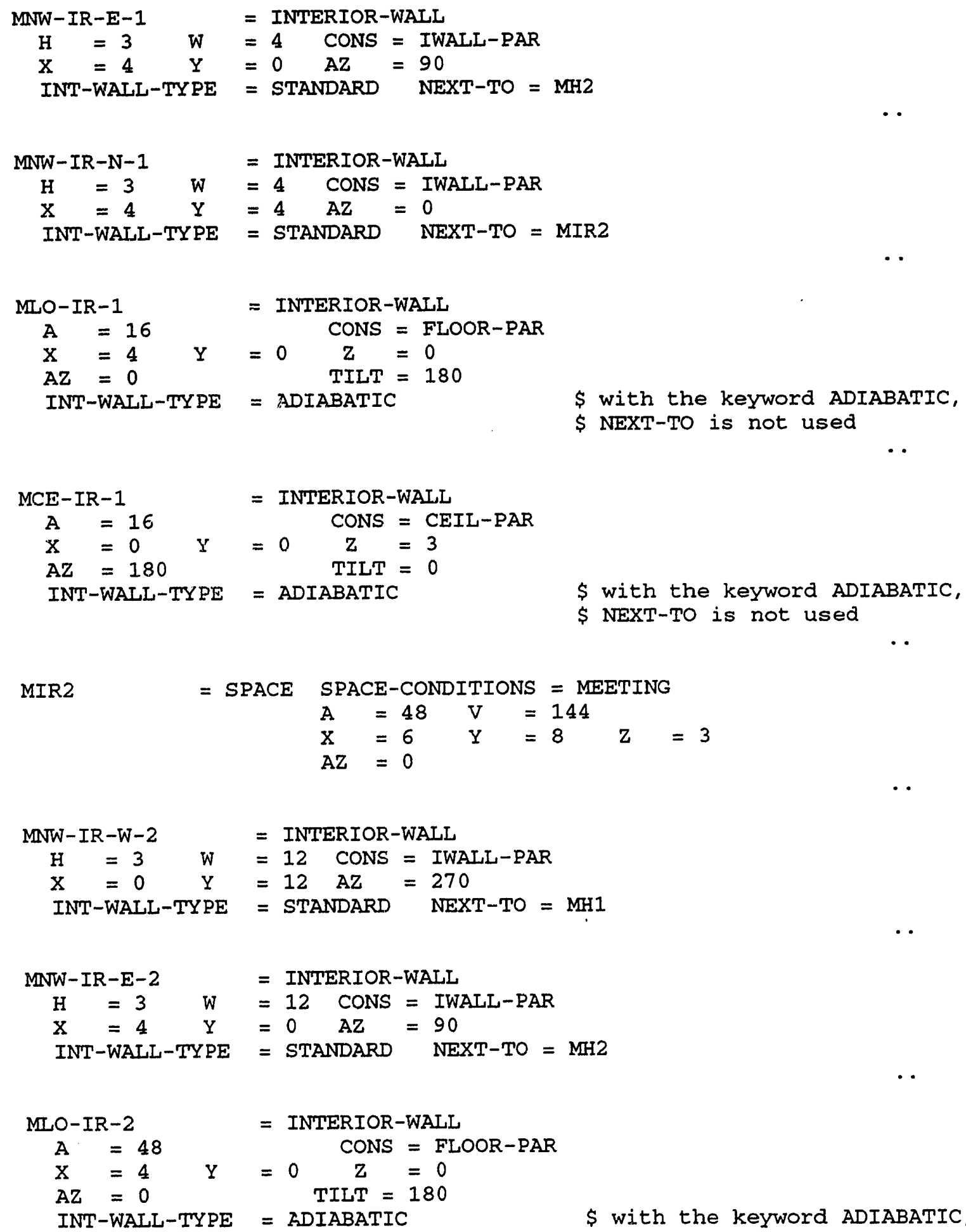

\$ with the keyword ADIABATIC, $\$$ NEXT-TO is not used

$$
\begin{aligned}
& \text { MCE-IR-2 = INTERIOR-WALL } \\
& \mathrm{A}=48 \quad \text { CONS }=\text { CEIL }-\mathrm{PAR} \\
& \mathrm{X}=\begin{array}{llll}
0 & \mathrm{Y}=\mathrm{Z}=3
\end{array} \\
& \overline{A Z}=180 \quad \text { TILT }=0 \\
& \text { INT-WALL-TYPE = ADIABATIC }
\end{aligned}
$$




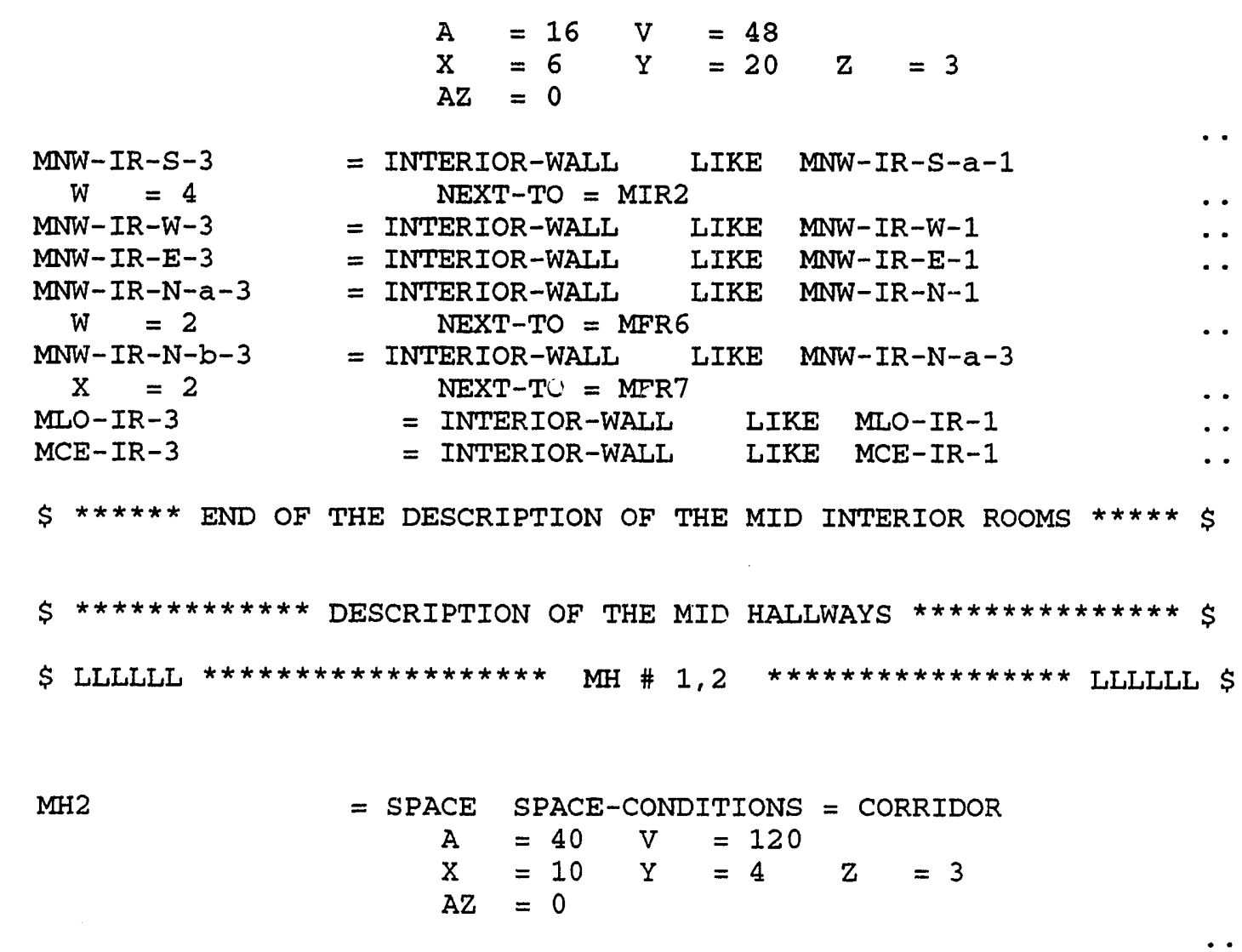

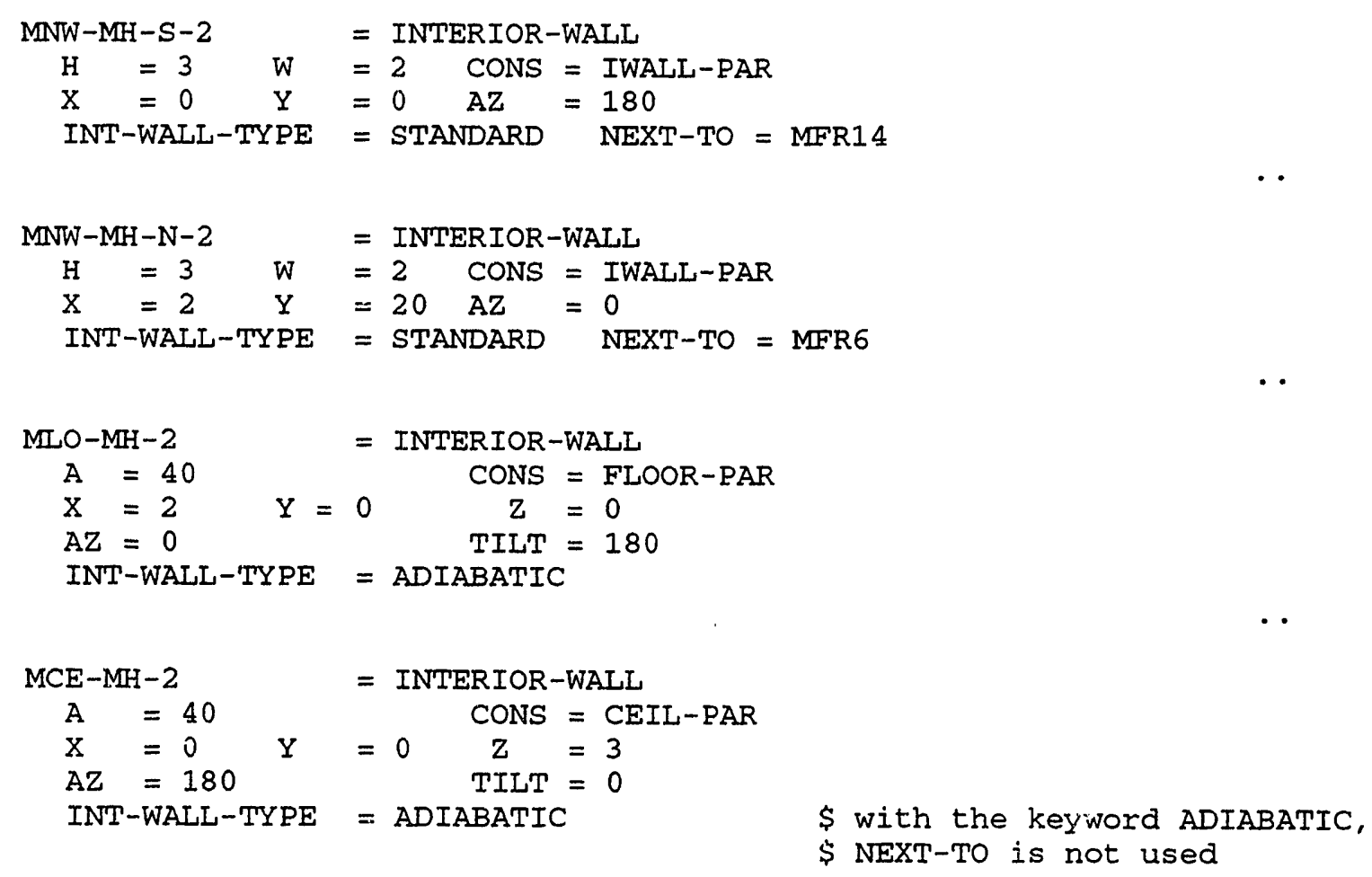

Nin 1

$$
\begin{aligned}
=\text { SPACE } & \text { LIKE } \mathrm{MH} 2 \\
X & =6 \quad Y=24 \\
A Z & =180
\end{aligned}
$$




$\begin{array}{lll} & & \text { NEXT-TO = MFR7 } \\ \text { MNW-MH-S-1 } & =\text { INTERIOR-WALL } & \text { LIKE MNW-MH-N-2 } \\ & & \text { NEXT-TO = MFR13 } \\ \text { MLO-MH-1 } & =\text { INTERIOR-WALL } & \text { LIKE MLO-MH-2 } \\ \text { MCE-MH-1 } & =\text { INTERIOR-WALL } & \text { LIKE MCE-MH-2 }\end{array}$

LOADS-REPORT

$$
\begin{array}{ll}
\text { SUMMARY } & =(L S-A, \text { LS-C, LS-D }) \\
\text { VERIFICATION } & =(L V-A) \\
\text { HOURLY-DATA-SAVE } & =\text { NO } \\
\text { REPORT-FREQUENCY } & =\text { HOURLY }
\end{array}
$$

LORSCH = SCHEDULE

$\begin{array}{llllll}\text { THRU AUG } & 22 & \text { (ALL) } & (1,24) & (0) \\ \text { THRU AUG } & 25 & \text { (ALL) } & (1,24) & (1) \\ \text { THRU DEC } & 31 & \text { (ALL) } & (1,24) & (0)\end{array}$

LRB-GLOB = REPORT-BLOCK VARIABLE-TYPE = GLOBAL VARIABLE-LIST $=(4,15)$

LRB-MFR 10 = REPORT-BLOCK VARIABLE-TYPE = MFR10 VARIABLE-IIST $=(1,3,4,6,10,12,14,35,37,44)$

LHR = HOURLY-REPORT REPORT-SCHEDULE = LORSCH REPORT-BLOCK $=($ LRB-GLOB, LRB-MFR10)

END

COMPUTE LOADS

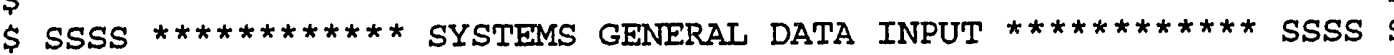
$\$$ DESCRIPTION OF THE SYSTEM APPLIED :

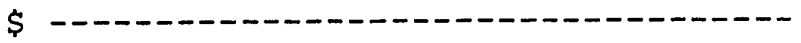

$\$$

$\$$ WE USE A VARIABLE AIR VOLUME SYSTEM, THE COOLING IS PROVIDED

$\$$ BY A HEAT PUMP, AND THE HEAT IS PROVIDED BY THERMOSTATICALLY

$\$$ CONTROLLED BASEBOARDS HEATERS. THERE IS A PREHEATER THAT

$\$$ RAISES THE AIR TO 17 C WHEN THE SUPPLY TEMPERATURE IS UNDER

$\$$ THIS VALUE.

$\$$

$\$$

$\$$

TYPE

LOW LIM

SET POINT
UPPER LIM

$$
21
$$$$
24
$$ 
INPUT-UNITS = METYR:C OUTPUT-UNITS = METRIC

PARAMETER SRATIO := 1.0

TITLE LINE-1 *MID FLOOR OF AN OFFICE BUILDING*

LINE-2 *SYSTEMS FOR THE EXHAUSTIVE DESCRIPTION*

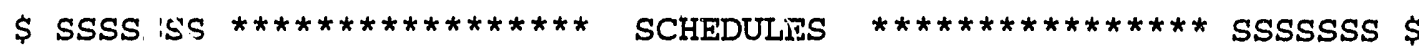

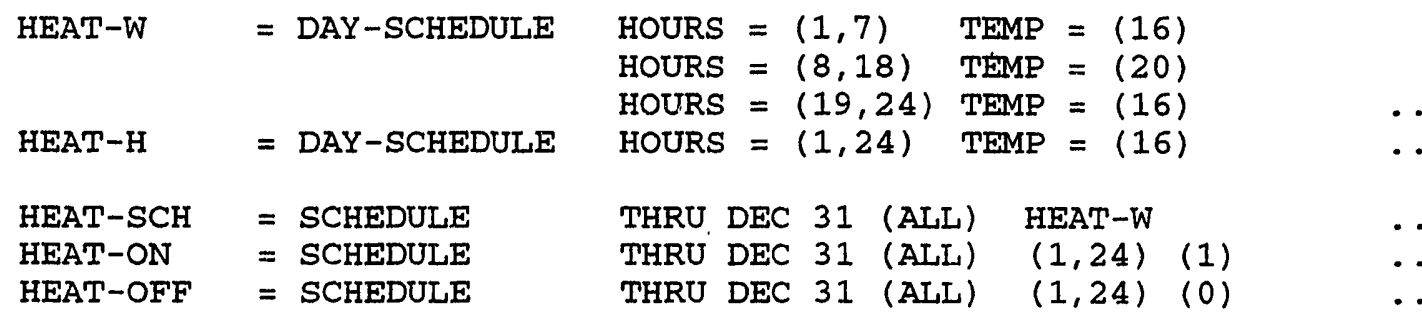

$\begin{array}{llllll}\text { COOL-W } & =\text { DAY-SCHEDULE } & \text { HOURS }=(1,24) & \text { TEMP }=(23) & & \ldots \\ \text { COOL-H } & =\text { DAY-SCHEDULE } & \text { HOURS }=(1,24) & \text { TEMP }=(27) & \\ \text { COOL-SCH } & =\text { SCHEDULE } & \text { THRU DEC } 31 \text { (ALL) } & \text { COOL-W } & \\ \text { COOL-ON } & =\text { SCHEDULE } & \text { THRU DEC } 31 \text { (ALL) }(1,24)(1) & \ldots \\ \text { COOL-OFF } & =\text { SCHEDULE } & \text { THRU DEC } 31 \text { (ALL) }(1,24)(0) & \ldots\end{array}$

\$ THE FANS PIN SWITCHED ON TWO HOURS BEFORE THE ARRIVAL OF THE

$\$$ EMPLOYEES AND ARE SWITCHED OFF ONE HOUR AFTER THEY HAVE LEFT

FAN-ON $\quad=$ SCH THRU DEC 31 (ALL) $(1,5)(0)(6,18)(1)(19,24)(0)$

FAN-OFF $\quad=$ SCH THRU DEC 31 (ALL) $(1,24)(0)$

S SSSSSS $* * \star * \star * \star * * * * \star * *$ ZONE DESCRIPTION $* * * * * * * \star * * * * * * *$ SSSSSS

Z-CONTROL = ZONE-CONTROL

$$
\begin{array}{ll}
\text { DESIGN-HEAT-T } & =19 . \\
\text { DESIGN-COOL-T } & =22 . \\
\text { HEAT-TEMP-SCH } & =\text { HEAT-SCH } \\
\text { COOL-TEMP-SCH } & =\text { COOL-SCH } \\
\text { THERMOSTAT-TYPE } & =\text { PROPORTIONAL } \\
\text { THROTTLING-RANGE } & =2.0 \\
\text { BASEBOARD-CTRL } & =\text { THERMOSTATIC }
\end{array}
$$

$\mathrm{R}-\mathrm{CHANGE}=\mathrm{ZONE}-\mathrm{AIR}$

\$ THE AIR CHANGE OF 2.25 VOL/h IS EQUAI TO HAVE A MINIMUM RENEWAI \$ $\$$ OF AIR OF 10 1/s/pers WHICH MATCHES THE ASHRAE REQUIREMENTS FOR \$ $\$$ OFFICE BUILDINGS

$$
\begin{array}{cc}
\text { OA-CHANGES } & =2.25 \\
84
\end{array}
$$




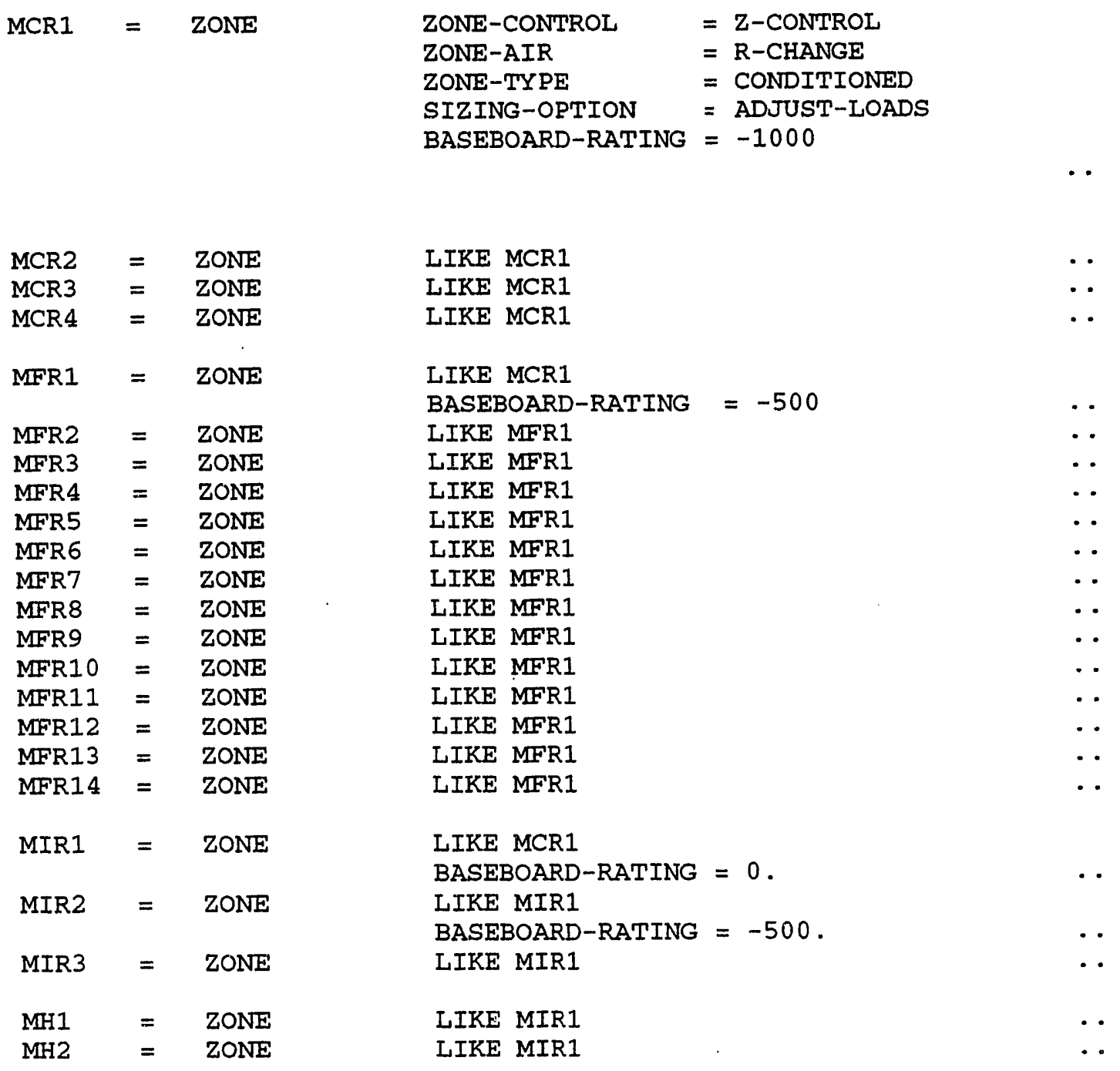

SYS-CONT = SYSTEM-CONTROL

$\begin{array}{ll}\text { MIN-SUPPLY-T } & =17 . \\ \text { COOL-CONTROL } & =\text { WARMEST } \\ \text { PREHEAT-T } & =16 . \\ \text { HEATING-SCHEDULE } & =\text { HEAT-OFF } \\ \text { COOLING-SCHEDULE } & =\text { COOL-ON }\end{array}$

SYS-AIR = SYSTEMI-AIR

OA-CONTROL $=$ FIXED

SYS-FAN = SYSTEM-FANS

SUPPLY-STATIC $=100$

\$ Pressure difference 


SUPPLY-EFF
FAN-SCHEDULE
FAN-CONTROL
FAN-PLACEMENT
MOTOR-PLACEMENT
RETURN-STATIC
RETURN-EFF

$=0.7$

$=$ FAN-ON

$=$ SPEED

$=$ DRAW-THROUGH

$=$ OUTSIDE-AIRFLOW

$=75$

$=0.7$

VAV-BOX-1 = SYSTEM-TERMINAI

VAV-BOX-2 = SYSTEM-TERMINAL

NOREAST = SYSTEM

SYSTEM-TYPE = VAVS

SYSTEM-TERMINAL $=$ VAV-BOX-1

SYSTEM-CONTROL = SYS-CONT

SYSTEM-AIR = SYS-AIR

SYSTEM-FANS = SYS-FAN

SIZING-RATIO = SRATIO

ZONE-NAMES $\quad=$ (MFR13, MFR14, MCR1, MFR1, MFR2 , MFR3 , MFR4 , MFR5, MCR2)

SOUWEST $=$ SYSTEM

SYSTEM-TYPE = VAVS

SYSTEM-TERMINAL = VAV-BOX-1

SYSTEM-CONTROL = SYS-CONT

SYSTEM-AIR = SYS-AIR

SYSTEM-FANS = SYS-FAN

SIZING-RATIO = SRATIO

ZONE-NAMES

= (MFR6, MFR7, MCR3, MFR8, MFR9 , MFR10 , MFR11, MFR12, MCR4)

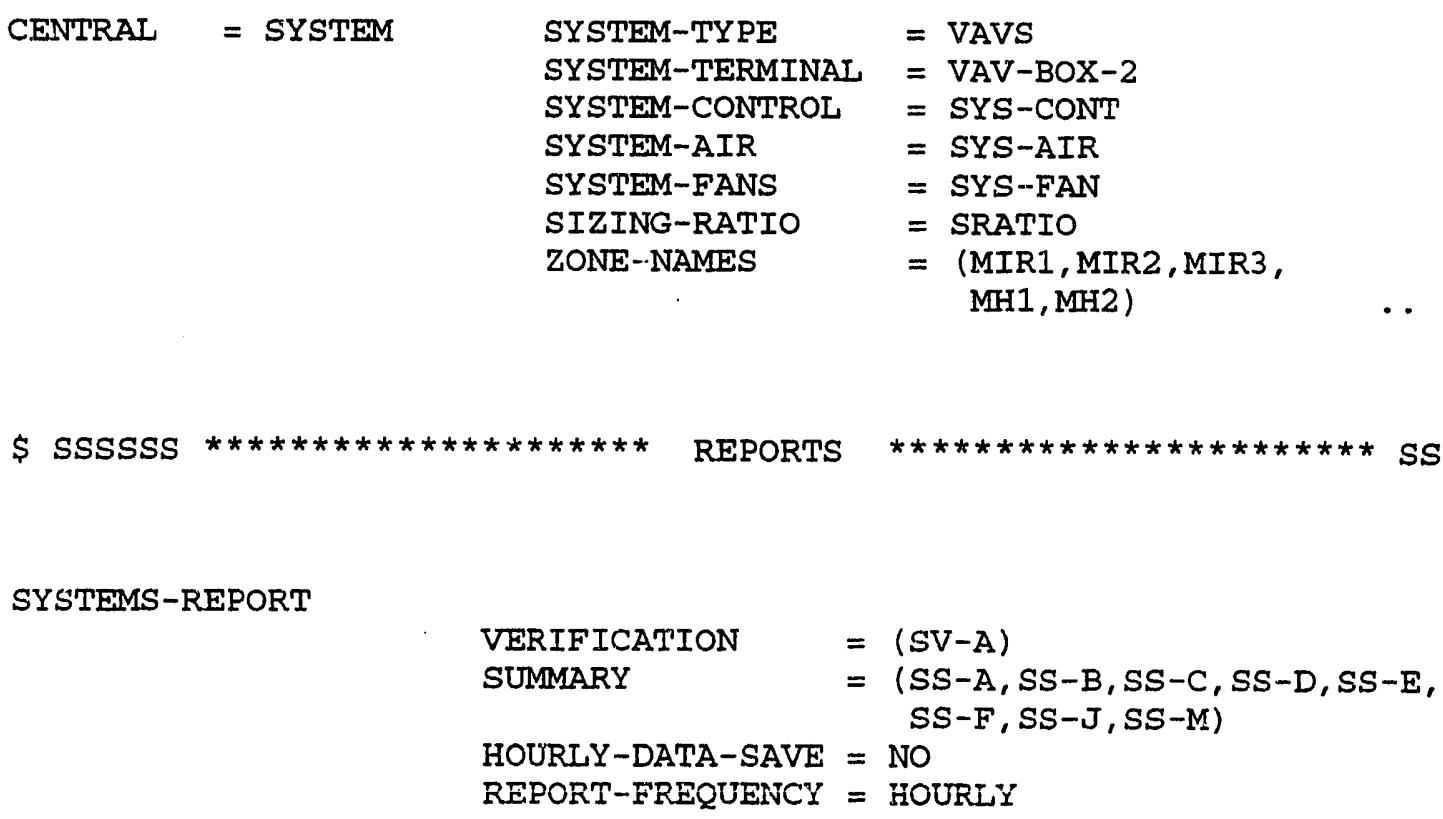

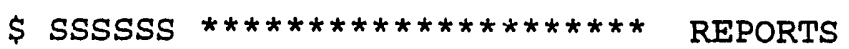

SYSTEMS-REPORT

SSSSSS \$ 


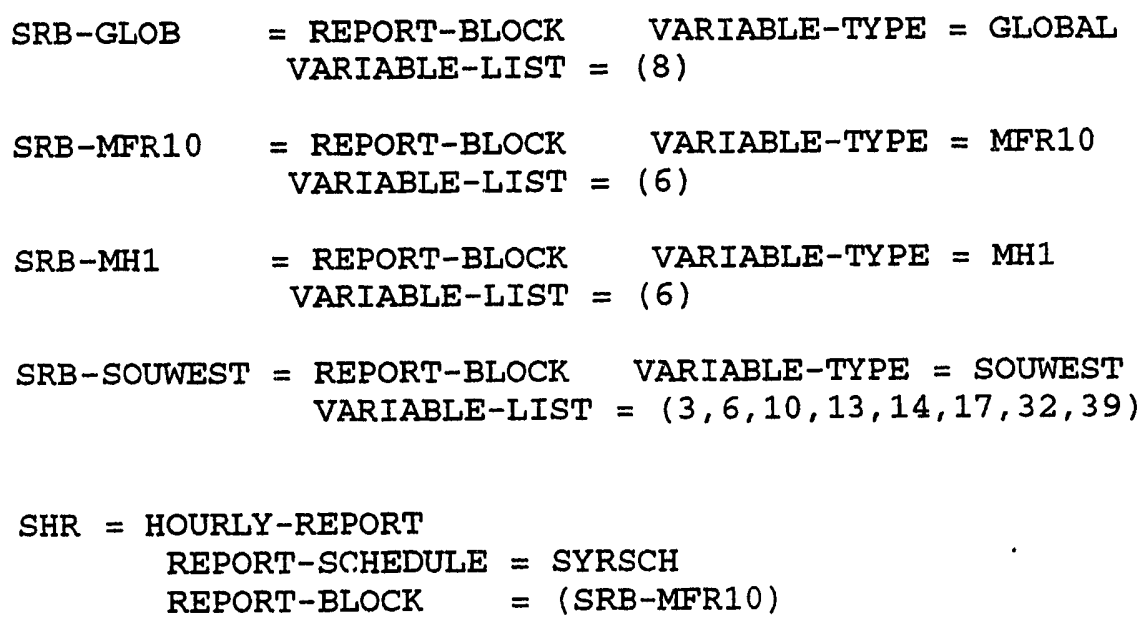




\section{Appendix}

The DOE-2 Program input for the Simulation of the One-Room Geometry 

$\$$ INPUT FILE FOR THE INVESTIGATION OF THE INFLUENCE OF THE DESC- $\$$ \$ RIPTION ON THE RESULT OF A SIMULATION WITH DOE-2 \$ $\$$ $\$$ PREPARATION FOR PARAMETRIC RUNS ON THE STRUCTURE OF THE SHELL. $\$$ WEATHER FILE = REDBIUFF.bin

$\$$ $\$$ $\$$

$\$$ The internal wall structure has been divided by 2 in order to $\$$ have a realistic thermal storage. The adjacent spaces are $\$$ supposed to be at the same temperature as the studied space, $\$$ $\$$ so only a half of the wall plays a role in the thermal storage $\$$ $\$$

\$ ILLLLL $* * * * * * * * * * * * * *$ GENERALDATA-INPUT

$\star * * * * * * * * * * * * *$ LLLLLLL $\$$

INPUT LOADS INPUT-UNITS = METRIC OUTPUT-UNITS $=$ METRIC $\quad$ O ABORT WARNINGS

DIAGNOSYIO CAUTIONS, WIDE, ECHO, LIMITS, LIBRARY-CONTENTS SINGLE-SPACED

TITLE

LINE-1 *DESCRIPTION OF ONLY ONE ROOM*

RUN-PERIOD

JAN $01 \quad 1984 \quad$ THRU DEC $31 \quad 1984$

SET-DEFAULT

FOR WINDOW SETBACK $\quad=0.1$

PARAMETER

$\begin{array}{ll}\text { EWALL-PAR } & =\text { EWALL-M } \\ \text { IWALL-PAR } & =\text { IWALL-M } \\ \text { IWALL-D-PAR } & =\text { IWALL-MD } \\ \text { CEIL-PAR } & =\text { CEIL-M } \\ \text { FLOOR-PAR } & =\text { FLOOR-M } \\ \text { GLASS-PAR } & =2 \text { IV-IR }\end{array}$

BUILDING-LOCATION

IATITUDE

LONGITUDE

TIME-ZONE

ALTITUDE

DAYLIGHT-SAVINGS

HOLIDAY

AZIMUTH

$=40.2$

$=122.2$

$=8$

$=140$

$=$ YES

$=\mathrm{NO}$

$=270$

\$ LLLLLI

MATERIALS

(DIN-NORM)

LLLLLI \$

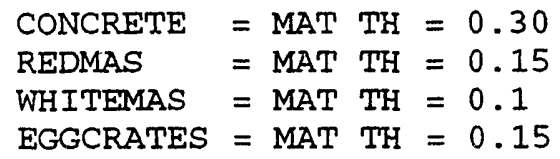

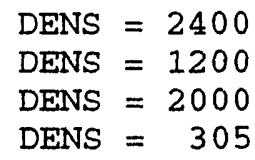

$S-H=1050 \ldots$
$S-H=900 \ldots$
$S-H=900 \ldots$
$S-H=1100 \ldots$ 


$\begin{array}{ll}\text { U-FLOOR } & =\text { MAT TH }=0.05 \\ \text { GYPSBRD } & =\text { MAT TH }=0.025 \\ \text { PLASTER } & =\text { MAT TH }=0.015 \\ \text { CEMENTPLA } & =\text { MAT TH }=0.02 \\ \text { MINWOOL1 } & =\text { MAT TH }=0.04 \\ \text { MINWOOL2 }=\text { MAT TH }=0.1 \\ \text { MINBRD1 }=\text { MAT TH }=0.1 \\ \text { ACOUTILES }=\text { MAT TH }=0.02 \\ \text { FELTMATS }=\text { MAT TH }=0.005 \\ \text { BARCH }=\text { MAT TH }=0.040 \\ \text { PLYWOOD }=\text { MAT TH }=0.04 \\ \text { PARTBRD }=\text { MAT TH }=0.04 \\ \text { PVC-LAYER }=\text { MAT TH }=0.004 \\ \text { ROOFMATE }=\text { MAT TH }=0.1 \\ \text { GRAVEL }=\text { MAT TH }=0.15 \\ \text { CARPET }=\text { MAT RES }=0.0625 \\ \text { AIRLAYER }=\text { MAT RES }=0.13 \\ \text { AIRSPACE }=\text { MAT RES }=0.2 \\ \text { METAL }=\text { MAT RES }=0.00002\end{array}$

$\begin{array}{ll}\text { COND }=0.47 & \text { DENS }=1400 \\ \text { COND }=0.4 & \text { DENS }=1000 \\ \text { COND }=0.7 & \text { DENS }=1400 \\ \text { COND }=1.4 & \text { DENS }=2000 \\ \text { COND }=0.036 & \text { DENS }=60 \\ \text { COND }=0.036 & \text { DENS }=90 \\ \text { COND }=0.04 & \text { DENS }=130 \\ \text { COND }=0.04 & \text { DENS }=130 \\ \text { COND }=0.047 & \text { DENS }=78 \\ \text { COND }=0.2 & \text { DENS }=800 \\ \text { COND }=0.15 & \text { DENS }=800 \\ \text { COND }=0.13 & \text { DENS }=700 \\ \text { COND }=0.23 & \text { DENS }=1300 \\ \text { COND }=0.035 & \text { DENS }=35 \\ \text { COND }=0.7 & \text { DENS }=1650\end{array}$

$S-H=1100 \ldots$

$\mathrm{S}-\mathrm{H}=800 \ldots$

$S-H=900 \ldots$

$\mathrm{S}-\mathrm{H}=1100 \ldots$

$\mathrm{S}-\mathrm{H}=600 \ldots$

$\mathrm{S}-\mathrm{H}=600 \ldots$

$\mathrm{S}-\mathrm{H}=600 \ldots$

$\mathrm{S}-\mathrm{H}=840 \ldots$

$\mathrm{S}-\mathrm{H}=880 \ldots$

$\mathrm{S}-\mathrm{H}=2200 \ldots$

$\mathrm{S}-\mathrm{H}=2520 \ldots$

$\mathrm{S}-\mathrm{H}=2700 \ldots$

$\mathrm{S}-\mathrm{H}=1470 \ldots$

$\mathrm{S}-\mathrm{H}=1000 \ldots$

$\mathrm{S}-\mathrm{H}=900 \ldots$

\$ THE KEYWORD OF EACH STRUCTURE IS COMPOSED OF THREE TERMS "1-2-3" BE \$ \$ LOW IS AN EXPLANATION OF THE PART 2 (ELEMENT OF THE SHELL) AND PART 3 \$ $\$$ (CHARACTERISTICS OF THE ELEMENT IN TERMS OF HEAT CAPACITY)

$\$$

PART $1: \quad$ FLO $\rightarrow$ FLOOR

$\$$ CEI $\rightarrow$ CEILING

$\$ \quad$ IWA $\rightarrow$ INTERIOR WALL

$\$ \quad$ EWA $\rightarrow$ EXTERIOR WALL

$\$$ PART $2: \quad$ EL $\rightarrow$ EXTRA-LIGHT

S L $\rightarrow$ LIGHT

$\$ \quad M \quad \rightarrow$ MEDIUM

H $\rightarrow$ HEATYY

\section{$\$$}

---- FLOOR STRUCTURE $\$$

L-FLO-EL = LAYERS

MAT $=$ (ACOUTILES AIRSPACE CONCRETE AIRLAYER PARTBRD CARPET)

$\mathrm{TH}=\left(\begin{array}{lllllll} & 0.02 & 0.15 & 0.30 & 0.03 & 0.04 & 0.01\end{array}\right)$

L-FLO-L = LAYERS

MAT $=($ MINWOOL2 PARTBRD CARPET $)$

$\mathrm{TH}=\left(\begin{array}{lll}0.025 & 0.02 & 0.01\end{array}\right)$

L-FLO-M = LAYERS

MA'P $=$ (CONCRETE MINBRD1 U-FLOOR FELTMATS $)$

$\mathrm{TH}=\left(\begin{array}{llll}0.15 & 0.015 & 0.08 & 0.005\end{array}\right)$

\$ ---- CEII.ING STRUCTURE

L-CEI-EL = LAYERS

MAT $=$ (CARPET PARTBRD AIRLAYER CONCRETE AIRSPACE ACOUTILES)

$\mathrm{TH}=\left(\begin{array}{llllll}0.01 & 0.04 & 0.03 & 0.30 & 0.27 & 0.02\end{array}\right) \quad \ldots$




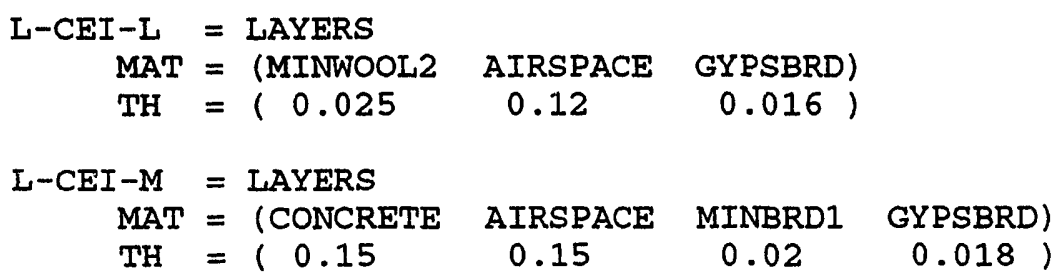

\$ - - INTERIOR WALLS --.- \$

\$ THE STRUCTURE OF THE INTERIOR WALL HAS BEEN DIVIDED BY TWO

$\$$ TO TAKE INTO ACCOUNT THE FACT THE STORAGE EFFECT CORRECTLY \$

L-IWA-EL = LAYERS

MAT $=($ MINWOOL2)

$\mathrm{TH}=(0.05)$

L-IWA-I = LAYERS

MAT $=$ (GYPSBRD MINWOOL2)

$\mathrm{TH}=\left(\begin{array}{ll}0.0125 & 0.045\end{array}\right)$

$L-I W A-L D=$ LAYERS

MAT $=$ (GYPSBRD MINWOOL2 GYPSBRD)

$\mathrm{TH}=\left(\begin{array}{lll}0.0125 & 0.09 & 0.0125\end{array}\right)$

L-IWA-M = IAYYERS

MAT $=$ (PLASTER REDMAS)

$\mathrm{TH}=\left(\begin{array}{ll}0.015 & 0.06\end{array}\right)$

L-IWA-MD = LAYERS

MAT = (PLASTER REDMAS PLASTER)

$\mathrm{TH}=\left(\begin{array}{lll}0.015 & 0.12 & 0.015\end{array}\right)$

\$ - - EXTERIOR WALLS - - - \$

L-EWA-EL = LAYERS

MAT $=($ MINWOOL 2$)$

$\mathrm{TH}=(0.12)$

L-EWA-L = LAYYRS

MAT $=$ (CEMENTPLA PARTBRD MINWOOL2 PARTBRD)

$\mathrm{TH}=\left(\begin{array}{llll}0.0125 & 0.0125 & 0.12 & 0.016\end{array}\right)$

L-EWA-M = LAYERS

MAT $=$ (MINWOOL2 REDMAS PLASTER)

$\mathrm{TH}=\left(\begin{array}{lll}0.12 & 0.15 & 0.015\end{array}\right)$

L-EWA-H = LAYERS

MAT $=$ (REDMAS AIRLAYER MINWOOL2 CONCRETE)

$\mathrm{TH}=\left(\begin{array}{cccc}0.1 & 0.05 & 0.12 & 0.20\end{array}\right)$

FLOOR-EL = CONSTRUCTION

FLOOR-L = CONSTRUCTION

FLOOR-M $=$ CONSTRUCTION

CEIL-EL = CONSTRUCTION

CEIL-L = CONSTRUCTION

$$
\begin{array}{lll}
\text { LAYERS } & =\text { L-FLO-EL } & \ldots \\
\text { LAYERS }=\text { L-FLO-L } & \ldots \\
\text { LAYERS }=\text { L-FLO-M } & \ldots \\
\text { LAYERS }=\text { L-CEI-EL } & \ldots \\
\text { LAYERS }=\text { L-CEI-L } & \ldots
\end{array}
$$




$$
\begin{aligned}
& \text { spotthesis.inp } \\
& \text { CEIL-M = CONSTRUCTION } \\
& \text { IWALL-EL = CONSTRUCTION } \\
& \text { IWALL-L = CONSTRUCTION } \\
& \text { IWALL-LD }=\text { CONSTRUCTION } \\
& \text { IWALL-M }=\text { CONSTRUCTION } \\
& \text { IWALL-MD }=\text { CONSTRUCTION } \\
& \text { EWALL-EL }=\text { CONSTRUCTION } \\
& \text { EWALL-L = CONSTRUCTION } \\
& \text { EWALL-M }=\text { CONSTRUCTION } \\
& \text { EWALL-H = CONSTRUCTION }
\end{aligned}
$$

$2 I V=$ GLATSS-TYPE

$$
\begin{array}{lll}
\text { PANES } & =2 \\
\text { GLASS-CONDUCTANCE } & =3.58 \text { \$without alpha-out\$ } \\
\text { VIS-TRANS } & =0.81 \\
\text { SHADING-COEF } & =0.72 \quad \ldots
\end{array}
$$

$2 I V-I R=$ GLASS-TYPE

$$
\begin{array}{lll}
\text { PANES } & =2 \\
\text { GLASS-CONDUCTANCE } & =1.605 \text { \$without alpha-out } \\
\text { VIS-TRANS } & =0.75 \\
\text { SHADING-COEF } & =0.38 \quad \ldots
\end{array}
$$

$3 I V=$ GLASS-TYPE

$$
\begin{array}{lll}
\text { PANES } & =3 \\
\text { GLASS-CONDUCTANCE } & =2.311 \quad \text { \$without alpha-out\$ } \\
\text { VIS-TRANS } & =0.74 \\
\text { SHADING-COEF } & =0.65 \quad \ldots
\end{array}
$$

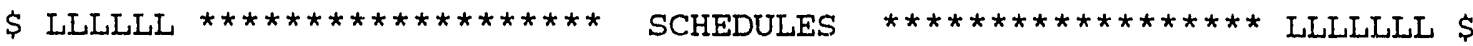

\$ THESE ARE THE SCHEDULES FOR THE MANAGEMENT OF THE SHADING DEVICE. \$ $\$$ WHEN THE VALUE OF DIRECT RADIATION GETTING INTO THE ROOM THROUGH \$

$\$$ THE WINDOWS EXCEEDS THE SPECIFIED VALUE, THE BLINDS WILL BE CLO- \$

$\$$ SED. $1<00 \mathrm{~W} / \mathrm{m} 2$ roughly correspond to $400 \mathrm{Btu} / \mathrm{sqft}$.

T-ALL-SOLAR-GAIN $=D-S C H \quad$ HOURS $=(1,24) \quad$ RADIATIONS - (120.) $\ldots$

$\begin{array}{lllll}\text { T-SOLAR-GAIN } & =W-S C H & \text { (ALL) } & \text { T-ALL-SOLAR-GAIN } & \ldots \\ \text { SOLAR-GAIN } & =\text { SCH } & \text { THRU DEC } & 31 \text { T-SOLAR-GAIN }\end{array}$

$\$$ THE SCHEDULES OF THE DEVICES AND THE EMPLOYEES ARE THE SAME i.e. \$ $\$$ F'ROM 9 am to $5 \mathrm{pm}$ ON A WORKING DA.Y.

$\begin{array}{ll}\text { WD--LIGHT } & =\mathrm{D}-\mathrm{SCH} \\ \text { WEH-LIGHT } & =\mathrm{D}-\mathrm{SCH} \\ \text { TEST-LIGHT } & =\mathrm{D}-\mathrm{SCH} \\ \text { LIGHT-ON } & =\mathrm{SCH}\end{array}$

LIGHT-ON

$$
\begin{array}{rlll}
(1,7)(0) \quad(8,18)(1) & (19,24)(0) & \ldots \\
& (1,24)(0) & \ldots \\
& (1,24)(1) & \ldots
\end{array}
$$

THRU DEC 31 (ALL) WD--LIGHT 


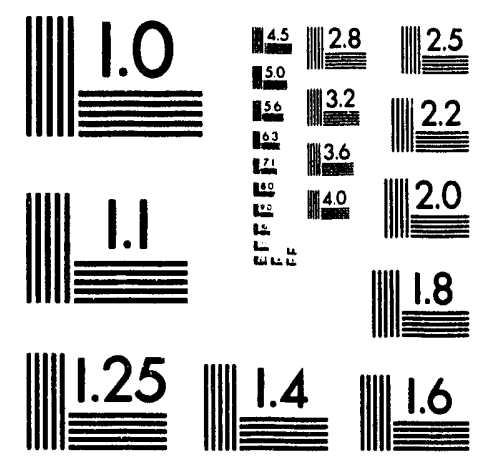



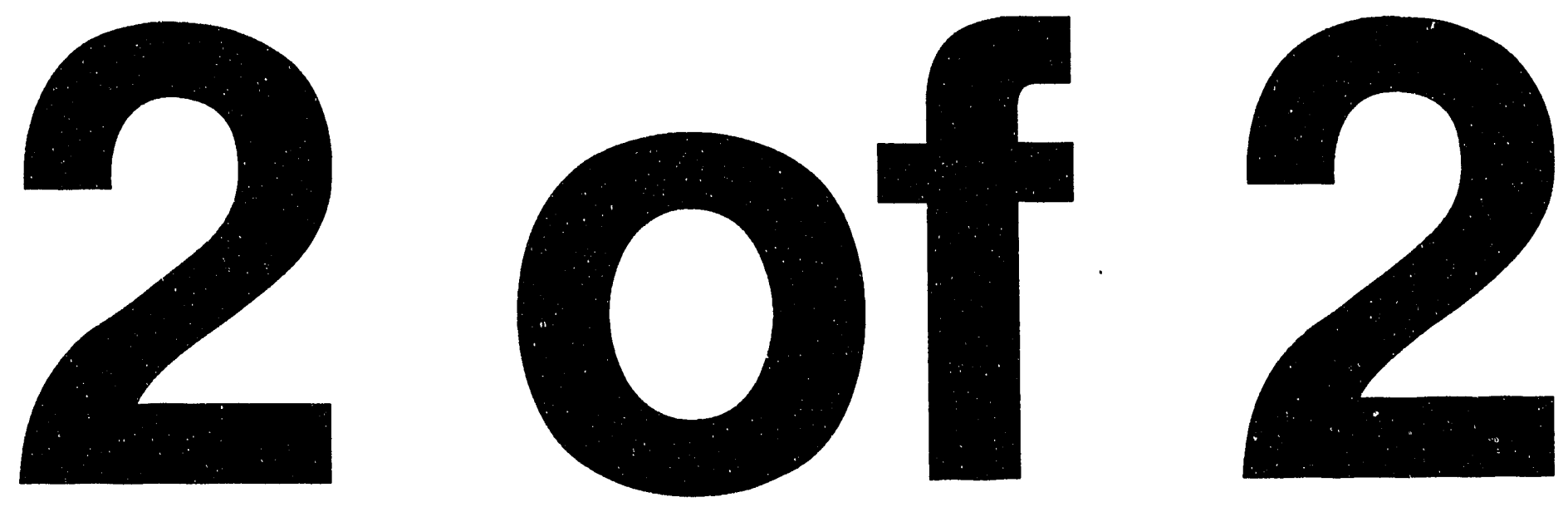


$\begin{array}{llllll}\text { WD--EQUIP } & =\text { D-SCH } & (1,8)(0)(9,17)(1)(18,24)(0) & \ldots \\ \text { WEH-EQUIP } & =\text { D-SCH } & (1,24)(0) & & \\ \text { TEST-EQUIP } & =\text { D-SCH } & (1,24)(1) & & \\ & & & & & \\ \text { EQUIP-ON } & =\text { SCH } & \text { THRU DEC } 31 \text { (ALL) WD--EQUIP }\end{array}$

\$ THERE IS NO INFILTRATION WHEN THE VENTILATION IS WORKING. THE \$ $\$$ INFILTRATION SCHEDULES ARE AS GIVEN BELOW.

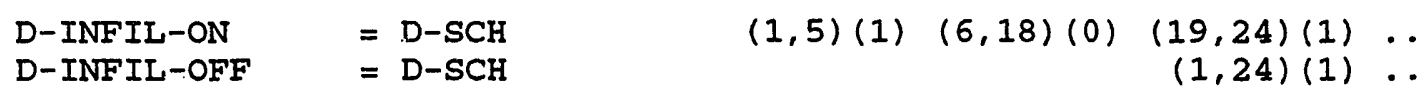

INFILTRATION-ON $=\mathrm{SCH}$

THRU DEC 31 (ALL) D-INFIL-ON

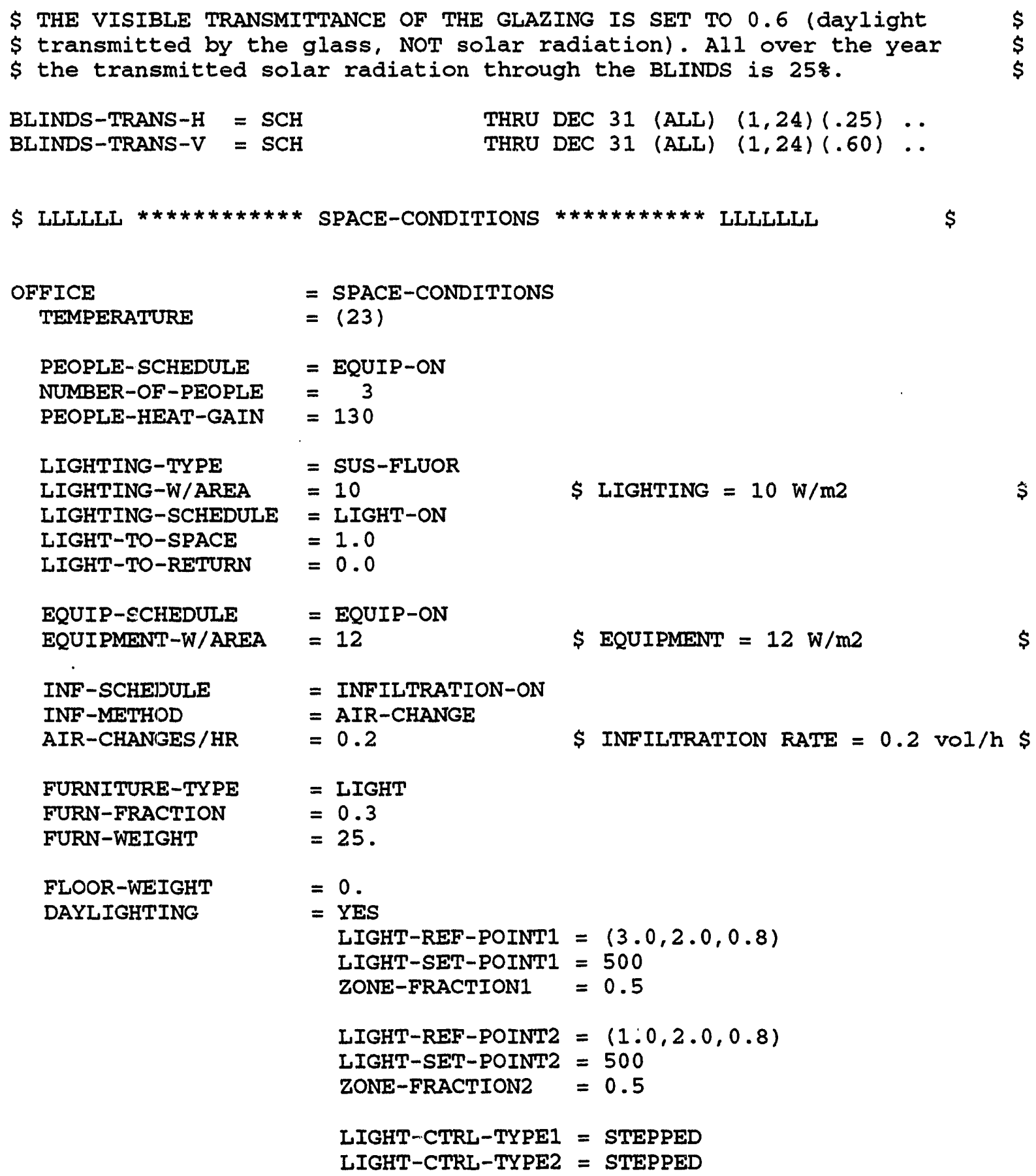




$=$ SPACE
MFR10
$A=16 \quad \mathrm{~V}=48$
$\mathrm{X}=0 \quad \mathrm{Y}=16 \quad \mathrm{Z}=3$
$\mathrm{AZ}=90$.
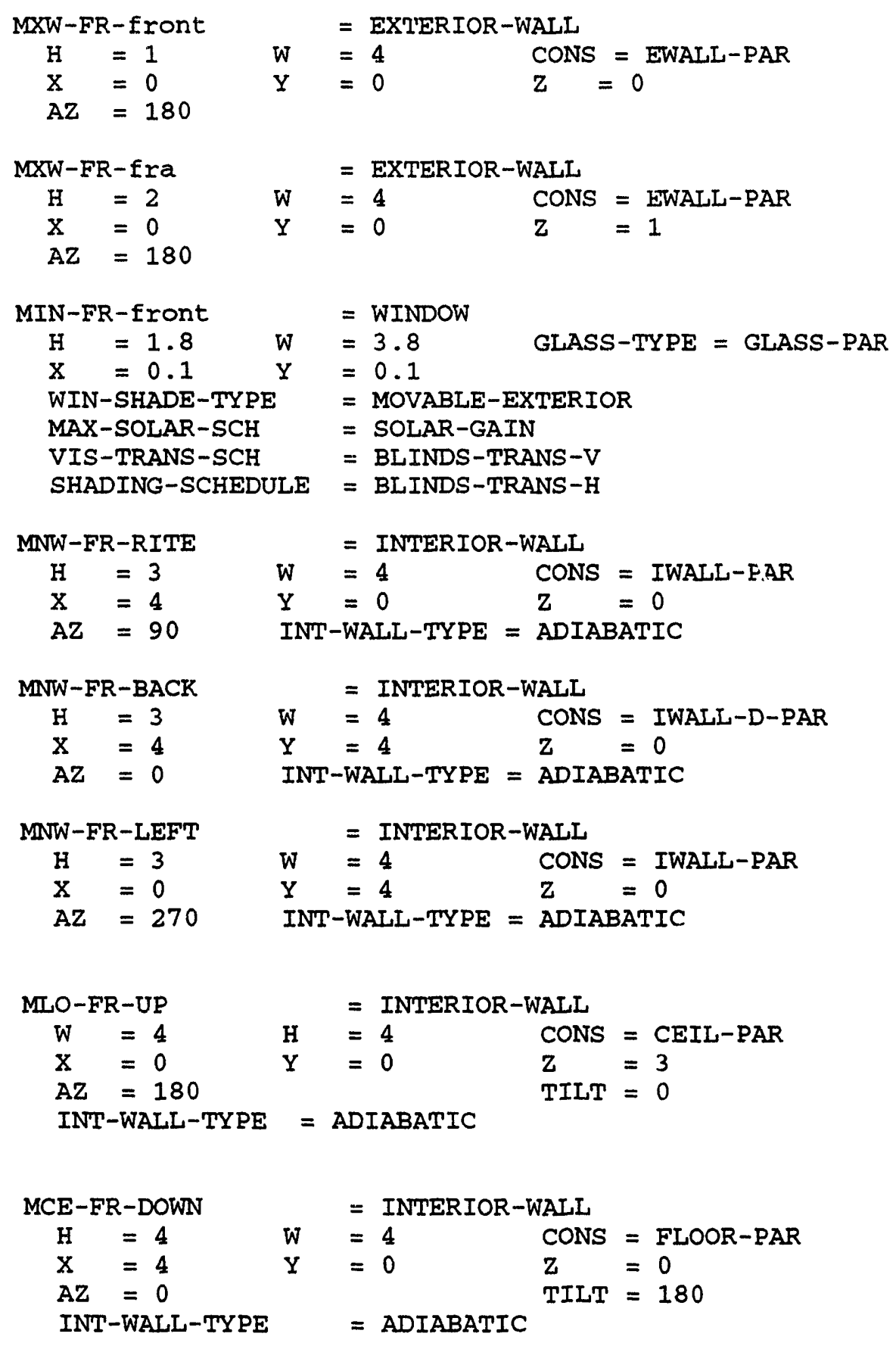
LOADS-REPORT

$$
\begin{array}{ll}
\text { SUMMARY } & =\text { (LS-A, LS-C, LS-D }) \\
\text { VERIFICATION } & =(\text { LV-A }) \\
\text { HOURLY-DATA-SAVE } & =\text { NO } \\
\text { REPORT-FREQUENCY } & =\text { HOURLY }
\end{array}
$$

REPSCH = SCHEDULE

$$
\begin{array}{lllll}
\text { THRU AUG } 22 & \text { (ALL) } & (1,24) & (0) \\
\text { THRU AUG } 25 & \text { (ALL) } & (1,24) & (1) \\
\text { THRU DEC } 31 & \text { (ALL) } & (1,24) & (0)
\end{array}
$$

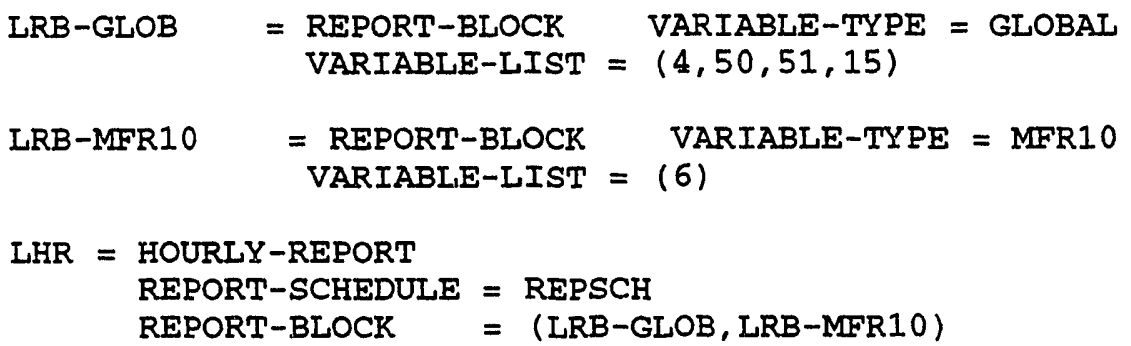

END

COMPUTE LOADS

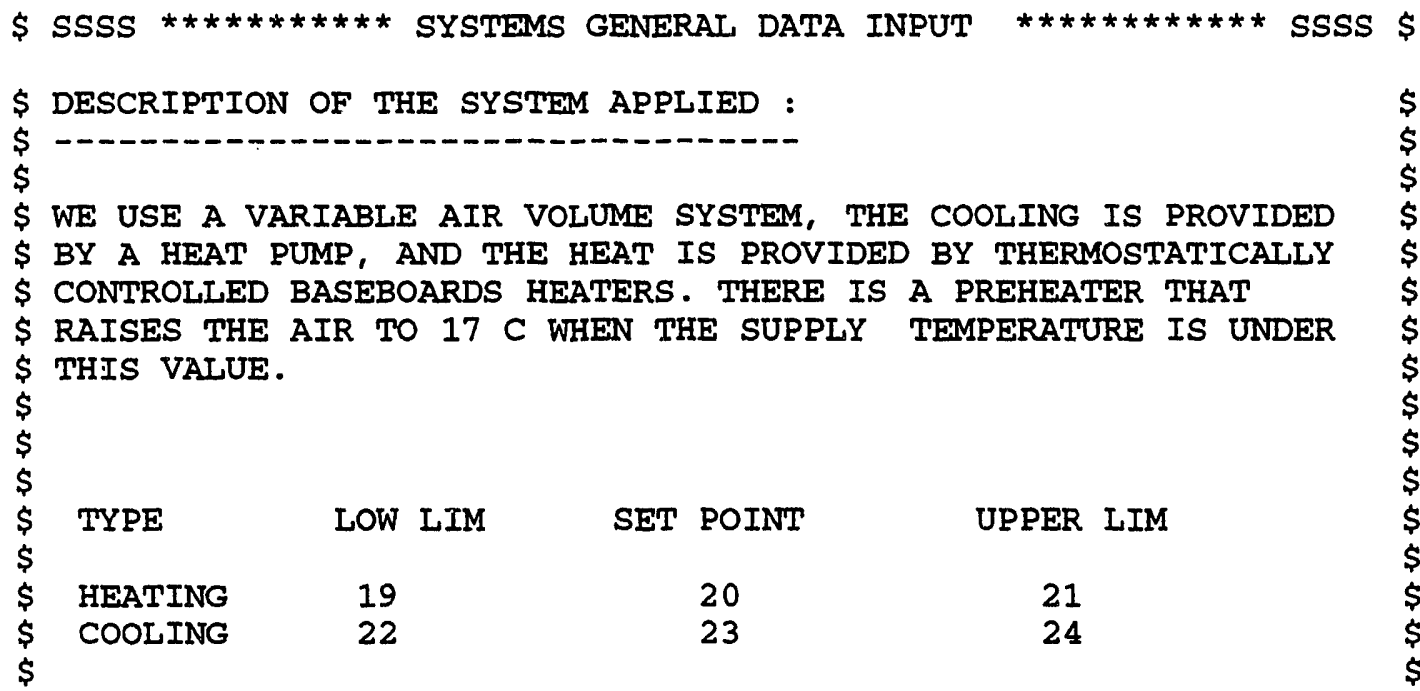

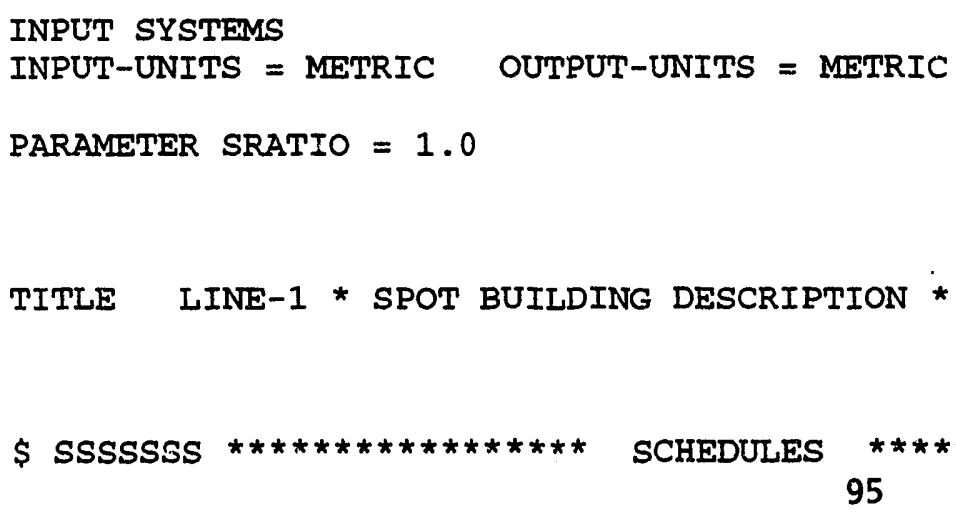




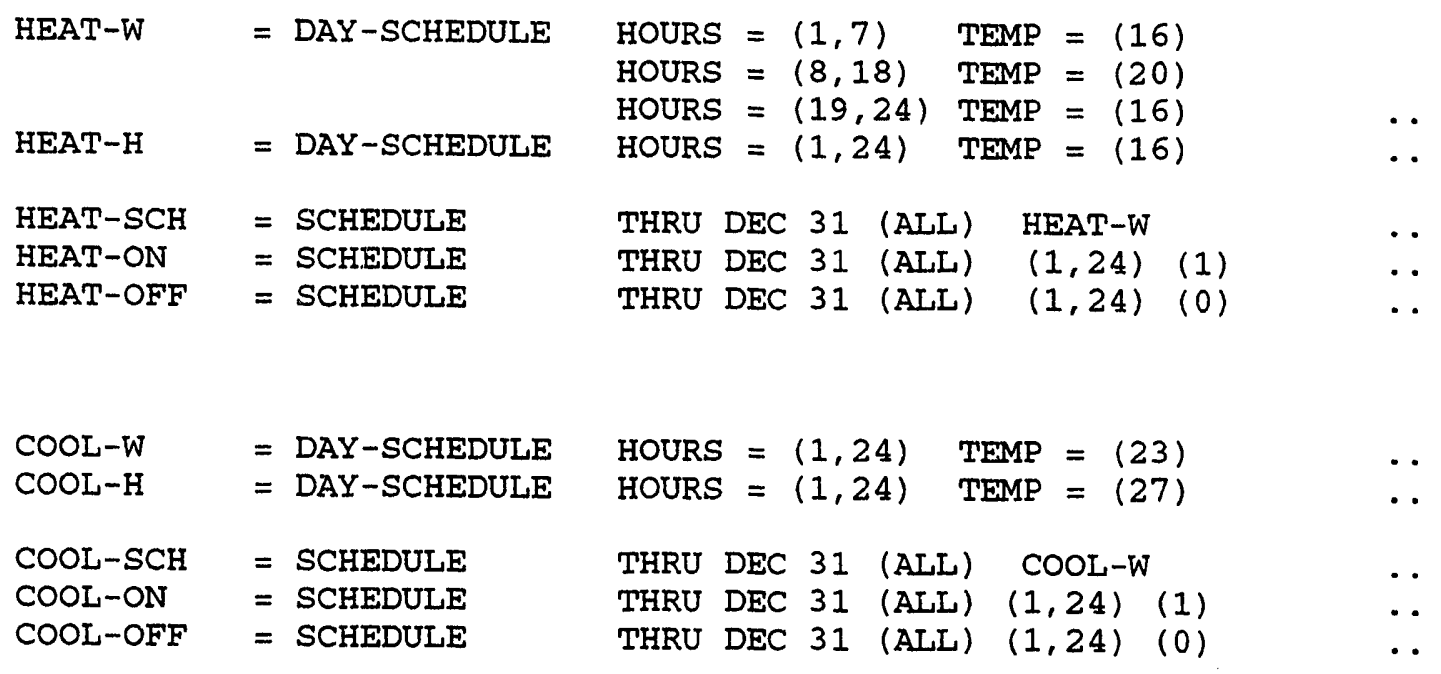

\$ THE FANS SWITCH ON TWO HOUR BEFORE THE ARRIVAL OF THE OCCUPANTS \$ $\$$ AND ARE TURNED OFF ONE HOUR AFTER THEY LEFT

$\begin{array}{llllllll}\text { FAN-ON } & =\text { SCH } & \text { THRU DEC } 31 & \text { (ALL) } & (1,5)(0) & (6,18)(1) & (19,24)(0) & \ldots \\ \text { FAN-OFF } & = & \text { SCH } & \text { THRU DEC } 31 & \text { (ALL) } & (1,24)(0) & & \end{array}$

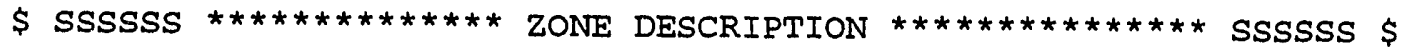

Z-CONTROL $=$ ZONE-CONTROL

$$
\begin{array}{ll}
\text { DESIGN-HEAT-T } & =19 . \\
\text { DESIGN-COOL-T } & =22 . \\
\text { HEAT-TEMP-SCH } & =\text { HEAT-SCH } \\
\text { COOL-TEMP-SCH } & =\text { COOL-SCH } \\
\text { THERMOSTAT-TYPE } & =\text { PROPORTIONAL } \\
\text { THROTTLING-RANGE } & =2.0 \\
\text { BASEBOARD-CTRL } & =\text { THERMOSTATIC }
\end{array}
$$

R-CHANGE $=$ ZONE-AIR

$\begin{array}{ll}\text { OA-CHANGES } & =2.25 \\ \text { ZON10 }=\text { ZONE } & =\text { Z-CONTROL } \\ \text { ZONE-CONTROL } & =\text { R-CHANGE } \\ \text { ZONE-TYPE } & =\text { CONDITIONED } \\ \text { SIZING-OPTION } & =\text { ADJUST-LOADS } \\ \text { BASEBOARD-RATING } & =-500\end{array}$




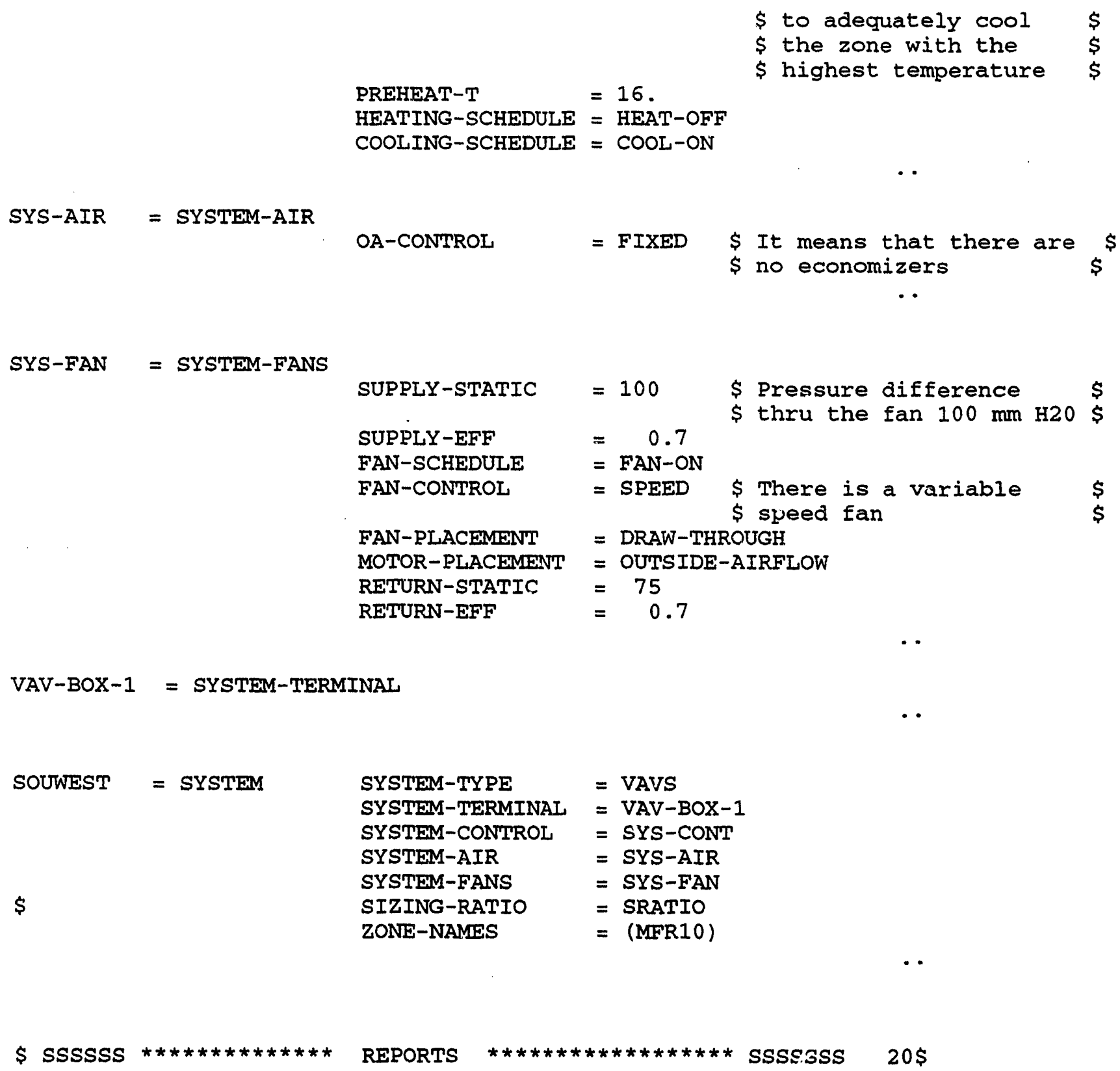

SYSTEMS-REPORT

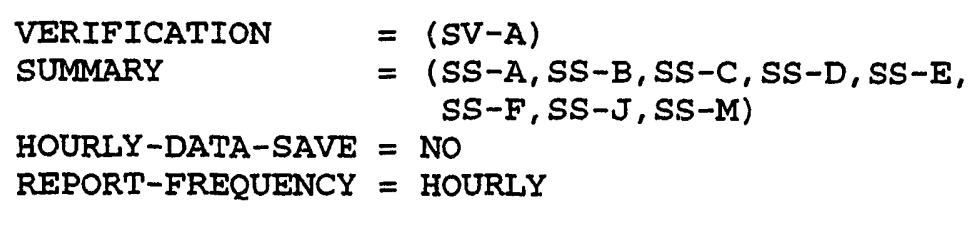

SYRSCH = SCHEDULE

(ALL) $(1,24)(0)$

(ALL) $(1,24) \quad(1)$

THRU AUG 25

THRU DEC 31

(AIL) $(1,24)(0)$

\footnotetext{
SRB-GLOB = REPORT-BLOCK VARIABLE-TYPE = GLOBAL VARIABLE-LIST $=(8)$

SRB-SPOT = REPORT-BLOCK VARIABLE-TYPE $=$ MFR10
} 


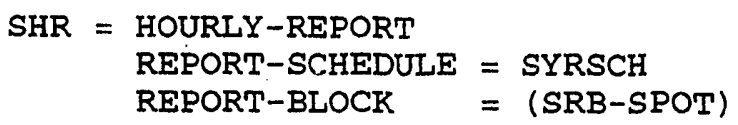

END

COMPUTE SYSTEMS

INPUT PLANT

INPUT-UNITS = METRIC OUTPUT-UNITS = METRIC

PL-EQ-1 = PLANT-EQUIPMENT

TYPE = ELEC-DHW-HEATER

SIZE $=-290$.

PL-EQ-2 = PLANT-EQUIPMENT

TYPE = HERM-REC-CHLR

SIZE $=-290$.

PLANT-REPORT

VERIFICATION $=(P V-A, P V-B, P V-C, P V-E)$

SUMMARY $=(P S-A, P S-C, P S-D, P S-H, B E P S)$

END

COMPUTE PLANT

STOP 

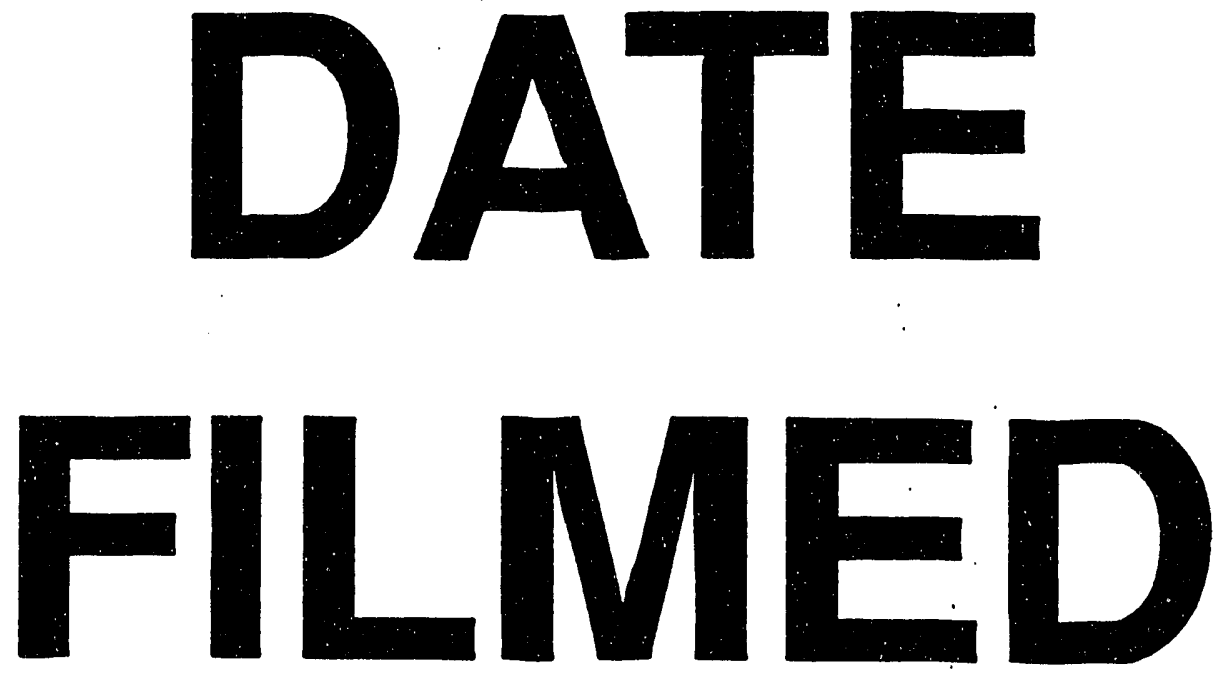

$10 / 7 / 93$
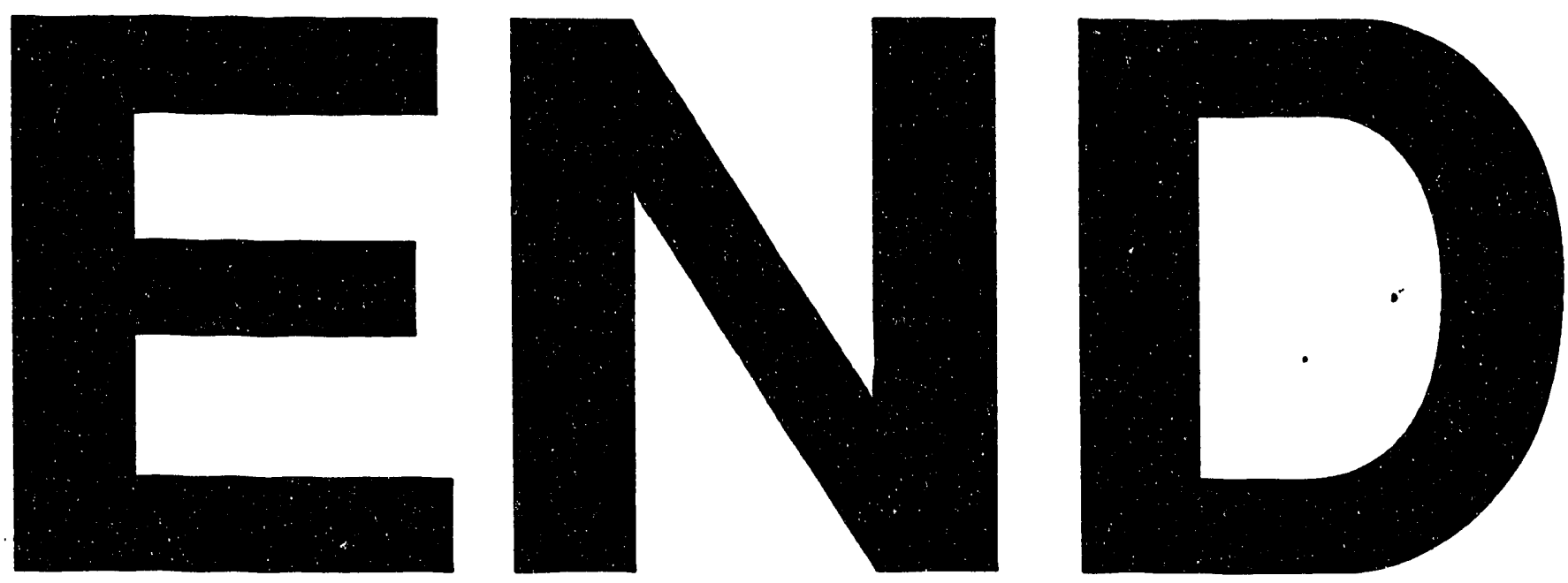
